\title{
Comparison of Two Orthodontic Sealants in Prevention of Enamel Demineralization : An In-Vitro and In-Vivo Study
}

Doyoung Choi

West Virginia University

Follow this and additional works at: https://researchrepository.wvu.edu/etd

\section{Recommended Citation}

Choi, Doyoung, "Comparison of Two Orthodontic Sealants in Prevention of Enamel Demineralization : An In-Vitro and In-Vivo Study" (2013). Graduate Theses, Dissertations, and Problem Reports. 259.

https://researchrepository.wvu.edu/etd/259

This Thesis is protected by copyright and/or related rights. It has been brought to you by the The Research Repository @ WVU with permission from the rights-holder(s). You are free to use this Thesis in any way that is permitted by the copyright and related rights legislation that applies to your use. For other uses you must obtain permission from the rights-holder(s) directly, unless additional rights are indicated by a Creative Commons license in the record and/ or on the work itself. This Thesis has been accepted for inclusion in WVU Graduate Theses, Dissertations, and Problem Reports collection by an authorized administrator of The Research Repository @ WVU. For more information, please contact researchrepository@mail.wvu.edu. 


\title{
Comparison of Two Orthodontic Sealants in Prevention of Enamel Demineralization : An In-Vitro and In-Vivo Study
}

\author{
Doyoung Choi, D.D.S.
}

\author{
Thsis Submitted to \\ School of Dentistry \\ at West Virginia University \\ in partial fulfillment of the requirements \\ for the degree of \\ Master of Science \\ in \\ Orthodontics
}
Peter Ngan, D.M.D., Chair
Elizabeth Kao, D.M.D.
Chris Martin, D.D.S.
Erdogen Gunel, Ph.D.

Department of Orthodontics

Morgantown, West Virginia

2013 


\section{ABSTRACT}

\section{Comparison of Two Sealants in Prevention of Enamel Demineralization : In-Vitro and In-Vivo Study}

\section{Doyoung Choi, D.D.S.}

Introduction Enamel demineralization adjacent to orthodontic brackets is one of the risks associated with orthodontic treatment. Among the techniques utilized to prevent demineralization, application of orthodontic sealants is widely used to provide mechanical coating and fluoride release for the underlying enamel. The purpose of this study was to compare the efficacy in enamel protection during fixed orthodontic treatment in-vitro and in-vivo between two orthodontic sealant products; Opal Seal (Opal Orthodontics by Ultradent, South Jordan, UT) and Pro Seal (Reliance Orthodontic Products, Itasca, IL). The null hypothesis was that there would be no significant difference in protection against enamel demineralization between Pro Seal and Opal Seal. Materials and Methods In-vitro: A total of 27 extracted human third molars with no enamel lesion were collected and cut in half to provide 54 samples. These samples were sterilized and randomly divided into three groups: Control, Opal Seal, and Pro Seal groups. The control group received no treatment. The samples in the sealant groups were etched with $37 \%$ phosphoric acid and treated with the assigned sealant according to the manufacturersôinstruction. The samples then underwent 0,2 , or 4 hours of brushing treatments, followed by 24 or 48 hours of demineralization and remineralization treatment. The depth and area of the lesion and thickness of remaining sealant were examined using confocal microscopy. In-vivo: A total of 19 patients who required comprehensive orthodontic treatment were recruited for the study. Tooth surfaces from second premolars to second premolars were treated with either Opal Seal or Pro Seal 
using a split-mouth technique. The extent of enamel lesions before and after 14 months of orthodontic treatment was examined with digital photography, using a Visual Scoring System. Data were analyzed using ANOVA and Tukey Kramer test for the in-vitro experiment and logistic regression for the in-vivo experiment. Results In-vitro: Significant difference in lesion depth was found between the control group $(40.11 \pm 16.77$ $\mu \mathrm{m})$ and sealant groups (Opal: $21.44 \pm 12.46 \mu \mathrm{m}$, Pro: $22.01 \pm 13.58 \mu \mathrm{m})(\mathrm{p}<0.0001)$. Significant difference in lesion area was found between the control group (35169.17 $\left.\pm 10816.08 \mu \mathrm{m}^{2}\right)$ and sealant groups (Opal: $15566.62 \pm 9339.36 \mu \mathrm{m}^{2}$, Pro: $\left.16685.12 \pm 10375.36 \mu \mathrm{m}^{2}\right)(\mathrm{p}<0.0001)$. No differences were found between two sealant groups. The remaining sealant thickness showed a linear decreasing pattern over brushing time. However, no significant differences were found in the remaining thickness between the two sealants. In-vivo: Significant correlation was found between the oral hygiene status and the probability of demineralization $(\mathrm{p}<0.0001)$. The incidence of white spot lesions increased exponentially with the decline in oral hygiene level. Conclusion The application of sealant reduced the depth and area of enamel lesions invitro. Pro Seal and Opal Seal provided comparable level of enamel protection in-vivo. The duration of sealant protection as demonstrated with an average of 11.3 hours of mechanical brushing was equivalent to 5.65 months of brushing twice a day clinically. It is recommended to reapply sealants every six month in order to provide the full benefit of sealant treatment especially among the patients with poor oral hygiene. 


\section{DEDICATION}

To my husband, Benedict William Leung, my best friend who will stay through everything in our lives, thank you. Thank you for being you and being with me. It has been a wonderful journey, and I canô wait for what lies in the future. You are the most generous, loving, and caring person I could ever ask for. I love you.

To my parents, Seungyoul Choi and Gapchul Kim, the best role models I have in my life, thank you. Your unconditional and endless sacrifice has shaped me as what I am here now. It will be impossible to repay you for all the love and care I have received. I love you, and the words cannot mean it enough.

To my sister, DoBin Choi, and my brother, DoHuem Choi, thank you for your support. You have been there throughout happiness and hardship in my life. I love you both so much.

To the rest of my family and friends, your support is what helped me to venture through. Thank you. 


\section{ACKNOWLEDGEMENTS}

I would like to take this opportunity to thank the following individuals who have contributed and assisted me throughout my specialty training:

Dr. Peter Ngan, for everything I have learned from him ï knowledge, humbleness, generosity, and positiveness. I hope to resemble him in my professional journey.

Dr. Chris Martin, for his kindness and fatherly figure I could depend on for the last three years.

Dr. Elizabeth Kao, for her ideas and help in designing and completing the laboratory section of this thesis.

Dr. Michael Hazey, for the clinical data from his private practice that made the in-vivo section of this thesis possible.

Dr. DoBin Choi, for the countless hours she devoted to the in-vitro section of this thesis.

Dr. Erdogan Gunel, for his assistance in the statistical analysis.

Drs. Karen Martin and Amanda Ammer, for their assistance with the confocal microscopy and image analysis. Imaging experiments and image analysis were performed in the West Virginia University Microscope Imaging Facility, which has been supported by the Mary Babb Randolph Cancer Center and NIH grants P20 RR016440, P30 RR032138/GM103488 and P20 RR016477.

Drs. Kerry Kirsch, Timothy Tremont, Edward McFarland, Michael Hazey, Thomas Jarrett, Daniel Foley, Glenn Boyles, Rajia Sebbahi, Lawrence Wright, Scott Little, and Jeffrey Gilmore, for passing on their didactic and clinical knowledge and for shaping my orthodontic career.

Dr. Alice Wang, for all the great memories shared at numerous trips and seminars. A true friend for life, thank you for making the last three years fun.

Dr. Chad Westfall, for his friendship. Thank you for the great times.

To my fellow residents; Maggie, Erica, Rob, Holly, Jung-Mee, Ronnie, Nicole, Lance, Deepa, Nick, Jen, and Travis. Thank you all for your friendship. 


\section{TABLE OF CONTENTS}

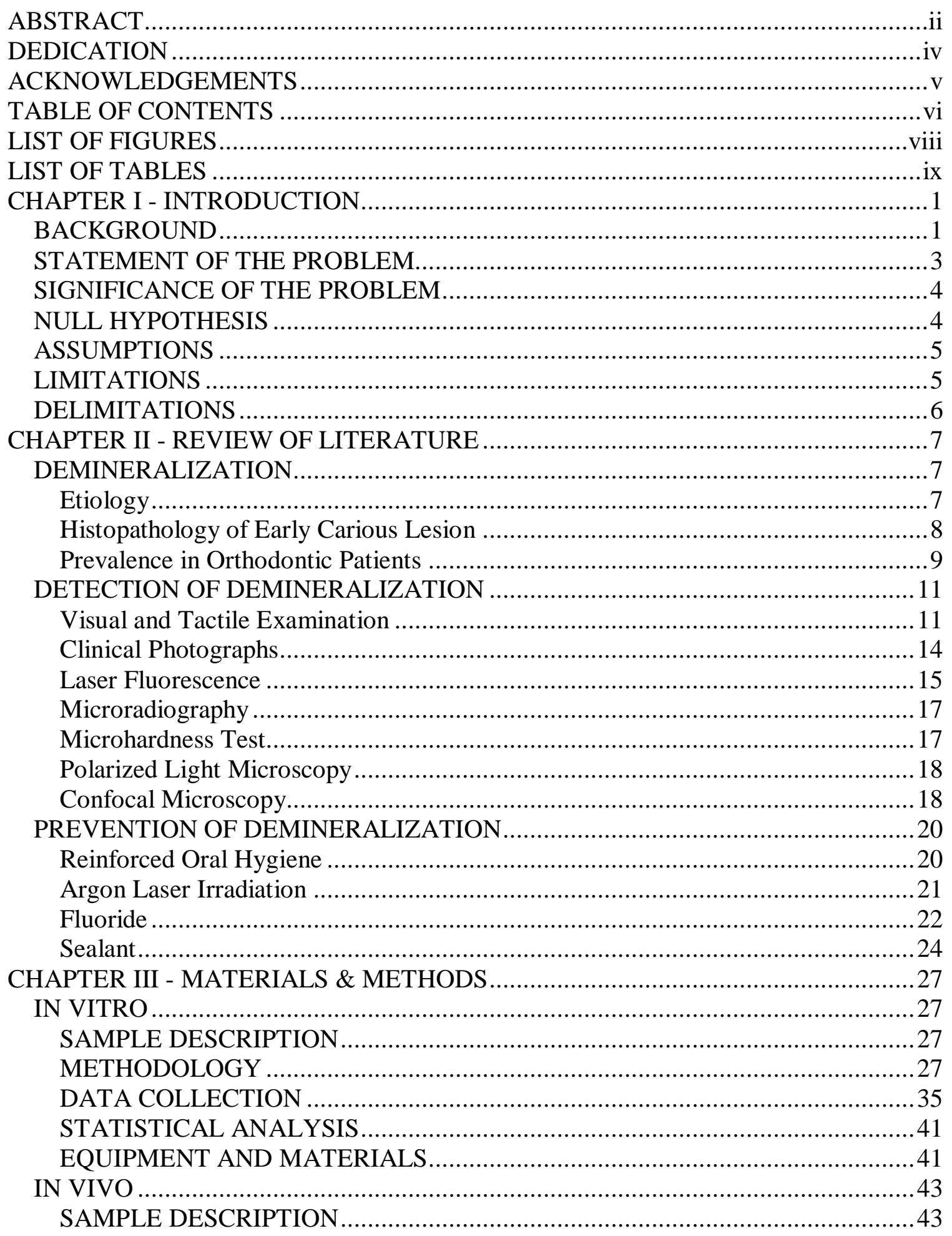




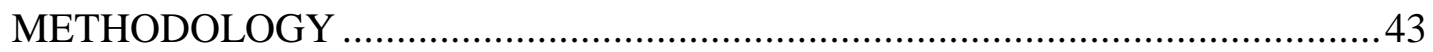

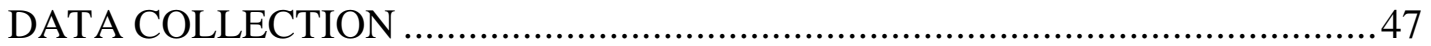

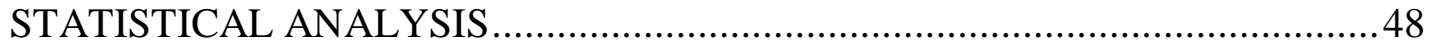

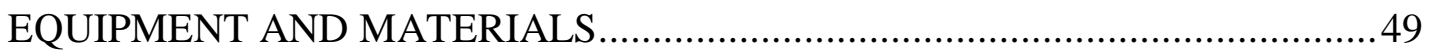

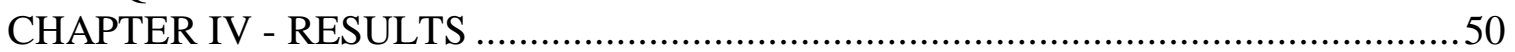

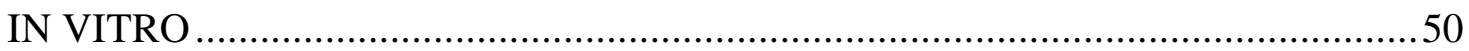

LESION DEPTH

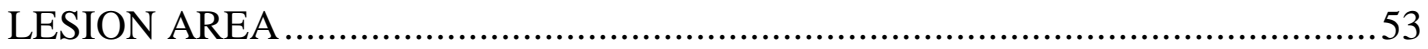

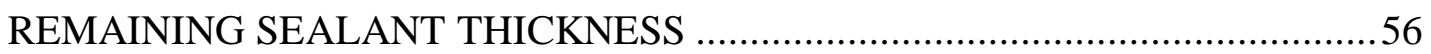

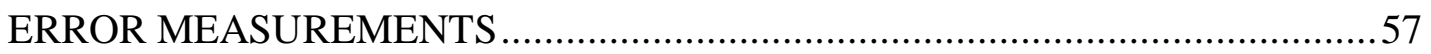

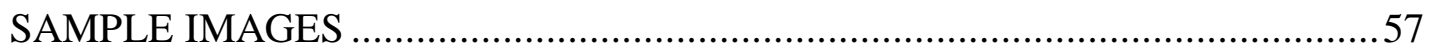

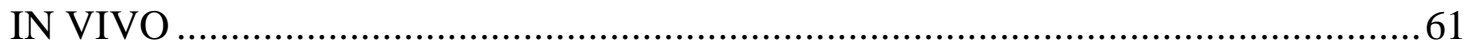

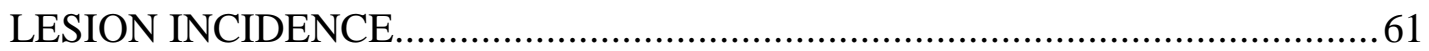

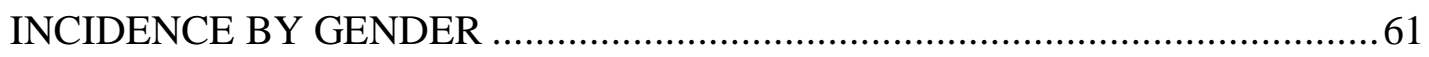

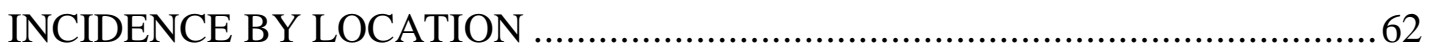

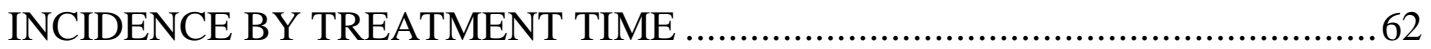

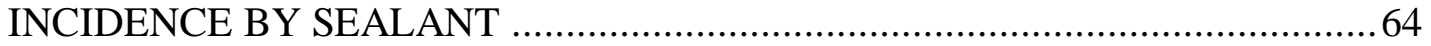

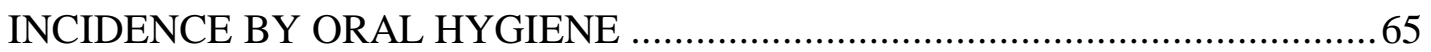

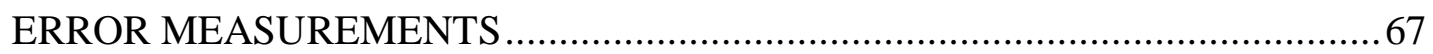

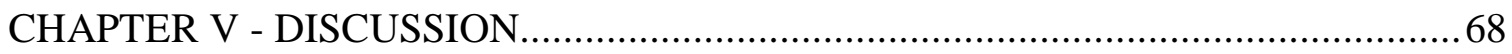

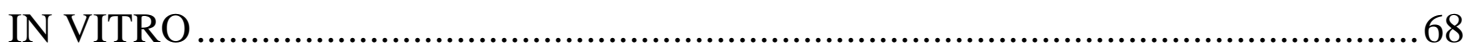

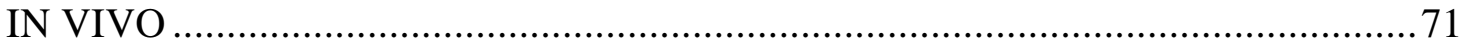

CHAPTER VI SUMMARY, CONCLUSION, AND RECOMMENDATIONS .............74

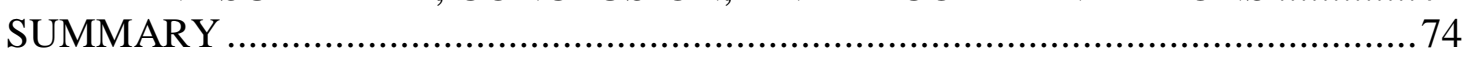

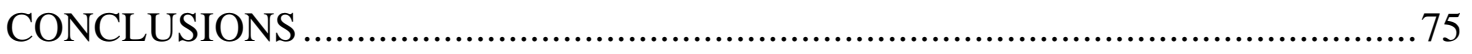

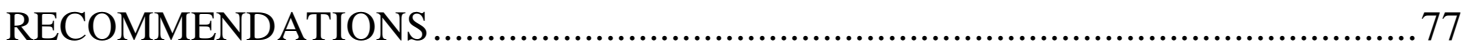

REFERANCES …

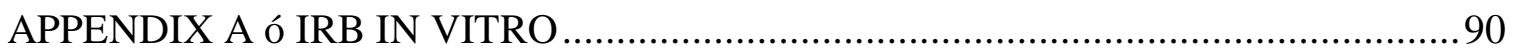

APPENDIX B Ï IRB IN VIVO …….............................................................

APPENDIX C $\mathrm{i}$ AUTHORIZATION TO USE OR DISCLOSE PROTECTED HEALTH

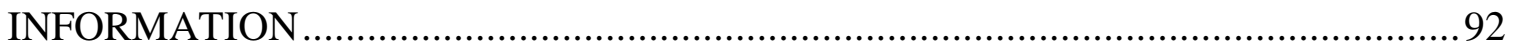

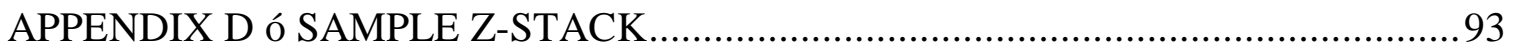

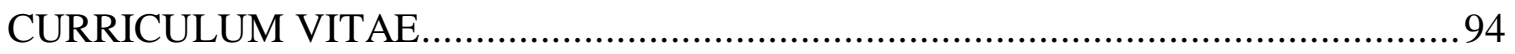




\section{LIST OF FIGURES}

Figure 1. Gingival areas of facial surfaces are affected by white spot lesions. ................ 1

Figure 2. Pro Seal manufactured by Reliance Orthodontic Products................................ 3

Figure 3. Opal Seal manufactured by Opal Orthodontics. ........................................... 3

Figure 4. Two 250 $\mu \mathrm{m}$-thick slices were made from mesial and distal areas....................36

Figure 5. Areas were scanned planoparallel to the cut surface in X. Y, and Z axis. ........39

Figure 6. Both mesial and distal slices were scanned with confocal microscopy in

occlusal and gingival areas. ................................................................................ 39

Figure 7. Thickness of remaining sealant and depth of lesion were measured

perpendicular to the tooth surface.

Figure 8. Six teeth, marked in blue, were examined in modified plaque and gingival indices.

Figure 9. Tukey Kramer analysis showed that there was no difference in lesion depths between Opal Seal and Pro Seal, but there was a significant difference between both sealant groups compared to control group.

Figure 10. ANOVA of lesion depth showed significant difference between control group and sealant groups. The depths of the lesions in two sealant groups were similar, yielding no statistically significant difference.

Figure 11. Tukey Kramer analysis showed that there was no difference in lesion areas between Opal Seal and Pro Seal, but there was a significant difference between both sealant groups compared to control group.

Figure 12. ANOVA of lesion area showed significant difference between control group and sealant groups. The areas of the lesions in two sealant groups were similar, yielding no statistically significant difference.

Figure 13. Thickness of Opal Seal and Pro Seal decreased at an equivalent rate over brushing time. There was no significant difference between the sealant thickness changes between two sealants.

Figure 14. Confocal image of a sample from the Opal Seal group with no lesion...........58

Figure 15. Confocal image of a sample from the Pro Seal group with no lesion .............58

Figure 16. Confocal image of a sample from the control group with lesion ...................59

Figure 17. Confocal image of a sample from the Sealant group with lesion...................60

Figure 18. Female teeth have shown less likely incidence for demineralization..............62

Figure 19. Total treatment time was plotted according to the change in demineralization

to show the increasing trend.

Figure 20. Incidence of demineralization showed so significant difference according to different sealant and arch.

Figure 21. Probability of having no demineralization decreased rapidly with higher oral hygiene score, meaning more unfavorable oral hygiene.

Figure 22. The rate demineralization incidence according to level of hygiene compliance shows increasing trend towards poor oral hygiene.

Figure 23. Change in sealant thickness was projected over brushing time to discover the linear formula. 


\section{LIST OF TABLES}

Table 1. ICDAS codes for caries objectively and meticulously categorize different stages

of enamel and dentin defects.

Table 2. Universal Visual Scoring System for smooth surface can be precise and accurate with corresponding clinical presentations.

Table 3. Six subgroups in each treatment group had three specimens, and each specimen was marked accordingly.

Table 4. Plaque index was calculated by using this scoring system. ...........................45

Table 5. Gingival index for a patient was calculated, using this scoring system.

Table 6. Patientô each arch was assigned to different oral hygiene groups according to plaque index and gingival index.

Table 7. Visual Enamel Demineralization Scoring Chart was used in evaluation of white

spot lesions................................................................................................... 48

Table 8. Multi-factorial ANOVA showed that every factor had significant effect on lesion

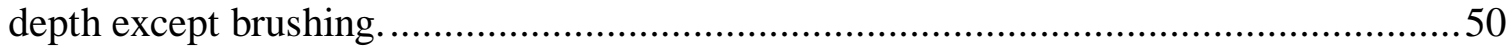

Table 9. Mean depth and std. deviation for each sealant group and $\mathrm{pH}$-cycling time......52

Table 10. Multi-factorial ANOVA showed that every factor had significant effect on

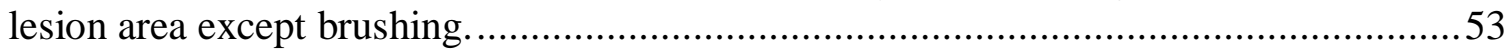

Table 11. Mean area and std. deviation for each sealant group and $\mathrm{pH}$-cycling time. .....55 Table 12. Multi-factorial ANOVA showed that brushing and demineralization factors had significant effect on remaining sealant thickness, while sealant type did not have any effect. .56

Table 13. The distribution of the studied samples according to sealants is shown here...64 


\section{CHAPTER I - INTRODUCTION}

\section{BACKGROUND}

Orthodontic treatments commonly entail cementing metal bands or bonding orthodontic brackets on all permanent teeth, and the treatments can range from 12 to 36 months, depending on the severity of the malocclusion. The location and complex shape of the brackets provide areas to which plaque can easily adhere, and it is more difficult for tooth brush bristles to access these areas. ${ }^{(1)}$ It has been found that there is a higher concentration of Streptococcus and Lactobacillus species in oral cavities with orthodontic appliances, subsequently lowering the $\mathrm{pH}$ of the oral environment. ${ }^{(1,2)}$ A low salivary $\mathrm{pH}$ increases the solubility of enamel and causes demineralization. According to Ogaard et al, a low $\mathrm{pH}$ maintained by the bacterial plaque around the orthodontic bands can initiate visible enamel demineralization in as little as 4 weeks. ${ }^{(1)}$ As the demineralization process takes place on the surface of the enamel, the incipient lesions appear white; hence they are called white spot lesions (Figure 1). ${ }^{(3)}$
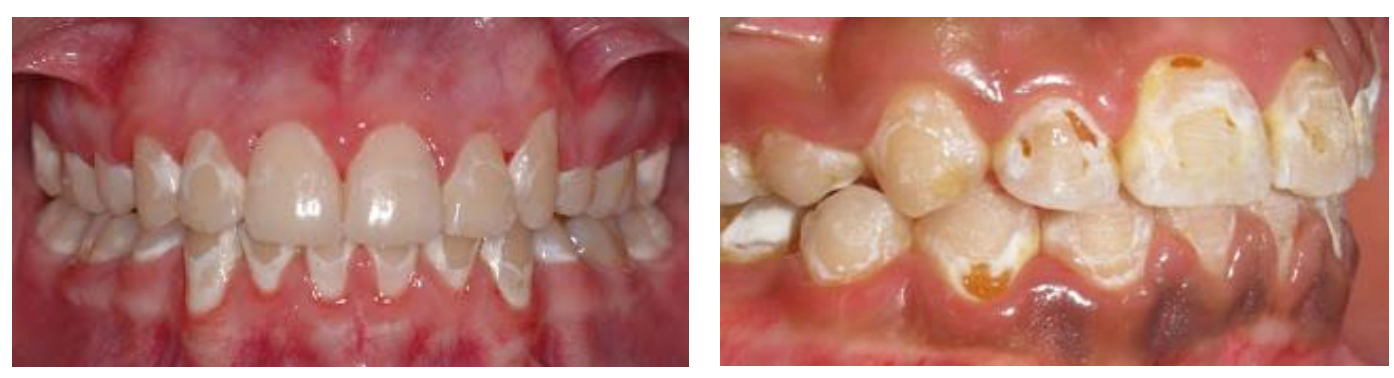

Figure 1. Gingival areas of facial surfaces are affected by white spot lesions. 
The detection of the lesions is usually accomplished through a visual examination in a clinical setting. ${ }^{(4)}$ It is the most readily available method, and the examination can be highly reliable with basic training. However, other methods have been utilized in several studies: computerized image analysis from digital photographs, ${ }^{(4)}$ microhardness testing, ${ }^{(2,5)}$ polarized light microscopy ${ }^{(6)}$ confocal microscopy, ${ }^{(7,8)}$ and laser fluorescence. ${ }^{(9-12)}$

Several approaches have been advocated to prevent demineralization during orthodontic treatments: enforced oral hygiene regimen, ${ }^{(13)}$ argon laser irradiation, ${ }^{(14)}$ micro-abrasion, ${ }^{(15)}$ and use of fluoride. ${ }^{(3,16-18)}$ Fluoride has demonstrated its superior capacity to protect enamel surfaces, and many forms of fluoride have been incorporated for clinical benefits. Another approach to reduce demineralization is the application of a sealant during the bonding procedure. ${ }^{(19,20)}$ Sealants provide a mechanical coating on the surface, and some sealants also contain fluoride in effort to maximize enamel protection. There are many sealant products commercially available to be utilized in orthodontic patients. However, several research papers have shown Pro Seal (Figure 2) to provide the most protection against demineralization, and it is considered to be the gold standard. ${ }^{(21 \text {, }}$ 22)

Opal Orthodontics recently manufactured a sealant called Opal Seal (Figure 3) with the claim that it is a superior product. Both products are highly filled light-curable sealants, which contain fluoride as one of their main components. Since the introduction of Opal Seal, there have not been any evidence-based studies evaluating its efficacy. The enamel protection of Pro Seal and Opal Seal will be evaluated in-vitro and in-vivo in this study. 


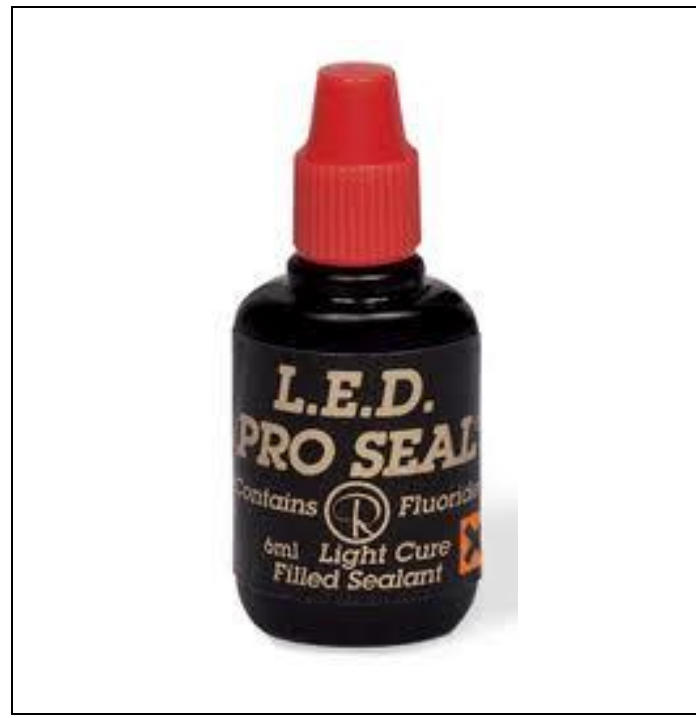

Figure 2. Pro Seal manufactured by Reliance Orthodontic Products.

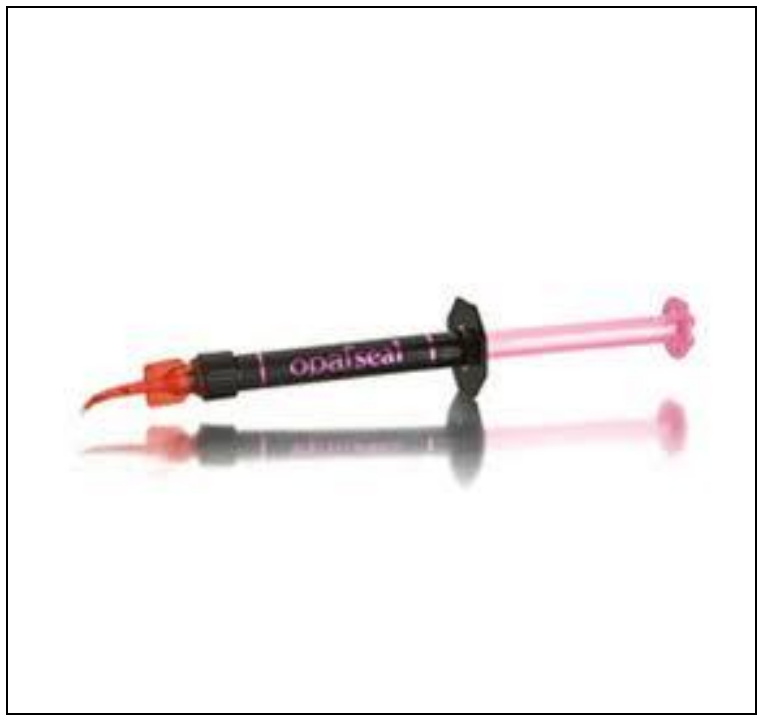

Figure 3. Opal Seal manufactured by Opal Orthodontics.

\section{STATEMENT OF THE PROBLEM}

Patients are at risk of enamel demineralization during the entire span of

orthodontic treatment. This can raise an aesthetic concern as well as a dental health concern. Sealants can be applied on the facial tooth surface to protect the enamel. This study will evaluate the efficiency of Opal Seal and Pro Seal in protection against enamel demineralization. 


\section{SIGNIFICANCE OF THE PROBLEM}

There have been few studies comparing Opal Seal and Pro Seal in-vitro; however, there has not been any study done in-vivo. Since clinical findings and recordings are of a tremendous value in Orthodontics, the efficacy of the two sealants will be compared invivo in this study. The findings from the in-vivo part of this study will be objectively compared to those from the in-vitro part of the study.
A. In-vitro: on 27 extracted tooth halves in oral-cavity-like simulation
B. In vivo: on 19 patients treated with long-term fixed orthodontic treatment with average span of 14 months

\section{NULL HYPOTHESIS}

$\underline{\text { In-vitro }}$

There would be no significant difference between Opal Seal and Pro Seal in the following

1. Depth of the lesion

2. Area of the lesion

3. Thickness of remaining sealant

$\underline{\text { In-vivo }}$

There would be no significant difference between Opal Seal and Pro Seal in the following

1. Incidence of white spot lesions

2. Degree of demineralization 


\section{ASSUMPTIONS}

The following were assumed for the purposes of this study.

1. Orthodontic appliances increase enamel demineralization.

2. The level of oral hygiene has an effect on the degree of demineralization.

3. The materials used in the study are clinically acceptable and efficient.

4. The amount of sealants applied on tooth surfaces is consistent.

5. The demineralizing solution will replicate the process of demineralization in vitro.

6. The remineralizing solution will replicate the process of remineralization in vitro.

\section{LIMITATIONS}

$\underline{\text { In Vitro }}$

1. The bacterial composition in the oral cavity cannot be duplicated.

2. The changes in $\mathrm{pH}$ and temperature of the oral cavity cannot be duplicated.

3. The effect of food intake and speech cannot be duplicated.

\section{In Vivo}

1. The degree of oral hygiene varies greatly among patients.

2. The rate of plaque accumulation varies among patients.

3. The composition of the oral flora varies among patients.

4. The length of the orthodontic treatment varies among patients.

5. Some orthodontic brackets have bond failure which requires rebonding to the tooth surface.

6. Visual interpretation of the data is subjective. 


\section{DELIMITATIONS}

$\underline{\text { In Vitro }}$

1. Non-defective and non-carious extracted teeth were used in the study.

2. All teeth were exposed to the standardized cycles of demineralization at the $\mathrm{pH}$ of 4.46 then remineralization at the $\mathrm{pH}$ of 7.

3. The simulation of tooth brushing was done on all extracted teeth by a standardized brushing apparatus.

4. All surface treatment and data interpretation was done by a single operator.

\section{$\underline{\text { In Vivo }}$}

1. Only patients with no pre-existing enamel decalcification were recruited.

2. Patients were randomly assigned to experimental groups.

3. Standardized bonding procedure was used for all participating patients.

4. Only two well-calibrated operators performed the bonding procedure.

5. Standardized oral hygiene instruction was be given to all participating patients.

6. Each patient served as the experimental sample and the control sample.

7. All data interpretation was done by a single operator. 


\section{CHAPTER II - REVIEW OF LITERATURE}

\section{DEMINERALIZATION}

\section{Etiology}

Demineralization is defined as the loss of minerals or mineral salts, ${ }^{(23)}$ and it is a more inclusive and correct term than decalcification since calcium is not the only substance removed from the tooth structure. The primary component of enamel is hydroxyapatite, $\mathrm{Ca}_{5}\left(\mathrm{PO}_{4}\right)_{3}(\mathrm{OH})$, which is a crystalline calcium phosphate. Thus, calcium and phosphate are the most prevalent elements to be lost in the process of demineralization,

In the oral cavity, the enamel surface is in balance between demineralization process and remineralization process. ${ }^{(24)}$ Minor amount of minerals is constantly absorbed and dissolved from the very outer surface of enamel depending on the $\mathrm{pH}$ of the oral cavity. The $\mathrm{pH}$ of lower than 5.5 has been shown to cause hydroxyapatite to dissolve into calcium and phosphate ions, which may result in dental caries. On the other hand, remineralization process takes place when the $\mathrm{pH}$ is increased and maintained. Extended period of remineralizing environment with the presence of fluoride in vitro has shown to arrest the carious activity and reverse the early enamel lesions. ${ }^{(25)}$ Dental caries takes its course when this balance is disrupted due to a change in the environment, such as a decrease in $\mathrm{pH}$ and an increase in bacterial load. ${ }^{(1,26)}$

Oral bacteria can play a major role in demineralization process. Streptococcus mutans (S. mutans) is one of the most well-known species that initiate dental carious lesions, while Lactobacillus is associated with further development of the lesion. 
Boersma et al found high level $\left(>10^{5}\right)$ of $S$. mutans and Lactobailli in orthodontic patients; however, they found a stronger correlation between the level of Lactobacilli and the degree of enamel demineralization, compared to the level of Streptococci. ${ }^{(27)}$ Diet with high sucrose content increases the potential initiation of bacterial colonization, seen in direct correlation between the caries rate and the $S$. mutans load. Once there is formation of a biofilm, a multi-species community in a highly organized structure, it can be much more difficult to eradicate. Dietary sucrose can then be metabolized by these bacterial species into acid byproduct, lowering the $\mathrm{pH}$ of the oral cavity. ${ }^{(1)}$

\section{Histopathology of Early Carious Lesion}

During the process of demineralization, a great extent of mineral loss takes place in the surface and subsurface enamel. ${ }^{(17)}$ This process creates pores within enamel rods, which causes the enamel surface to appear opaque white due to an optical phenomenon. ${ }^{(28)}$ Thus, the early stage carious lesions are called white spot lesions. As a white spot lesion develops, there tends to be more mineral loss in the subsurface than the surface, which gradually makes it more difficult to reverse the process. ${ }^{(3)}$

Examined in polarized light microscopy, typical white spot lesions present in four distinct zones with different appearances and varying processes of demineralization: translucent zone, dark zone, body of the lesion, and surface zone. Translucent zone lacks structural rod outlines, and $1 \%$ of porosity is noticed in this zone due to mineral loss, creating 10 times greater space within the enamel structure. ${ }^{(24,29)}$ However, the course of hypermineralization has been shown in the translucent zone, responsible for increased microhardness. ${ }^{(24)}$ Dark zone, also known as positive zone, exhibits further 
demineralization. The dark appearance of this zone under the microscope is due to the micropores, measuring up to $5 \%$ of the volume loss. ${ }^{(24)}$ It has been suggested that remineralization can take place in the dark zone through the micropores. ${ }^{(30)}$ The body of the lesion is the largest zone with the most demineralization. The degree of tissue loss can be up to $25 \%$ of the total volume. ${ }^{(24)}$ Lastly, the surface zone is a thin enamel layer that is intact and covering the lesion. The mineral loss stays less than 5\% in this zone, and the existing pores are the pathways for remineralization process. ${ }^{(24)}$

\section{Prevalence in Orthodontic Patients}

Many orthodontic patients are at risk of both increased bacterial load and decreased $\mathrm{pH}$ of the oral cavity. The process of enamel demineralization can be visually observed in as little as 4 weeks. ${ }^{(1)}$ Ođ̊Reilly and Featherstone found that a significant degree of demineralization occurred in 1 month, even with the use of fluoride toothpaste on a daily basis. ${ }^{(2)}$ The shape and location of the common orthodontic appliances make it difficult for the patients to perform conventional oral hygiene, ${ }^{(31,32)}$ and the rough surface of bonding material also facilitates mechanical adherence of plaque. ${ }^{(31)}$ Even with vigorous oral hygiene instruction, Arslan observed diminished oral hygiene status

during orthodontic treatment. ${ }^{(33)}$ Balenseifen found an increased amount of dental plaque as well as carbohydrate in the oral cavities of orthodontic patients. ${ }^{(34)}$ Ogaard et al found a significant increase in the number of Streptococci and Lactobacilli species in patients who undergo orthodontic treatment. ${ }^{(1)}$ These two species are acidogenic in nature since their acidic byproduct from digesting carbohydrates, and they lower the $\mathrm{pH}$ of the oral cavity. ${ }^{(1,34)}$ 
A study conducted by Gorelick et al revealed that the incidence of white spot lesions among orthodontic patients was $50 \%$, compared to $25 \%$ found in the untreated population. ${ }^{(29)}$ Ogaard et al evaluated the white spot lesions in orthodontic patients at a minimum of 5 years post-treatment, and they concluded that there was a significantly higher prevalence among the treated group compared to the untreated group. ${ }^{(35)}$ The study done by Boersma et al noted $97 \%$ occurrence of white spot lesions during orthodontic treatment, with a higher prevalence among male patients (40\%) than female patients $(22 \%) .{ }^{(27)}$ Al Maaitah et al did not find significant correlation between patient $\hat{\Theta}$ sex and the incidence of white spot lesions. In their study, however, male patients showed a greater degree of demineralization once the demineralization process took place. ${ }^{(36)}$ Al Maaitah et al also found that the incidence largely depends pretreatment age, oral hygiene, and clinical status of the first molars. ${ }^{(36)}$ Geiger et al also found a positive correlation between the length of the treatment and the incidence and severity of white spot lesions. ${ }^{(37)}$ White spot lesions occur most frequently in the maxillary arch, ${ }^{(38)}$ especially in gingival one third of the facial surfaces. ${ }^{(39)}$ Maxillary lateral incisors showed the highest susceptibility to white spot lesions in Gorelick $\hat{Q}$ study, followed by maxillary central incisors, mandibular first molars, and premolars. ${ }^{(29)}$ Geiger also found that the maxillary lateral incisor was most prone to decalcification; however, it was followed by the mandibular first premolar, the maxillary canine, and the mandibular first molar in this order. ${ }^{(37)}$ The incidence of white spot lesions is not affected by the right or left side of the oral cavity. ${ }^{(29)}$ 


\section{DETECTION OF DEMINERALIZATION}

\section{Visual and Tactile Examination}

During the formation of white spot lesions, minerals are lost in the subsurface enamel through the microscopic pores created on the outer surface. ${ }^{(24,28)}$ The size and distribution of a white spot lesion, as well as the intensity of its opacity, can be evaluated visually. The increase in irregularity of the enamel surface and resulted surface roughness can be evaluated tactilely, using a dental explorer. ${ }^{(40)}$ White spot lesions traditionally have been evaluated via visual and tactile examinations in a clinical setting. ${ }^{(41)}$ Even though this method has a low sensitivity with a high specificity in detecting carious lesions, many studies have been conducted by using this conventional method in-vivo. ${ }^{(16,32,37,42)}$ In order to ensure the soundness of the examination, the examiners need to be calibrated. ${ }^{(23)}$ Topping and Pitts introduced International Cries Detection and Assessment System (ICDAS) in which the enamel lesions are objectively categorized (Table 1). ${ }^{(40)}$ ICDAS has been found to have acceptable accuracy in detecting enamel lesions with high specificity, and its accuracy was significantly increased by gathering various indicators, such as visual appearance, location of the lesion, tactile sensation, and gingival health. ${ }^{(43,44)}$ Kuhnisch et al have suggested that reliable evaluation can be performed by utilizing a precise scoring system, called the Universal Visual Scoring System. ${ }^{(45)}$ In this system, smooth surface caries is evaluated according to the severity and the discoloration of the lesions, following the guideline (Table 2). 


\begin{tabular}{|c|l|}
\hline Code & Presentation \\
\hline 0 & Sound tooth surface ï no evidence of caries \\
\hline 1 & First visual change in enamel after prolonged air drying \\
\hline 2 & Distinct visual change in enamel with no air drying \\
\hline 3 & $\begin{array}{l}\text { Localized enamel breakdown with no visible dentin or underlying } \\
\text { shadow }\end{array}$ \\
\hline 4 & Underlying dark shadow from dentin but without cavitation into dentin \\
\hline 5 & Distinct cavity with visible dentin \\
\hline 6 & $\begin{array}{l}\text { Extensive distinct cavity with visible dentin involving half of the tooth } \\
\text { surface or more }\end{array}$ \\
\hline
\end{tabular}

Table 1. ICDAS codes for caries objectively and meticulously categorize different stages of enamel and dentin defects. 


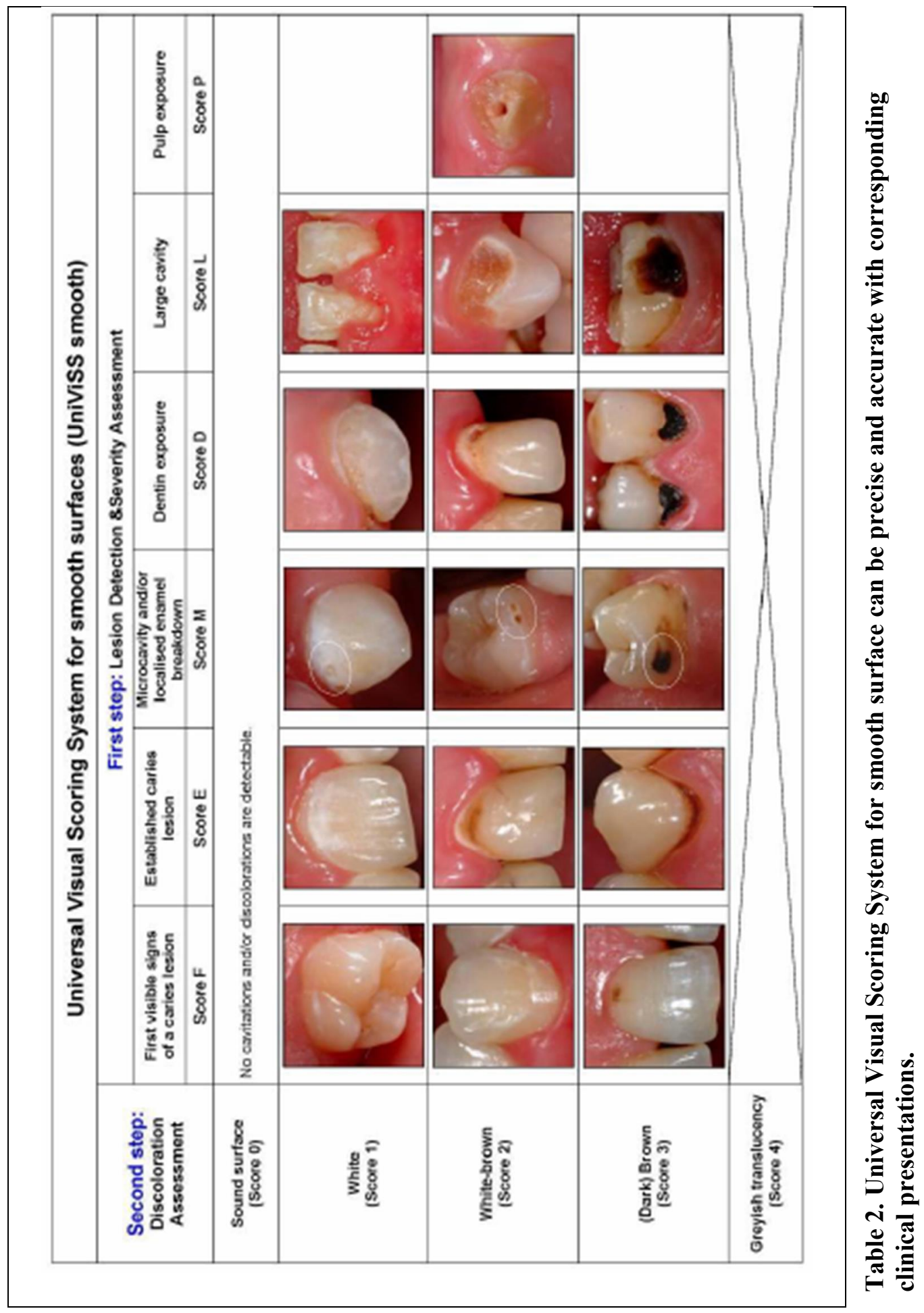




\section{Clinical Photographs}

Photographs have been used in many studies, evaluating the development of white spot lesions in-vivo. ${ }^{(4,19,38)}$ While the visual examination method needs to be performed at the beginning and at the end of the study, which could be multiple months apart; the photographs can be stored during the study period and evaluated at one time point by the examiner. ${ }^{(23)}$ Benson et al also advocated the possibility of blinding in which the photographs can be randomly organized, enabling objective judgment. ${ }^{(23)}$

Traditionally, photographic slides were taken at a designated distance from the tooth surface at a $90^{\circ}$ angle. ${ }^{(46)}$ The camera should be equipped with a macro lens, a filter, and a ring flash. Some photographic slides have been converted into digital images to facilitate the storage and the evaluation at 1:1 magnification. ${ }^{(4)}$ Nowadays, most of the clinical photographs are taken in a digital format, and the magnification can be adjusted with ease. Alteration of the saturation and enhancement of the color of the image can be readily done by utilizing computer software. If a proper photographic technique is practiced, its benefit can offset its short-comings. ${ }^{(23)}$

Benson et al advocates that photographs can be inexpensive and portable method of detecting caries, compared to newly developed equipment, specifically compared to Quantitative Light-induced Fluorescence (QLF). ${ }^{(4)}$ The extent of demineralization can be overestimated using photographic examination, ${ }^{(4,47)}$ but the accuracy of the examination can be significantly heightened by preparing clean and dry tooth surfaces. ${ }^{(48)}$ 


\section{Laser Fluorescence}

A novel technique, using the mechanism of optical refraction, has been adopted by dental caries detection devices. Enamel is fluorescent in nature because of its inorganic and organic components, and as these components become deprived in carious lesions, its fluorescence gets altered in the area. ${ }^{(49)}$ Angmar-Mansson and ten Bosch postulated four possible mechanisms for this decreased fluorescence in enamel lesions: the light scattering in the lesion having a shorter path; the scattered light acting as a barrier; molecular environment being changed; and proteinic chromophores being removed. ${ }^{(50)}$ Currently, there are two main laser fluorescence devices in the market: QLF and DIAGNOdent.

\section{A. QLF device}

The device produces a visible blue light with a wavelength range of $370 \mathrm{~nm}$ to 480nm from an argon laser. ${ }^{(41)}$ As the light passes through a tooth surface, yellow to orange fluorescence is induced, and the fluorescent image is captured by the device. Demineralized area is darker in the image compared to the natural enamel. ${ }^{(41)}$ Benson et al found very high specificity and sensitivity with QLF in detection of early demineralization, and they concluded that mineral loss can be more accurately quantified using QLF, compared to photographs. ${ }^{(4)}$ Boersma et al observed a same pattern of caries detection between visual examination and QLF; however, QLF was more sensitive to detecting early enamel lesions, which was also found in HeinrichWeltzienôs study. ${ }^{(27,48)}$ In order to achieve accurate readings, the tooth surface has to be free of restorative material, plaque, calculus, stain, and 
overgrowth of gingiva. ${ }^{(48)}$ Even though QLF equipment is expensive, technique-sensitive, and in need of dark surroundings, the possibility of quantitative analysis of caries is a significant advantage. ${ }^{(4)}$

\section{B. DIAGNOdent}

DIAGNOdent was invented in 1998 in Germany, and since then it has been successful in detecting occlusal and proximal caries. ${ }^{(11)}$ Many studies have shown its clinical application in detection of smooth surface caries. ${ }^{(51-53)}$ The device produces a visible red light with a wavelength of $655 \mathrm{~nm}$, and only through the defective enamel structure is the fluorescence produced due to bacterial byproduct. ${ }^{(41,49)}$ Once the fluorescence as well as ambient light is captured by the device, any ambient light gets suppressed, and the fluorescent light is registered to give a numeric value between 0 and $99 .{ }^{(41)}$ Drying the tooth surface for 10 seconds increases the accuracy and reproducibility, ${ }^{(12)}$ and its intra-examiner agreement has been shown to be very high $(0.96)$ with moderately high inter-examiner agreement $(0.75) .{ }^{(51)}$ Croll and Tyma acknowledge the ingenuity of the device; however, they also emphasize that clinicians should utilize it as confirming information to other procedures, including clinical observation, tactile examination, and radiographic evaluation. ${ }^{(49)}$ 


\section{Microradiography}

Microradiography, also called historadiography, is one of the former methods of studying the density of a tissue sample. Several studies have utilized microradiography to semi-quantify mineral loss from the tooth structure. ${ }^{(54,55)}$ A tooth sample with carious lesion is thinly prepared at the thickness of 100 to $150 \mu \mathrm{m}$ and placed on high-resolution radiographic film along with an aluminum wedge with $25 \mu \mathrm{m}$ steps, which provides a standard density measurement. ${ }^{(56)}$ The specimen is irradiated to capture a radiographic image, and the image is examined under a microscope to evaluate the mineral density and tissue loss. Once the relative thicknesses are measured from the radiographic image, mineral content can be calculated by using the X-ray linear attenuation coefficients of aluminum (109.138) and enamel hydroxyapatite (205.245). ${ }^{(57)}$

\section{Microhardness Test}

Microhardness testing is often utilized on solid materials to evaluate their resistance to a given force, such as dental ceramic and composite materials. ${ }^{(58,59)}$ Among several hardness testing methods, Knoop microhardness testing is the one mostly used in in-vitro enamel demineralization studies. ${ }^{(2,5,60,61)}$ This method requires a small amount of specimen, and it shows a direct correlation between the microhardness and the mineral loss of the enamel. A cross-sectional wafer of enamel is prepared, and a pyramidal-shape diamond point is pressed against the surface at a set load. The depth of the indentation is then compared to the Knoop Microhardness Number to evaluate the materialôs hardness. ${ }^{(62)}$

$$
\text { Knoop Microhardness Number }=\frac{\text { Load }(\mathrm{kgf})}{\text { Impression area }\left(\mathrm{mm}^{2}\right)}
$$




\section{Polarized Light Microscopy}

Examination of enamel under a microscope reveals orderly stacked enamel prisms. Among these tightly locked prismatic enamel crystals is interprismatic enamel, which has a perpendicular orientation to the prismatic enamel. Due to the orientation of these enamel substances, human enamel is considered birefringent with two different refractory indices. A polarized light shined through an enamel specimen can either travel through the parallel crystals or get reflected by perpendicular crystals. ${ }^{(6)}$ Perpendicular axis signal is present but at a very low degree in sound enamel. As the enamel undergoes demineralization process, the perpendicular axis signal is increased due to the high depolarization. This phenomenon allows the extent of demineralization to be quantified. Once a $200 \mu \mathrm{m}$ specimen is prepared from the affected enamel lesion, it is examined under a polarizing microscope to evaluate the mineral loss, which is represented by the loss of birefringence in the carious lesion..$^{(6,57)}$

\section{Confocal Microscopy}

Confocal microscopy has been extensively used in cell biology, but recent improvement in this technique has enabled even in-vivo examination of skin and corneal cells. ${ }^{(63-65)}$ In dentistry, enamel and dentin structures as well as tooth-restoration interface

have been visualized and studied using confocal microscopy in vitro. ${ }^{(66,67)}$ The sample is scanned with a spot size laser light source, and the reflected light gets registered to produce an image. Stray light from the out-of-focus planes is eliminated by a pinhole placed in front of the detector, which increases the optical resolution and contrast of the image. Digital software programs can easily record and process a series of twodimensional images at different depths to produce three-dimensional structures up to a 
few hundreds of microns. This process eliminates the need for thin section preparation during which valuable information can be lost. ${ }^{(65)}$

In order to visualize the pathological process within hard tissues, such as enamel, dentin, and bone, fluorescence dye has been utilized to stain the specimens. ${ }^{(56)}$ Most commonly used dye is rhodamine B dye, which is mostly taken up in porous area and able to show the lesions. ${ }^{(7)}$ Kwon et al studied the patterns of dye penetration into enamel and dentin tissues and concluded that water-soluble rhodamine B dye molecules can travel through interprismatic spaces in the enamel and dentinal tubules in the dentin. ${ }^{(68)}$ Fontana et al also showed that the most suitable images were produced when a $0.1 \mathrm{~m} M$ rhodamine B solution was used for confocal microscopy. ${ }^{(56)}$

In dentistry, confocal microscopy has been utilized by many investigators to evaluate subsurface changes of enamel and dentin. Cook et al and Watson et al extensively studied the cutting surfaces resulted from air abrasion and restorative tooth preparation by visualizing the tooth samples using confocal microscopy. ${ }^{(69,70)}$ Microleakage of endodontically treated teeth could be visually examined by this technique ${ }^{(71)}$ and the effect of bleaching on enamel surface was well documented by Berger et al. ${ }^{(66)}$ Behnan et al applied the confocal microscopy technique to their orthodontic demineralization study and concluded that light-cured ýlled resin and fluoride varnish have a higher potential of preventing demineralization than amorphous calcium phosphate (ACP) cement or casein phosphopeptide-ACP paste. ${ }^{(7)}$

Fontana et $\mathrm{al}^{(56)}$ acknowledged the convenience of no need to prepare a thin enamel section in confocal microscopy, which would have been necessary in microradiography. By using $100 \mu \mathrm{m}$ sections in transversal microradiography and enamel 
sections cut in half in confocal microscopy, three parameters in both methods were compared: area of the lesion, total dye fluorescence intensities, and average dye fluorescence intensities. It was concluded that the values in each parameter were significantly correlated, supporting the capability of confocal microscopy in generating the same findings without a thinly prepared sample. ${ }^{(56)}$

Another correlational study conducted by Gonzales-Cabezas et al supported the findings of Fontana et al. ${ }^{(56,72)}$ The same parameters were evaluated between microradiography and confocal microscopy for enamel remineralization, and the lesion area was found to be more correlated than the other parameters. The study confirmed the potential value of confocal microscopy, and the authors concluded that this method could be adequately used in quantifying demineralization and remineralization of enamel specimens. $^{(72)}$

\section{PREVENTION OF DEMINERALIZATION}

\section{Reinforced Oral Hygiene}

Many orthodontic patients with fixed appliances on labial tooth surfaces experience difficulty performing appropriate oral hygiene techniques, especially with bonding materials providing rough surfaces for plaque to easily adhere. ${ }^{(31,32)}$ According to Al Maaitah et al, patient $\hat{Q}$ initial oral hygiene status has a positive correlation with his or her tendency to develop white spot lesions during orthodontic treatment. ${ }^{(36)}$ Patientsô behavior may be modified by periodic reinforcement by a clinician; however, it has been reported that any permanent change in their behavior would be difficult to achieve. ${ }^{(37)}$ Arslan et al found a positive correlation between the incidence of white spot lesions and 
the frequency of oral hygiene instructions during the treatment period, showing that patients with poor oral hygiene require more oral hygiene instruction throughout their treatment to reduce enamel demineralization. ${ }^{(33)}$ Regarding the use of the electric toothbrush, Heintze et al advocated that it would help the patients with poor oral hygiene to obtain a better removal of dental plaque. ${ }^{(73)}$ Heasman et al, on the other hand, did not find a significant difference between electric-toothbrush users and manual-toothbrush users. $^{(74)}$

\section{Argon Laser Irradiation}

Argon laser irradiation method was recently introduced to the orthodontic patient management. Argon laser has various wavelengths, but demineralization studies routinely have used the wavelength range of $470 \mathrm{~nm}$ to $488 \mathrm{~nm}$, which appears blue to green to human eyes. ${ }^{(14)}$ The mechanism is not well understood, but some studies have shown its ability to change the micromorphology of the enamel surface and render a hardened external surface. ${ }^{(75,76)}$ Blankenau et al introduced the use of argon laser to reduce demineralization, and a $29.1 \%$ decrease in lesion depth was reported in their study. ${ }^{(75)}$ Noel et al also supported this finding in their study, where $15 \%$ and $22 \%$ reduction of the lesion depth was observed with 5-second and 10-second argon laser curing. ${ }^{(76)}$ In the study done by Adserson et al, the enamel surfaces treated with argon laser alone showed more than $90 \%$ decrease in lesion depth and decrease in lesion area, compared to the control group. ${ }^{(14)}$ However, in-vivo study conducted by Elaut found no statistically significant difference in the level of plaque accumulation and the incidence of decalcification. ${ }^{(77)}$ 


\section{Fluoride}

Fluoride has been in many applications in reducing enamel demineralization, ranging from fluoridation of drinking water to fluoride-releasing restorative materials. Fluoride ion can be incorporated into enamel crystalline, forming fluorhydroxyapatite structure, which is more resistant to dental caries than hydroxyapatite. ${ }^{(25,78)}$ Calcium fluoride, a cariostatic reaction product of fluoride treatment, is able to stay in dental plaque, and high concentration of calcium fluoride in plaque can later be incorporated into enamel structure. ${ }^{(78,79)}$

\section{Topical Fluoride}

The use of topical fluoride, in the forms of sodium fluoride toothpaste, stannous fluoride rinse, and acidulated phosphofluoride rinse, has been exclusively advocated by many authors. ${ }^{(16,17,80,81)}$ Geiger et al found a $25 \%$ reduction in the incidence of white spot lesions among patients that had in-office acidulated phosphate gel treatment and fluoride rinse at home. ${ }^{(37)}$ One-time application of topical fluoride has little or no effect on preventing demineralization; thus, it is more beneficial to have the patients to practice regular use of topical fluoride. ${ }^{(37,80)}$ However, more than $50 \%$ of patients showed little or no compliance, and the reduction in demineralization was observed only in the compliant patient group, $11 \%$ of all participants. ${ }^{(37)}$ Stratemann and Shannon observed a reduction in incidence of enamel demineralization by half with the use of $0.4 \%$ stannous fluoride rinse. ${ }^{(82)}$ They concluded that the frequency of application was the most important factor, and the exposure to topical fluoride should be daily. ${ }^{(82)}$ Alexander et al found either onetime use of a highly concentrated fluoride dentifrice daily or two-time use of a highly concentrated fluoride gel daily can be effective in preventing enamel demineralization. ${ }^{(16)}$ 


\section{$\underline{\text { Fluoride varnish }}$}

Fluoride varnish is commonly used for pediatric patients because it quickly hardens, eliminating the possibility of swallowing a high concentration of fluoride. Fluoride varnish applied in orthodontic patients has shown promising results in many studies. $^{(3,18,83)}$ Vivaldi-Rodrigues et al found a $44.3 \%$ reduction in the incidence of white spot lesions among the patients treated with fluoride varnish every 3 month. ${ }^{\left({ }^{83}\right)}$ In a study conducted by Shafi, the incidence of enamel demineralization was $7.4 \%$ in teeth treated with fluoride varnish, compared to $23 \%$ in control group. ${ }^{(84)}$ Todd et al noted a $50 \%$ reduction in both depth and area of the lesion in-vitro, and the study showed that fluoride facilitated the uptake of calcium and phosphate ions by enamel structure. ${ }^{(85)}$ Gontijo et al observed an increase in Calcium fluoride deposition in enamel after the fluoride varnish treatment. ${ }^{(86)}$ Farhadian et al strongly suggested the use of fluoride varnish for susceptible non-cooperative patients, once their study showed a $40 \%$ reduction in lesion depth from a one-time application of fluoride varnish, containing 12.6\% Calcium fluoride and $6 \%$ Sodium fluoride. ${ }^{(18)}$

\section{Fluoride-releasing resin and cements}

Since the benefit of fluoride has been well established, several bonding agents and cements with fluoride have been manufactured. Many studies confirmed that the release of fluoride from these materials aids in prevention of demineralization. ${ }^{(60,87)}$ In a study conducted by De Moura et al, the use of resin-modified glass ionomer cement significantly reduced the incidence of carious lesions due to the fluoride release in a cariogenic-challenging enviroment. ${ }^{(60)}$ Gorton and Featherstone reached the same conclusion; however, the effect of fluoride did not affect the whole mouth. ${ }^{(61)}$ McNeill et 
al evaluated the long-term change in the fluoride release from resin materials and concluded that the rate of fluoride release constantly decreased over time after a peak on the first day of application; however, even after 6 months, the amount of fluoride release was higher than what was necessary to prevent demineralization process. ${ }^{(87)}$ Oggard et al observed no elevation in fluoride concentration in saliva during a 6-month period and came to a conclusion that the cariostatic potential of fluoride-releasing cements was due

to the localized release of fluoride rather than the incorporation of fluoride into saliva. ${ }^{(79)}$ Bishara et al speculated that the prevention of demineralization was either from consistent fluoride release at a low concentration or from the burst of fluoride release at the time of application, changing the enamel structure. ${ }^{(88)}$

\section{Sealant}

Pit and fissure sealant, mainly composed of bis-Glycidyl methacrylate, was first introduced in dentistry as a preventive measure in 1960ôs, and it has successfully decreased the incidence of occlusal caries over a long period of time. ${ }^{(89)}$ Simonsen proved the efficacy of pit and fissure sealants by observing $27.6 \%$ of complete and $35.4 \%$ of partial retention rates 15 years after their application, along with $74 \%$ of the teeth with sound enamel. ${ }^{(90)}$

Sealants have been adopted by orthodontics since composite bonding of brackets has become a common practice. In 1980, Ceen tested several filled and unfilled sealants to conclude that the thickness of the sealant layer varies greatly among various products, spanning from 0 to $228 \mu \mathrm{m} .{ }^{(91)}$ Ceen explained that the main problem was the oxygen inhibition of polymerization, leading to the loss of sealant due to ñwashingò. ${ }^{(91)}$ 
Zachrisson also described this phenomenon and further concluded in his study that sealants failed to protect the enamel because of non-polymerization due to oxygen inhibition, technique sensitivity, and low abrasion resistance. ${ }^{(92)}$ In a clinical setting, Wenderoth et al and Leizer et al both observed no significant difference in prevention of enamel demineralization between sealant and control groups, partially due to the sensitivity of the technique. ${ }^{(38)}$ Farrow et al supported the same conclusion in their invitro study, where unfilled sealant, filled flowable composite, and adhesive were compared to control group. ${ }^{(93)}$

However, many other in-vitro and in-vivo studies have shown the benefit of the use of sealants for orthodontic patients. ${ }^{(5,19-21,94)}$ Frazier et al examined the enamel surfaces under polarized light microscopy and found $80 \%$ less incidence of demineralization in the teeth treated with unfilled resin. ${ }^{(20)}$ Buren et al also noted $72 \%$ reduction in lesion depth among the specimens treated with unfilled sealant. ${ }^{(21)} \mathrm{Hu}$ and Featherstone, on the other hand, found that the degree of mineral loss in unfilled resin group was similar to that in control group. ${ }^{(5)} \mathrm{Hu}$ and Featherstone also evaluated the efficacy of Pro Seal, a filled fluoride-releasing light-cured sealant, and found almost complete inhibition of demineralization. They concluded that the thickness and the abrasion resistance of sealants highly affect the duration of the protection. ${ }^{(5)}$ Banks and Richmond, however, found no statistically significant difference between viscous and non-viscous sealants, and both types of sealants provided protection against demineralization by reducing the incidence of white spot lesions by $13 \%{ }^{(39)}$ Van Bebber et al studied the retention rate of the highly filled sealants, $30 \%$ and 50\%, to that of Pro Seal, which has a filler content of $18 \%$. In their study, sealants with higher filler content 
showed less retention rate due to the increased difficulty of application caused by high viscosity. ${ }^{(46)}$

In Behnanôs in-vitro study, the depth and the severity of lesions were significantly reduced in Pro Seal treated specimens, ${ }^{(7)}$ and the same trend was found in Burenôs study where $92 \%$ reduction of the lesion depth was recorded with the use of Pro Seal. ${ }^{(21)}$ Heining and Hartmann clinically observed the incidence of white spot lesions in sealant group to be reduced to half when compared to control group, and this was in agreement with the findings that Ghiz et al achieved in their study. ${ }^{(19,95)}$ Ghiz et al concluded that sealant treatment was more beneficial if the patient had fair to poor oral hygiene. ${ }^{(19)}$ In the study reported by Tanna et al, demineralization took place in the sealant treated teeth only when there was a break in the sealant layer. ${ }^{(94)}$ Frazier observed similar results and speculated the reasons for the breaks in sealant layer to be possible contamination of the surface or incomplete application of the materials. ${ }^{(20)}$ 


\section{CHAPTER III - MATERIALS \& METHODS}

This chapter includes the sample description, methodology, instrumentation, data collection, statistical analysis, equipment, and materials for the in-vitro and in-vivo studies.

\section{IN VITRO}

\section{SAMPLE DESCRIPTION}

Twenty-seven extracted human molars were utilized for this study. The selection criteria included: no enamel defect and free of restorations or carious lesions.

\section{METHODOLOGY}

This in-vitro study received approval as a Not Human Subject Research by the Institutional Review Board at West Virginia University.

The extracted teeth samples were submerged in deionized water in a glass container and sterilized in a steam autoclave for 45 minutes at $250^{\circ} \mathrm{F}$ in liquid cycle (VacoMatic Series 3000, American Sterilizer Corp. Erie, PA). ${ }^{(94)}$ Hard and soft tissue debris was removed using a sharp blade. The roots were removed at the cemento-enamel junction using separating discs on straight hand piece. The crowns of the teeth were sectioned into buccal and lingual halves using the separating discs (Figure 4). 


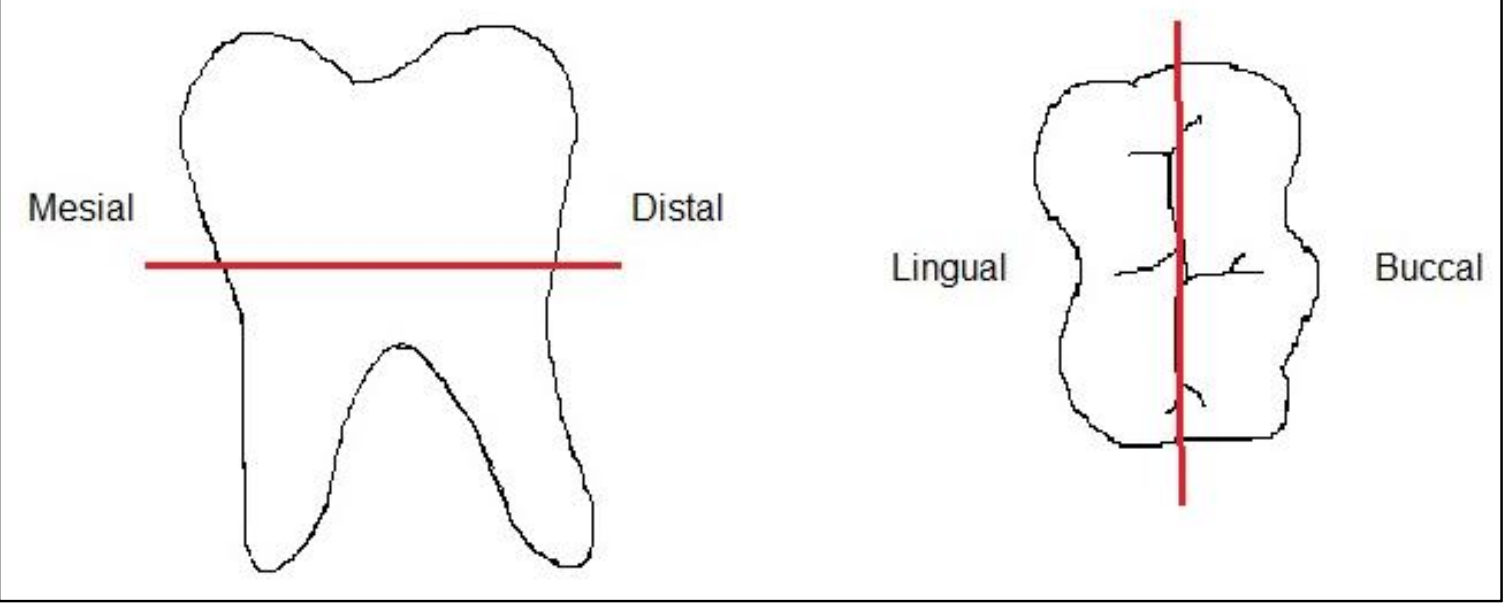

Figure 4. Extracted molars were sectioned at CEJ to remove roots and occlusally into halves.

The prepared specimens were examined for any enamel defects or pre-existing decalcification. The crown samples were mounted in orthodontic resin with the buccal or lingual surfaces facing upward (Figure 5). Individual samples were properly positioned at the center of plastic square mounting molds (Polysciences Inc., Warrington, PA), and orthodontic resin (Dentsply Caulk, Milford, DE) of about $5 \mathrm{~mm}$ thickness was added by salt and pepper technique. The orthodontic resin was completely cured in a pressure pot at $20 \mathrm{lbs}$ of pressure for 20 minutes. The specimen was stored in deionized water until further use. 


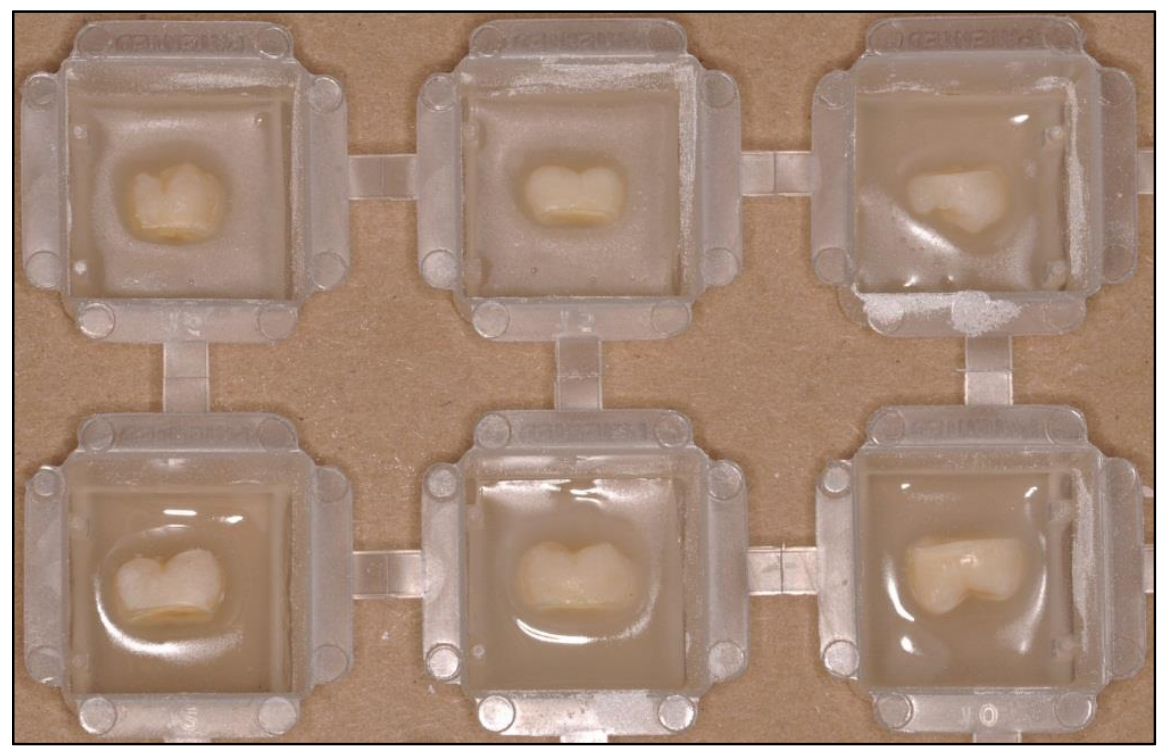

Figure 5. Molar halves were placed in plastic square mounting molds and fixated with resin.

In order to seal any exposed dentin and pulp, nail varnish (Loreal Nail Varnish, Loreal, New York, NY) was applied at the junction of the tooth and orthodontic resin (Figure 6). The samples were dried with compressed air, and a uniform layer of nail varnish was applied on the perimeter of the mounted crown leaving as much of the enamel surface exposed as possible. After 10 minutes of drying at room temperature, a second layer of nail varnish was added. Once the nail varnish was allowed to dry for 10 minutes at room temperature, the specimen was stored in deionized water.
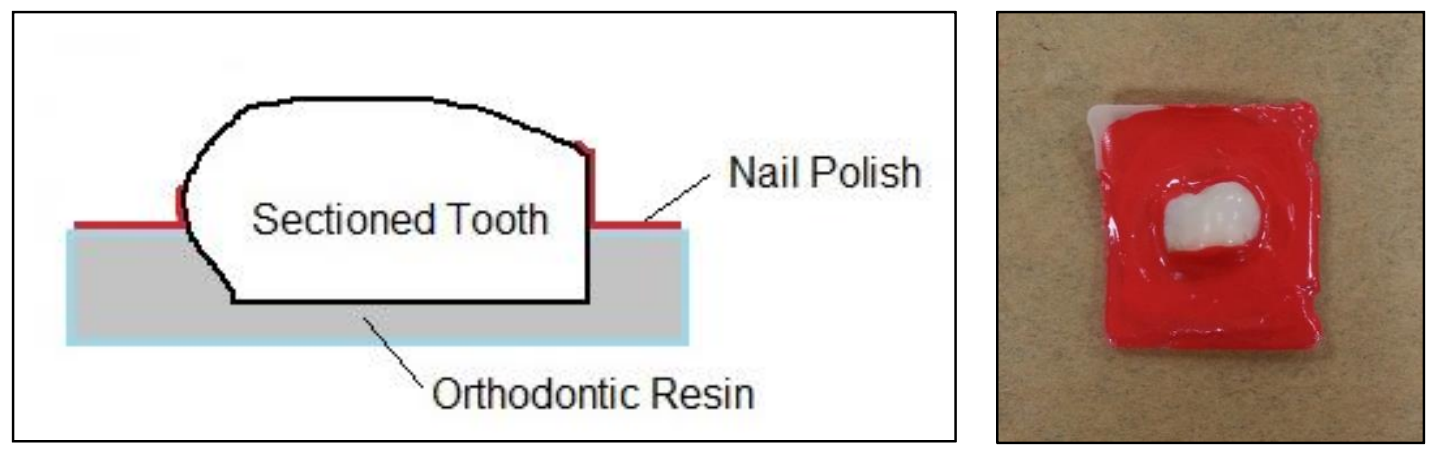

Figure 6. Two coats of nail polish was applied at the periphery of the samples. 
The fifty-four mounted samples were divided into three groups of eighteen: Control group, Opal Seal group, and Pro Seal group. Control group was stored in deionized water until further use. Opal Seal group and Pro Seal group were treated with the following appropriate bonding protocol:

\section{Opal Seal Group Bonding Protocol}

1. Apply gel type $37 \%$ phosphoric acid etch (Ultradent Product Inc., South Jordan, UT) for 20 seconds

2. Rinse with copious water and dry with compressed air from air/water syringe

3. Apply a thin coat of Opal Seal

4. Cure for 20 seconds with an LED curing light (3M Unitek Dental Products, Monrovia, CA)

5. Store in deionized water until further use

\section{Pro Seal Group Bonding Protocol}

1. Apply gel type $37 \%$ phosphoric acid etch for 20 seconds

2. Rinse with copious water and dry with compressed air from air/water syringe

3. Apply a thin coat of Opal Seal

4. Cure for 20 seconds with an LED curing light

5. Store in deionized water until further use

All three treatment groups underwent an oral-cavity-simulated environment, consisting of mechanical brushing treatment, demineralization treatment, and 
remineralization treatment. Several pilot studies were carried out to determine the appropriate time span of each treatment in order to discern the difference in outcomes between treatment groups and control group.

\section{Brushing Treatment}

The brushing apparatus was fabricated using an Oral-B Braun® Ultra ${ }^{\mathrm{TM}}$ Plaque Remover (Braun Inc. Lynnfield, MA) with a 50g weight attached on the brush head to apply a constant pressure (Figure 7).

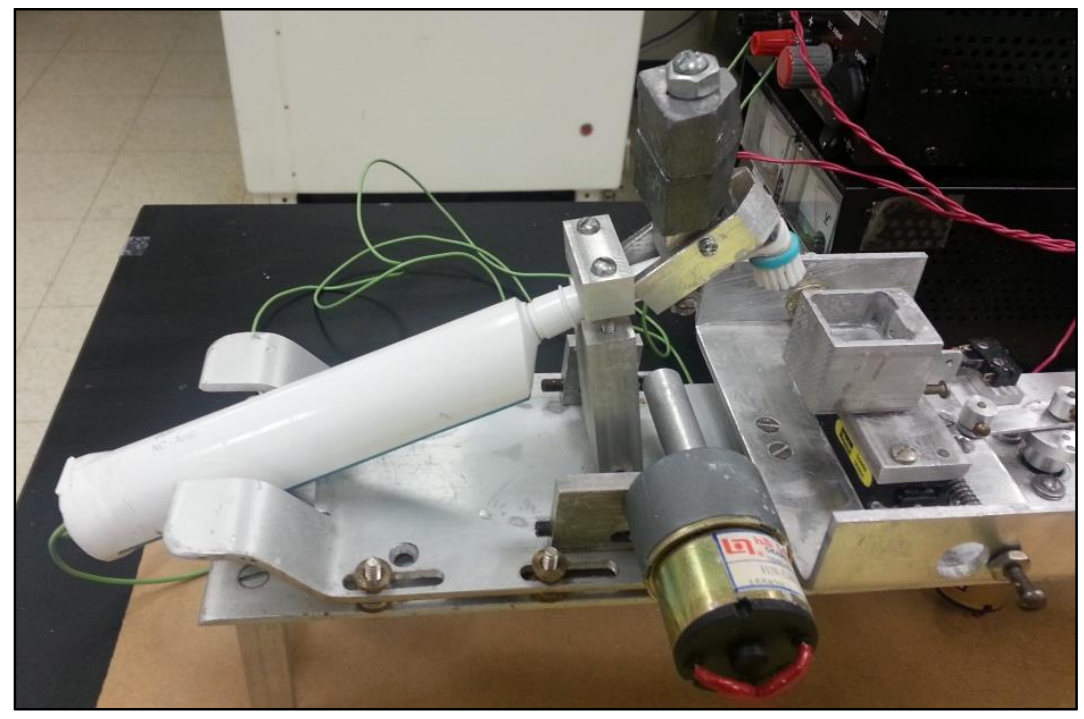

Figure 7. The tooth brushing apparatus was fabricated for uniform brushing treatment.

Toothpaste slurry was made by mixing $10 \mathrm{~g}$ of toothpaste (Colgate Total with $0.24 \%$ sodium fluoride, Colgate Palmolive, New York, NY) in 50mL of deionized water. A mounted sample was placed in the brushing apparatus, and the toothpaste slurry was added on the tooth surface. Hypothetically, a 2-minute tooth brushing twice a day for one month would yield about two hours of mechanical brushing time. Each sample underwent two hours of mechanical tooth brushing with the toothpaste slurry. At the end 
of two hour treatment, the samples were rinsed with deionized water and then stored in deionized water until further use.

\section{Demineralization Treatment}

Ten Cate $\hat{Q}$ demineralization solution with $\mathrm{pH}$ of 4.4 was made with $2.2 \mathrm{mmol} / \mathrm{L}$

$\mathrm{Ca}^{2+}, 2.2 \mathrm{mmol} / \mathrm{L} \mathrm{PO}_{4}{ }^{2-}$, and 50mmol/L acetic acid. ${ }^{(25)}$ The samples in each group were arranged around the outer edge of a 120x90 Pyrex dish (Corning, NY). A 50mm magnetic stirring rod was placed in the middle, and $500 \mathrm{ml}$ of ten Cateôs solution was added to the dish. The Pyrex dish was placed on a stirring plate (Allied Fisher Scientific Thermix stirring plate, Model 310T) at a speed of approximately $75 \mathrm{rpm}$. The samples were kept at room temperature for 24 hours. The $\mathrm{pH}$ of the solution was checked at midpoint and adjusted as needed. After 24 hours, the samples were removed from the solution and thoroughly rinsed with deionized water and stored in deionized water until further use. The demineralization solution was discarded.

\section{$\underline{\text { Remineralization Treatment }}$}

The remineralizing artificial saliva solution with $\mathrm{pH}$ of 7 was made with $20 \mathrm{mmol} / \mathrm{L} \mathrm{NaHCO} 3,3 \mathrm{mmol} / \mathrm{L} \mathrm{NaH}_{2} \mathrm{PO}_{4}$, and $1 \mathrm{mmol} / \mathrm{L} \mathrm{CaCl}_{2}$. The samples were arranged around the outer edge of a 120x90 Pyrex dish with a 50mm magnetic stirring rod in the middle. The samples were submerged in $500 \mathrm{ml}$ of artificial saliva solution, and the Pyrex dish was placed on a stirring plate at a speed of approximately $75 \mathrm{rpm}$. The samples were kept at room temperature for four hours. After four hours, the samples 
were removed from the solution and thoroughly rinsed with deionized water and stored in deionized water until further use.

The samples were categorized according to the lengths of brushing treatment $(0$, 2 , or 4 hours) and demineralization/Remineralization treatment ( 24 or 48 hours). Each group was divided into six subgroups of three samples (Table 3). Each Opal Seal, Pro Seal, and control group had six categories: (1) 0-hour brushing and 24-hour demineralization/remineralization (pH-cycling), (2) 2-hour brushing and 24-hour $\mathrm{pH}$ cycling, (3) 4-hour brushing and 24-hour pH-cycling, (4) 0-hour brushing and 48-hour pH-cycling, (5) 2-hour brushing and 48-hour pH-cycling, and (6) 4-hour brushing and 48hour $\mathrm{pH}$-cycling. 


\begin{tabular}{|c|c|c|c|c|}
\hline \multirow{2}{*}{\multicolumn{2}{|c|}{ Group }} & \multicolumn{3}{|c|}{ Simulation Treatment Hours } \\
\hline & & \multirow{2}{*}{$\frac{\text { Brushing }}{0}$} & \multirow{2}{*}{$\frac{\text { Demineralization }}{24}$} & \multirow{2}{*}{$\frac{\text { Remineralization }}{24}$} \\
\hline \multirow{6}{*}{ Control } & $0-24-24$ & & & \\
\hline & $0-48-48$ & 0 & 48 & 48 \\
\hline & $2-24-24$ & 2 & 24 & 24 \\
\hline & $2-48-48$ & 2 & 48 & 48 \\
\hline & $4-24-24$ & 4 & 24 & 24 \\
\hline & $4-48-48$ & 4 & 48 & 48 \\
\hline \multirow{6}{*}{ Opal Seal } & $0-24-24$ & 0 & 24 & 24 \\
\hline & $0-48-48$ & 0 & 48 & 48 \\
\hline & $2-24-24$ & 2 & 24 & 24 \\
\hline & $2-48-48$ & 2 & 48 & 48 \\
\hline & $4-24-24$ & 4 & 24 & 24 \\
\hline & $4-48-48$ & 4 & 48 & 48 \\
\hline \multirow{6}{*}{ Pro Seal } & $0-24-24$ & 0 & 24 & 24 \\
\hline & $0-48-48$ & 0 & 48 & 48 \\
\hline & $2-24-24$ & 2 & 24 & 24 \\
\hline & $2-48-48$ & 2 & 48 & 48 \\
\hline & 4-24-24 & 4 & 24 & 24 \\
\hline & $4-48-48$ & 4 & 48 & 48 \\
\hline
\end{tabular}

Table 3. Six subgroups in each treatment group had three specimens, and each specimen was marked accordingly. 


\section{DATA COLLECTION}

Each specimen was completely enclosed in orthodontic resin in order to avoid any damage to the treated surface and to facilitate sectioning of the samples. The square orthodontic resin mounting with the embedded sample was placed back in the plastic resin forming jig. Orthodontic resin was added via salt and pepper technique to fully enclose the sample (Figure 8). The enclosed samples were placed in a pressure pot at 20 lbs air pressure for 20 minutes to ensure the complete setting of the resin. The samples were stored in deionized water until further use.

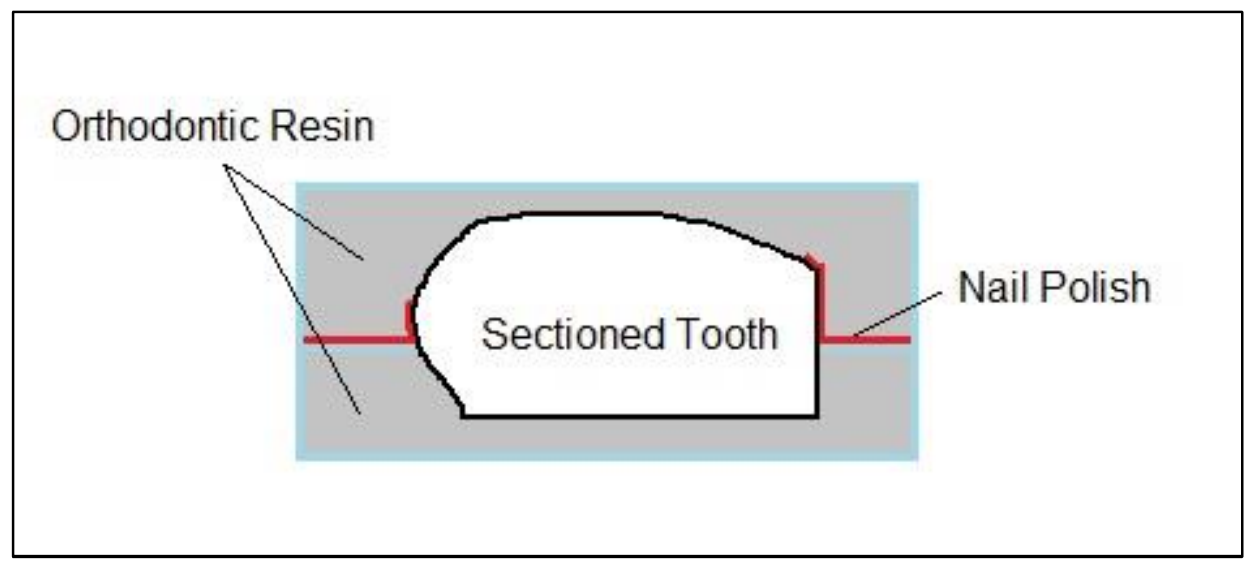

Figure 8. Samples were fully enclosed in orthodontic resin in order to prevent demage.

Each sample was sectioned using Beuhler ${ }^{\circledR}$ Isomet ${ }^{\mathrm{TM}}$ Low Speed Saw (Beuhler, Lake Bluff, IL) with a 4ò diamond wafering blade (Beuhler, Lake Bluff, IL). A first cut was made after placing the sample with the treated enamel surface perpendicular to the blade (Figure 9). The blade was placed in an occluso-gingival direction. A second cut was made in the same direction after adjusting the blade by $\sim 250 \mu \mathrm{m}$. This created a sample section of $\sim 250 \mu \mathrm{m}$ in a mesio-distal dimension. Two of these slices were made 
from each sample: one from mesial and the other from distal (Figure 10). The sectioned samples were stored in deionized water until further use.

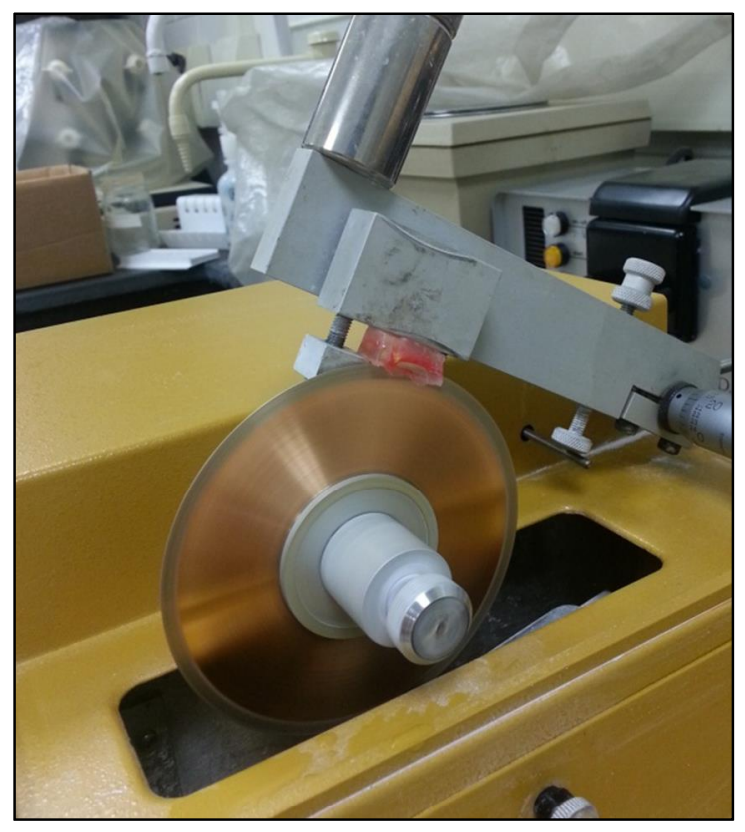

Figure 9. Low speed saw blade was placed perpendicular to the treated enamel surface.

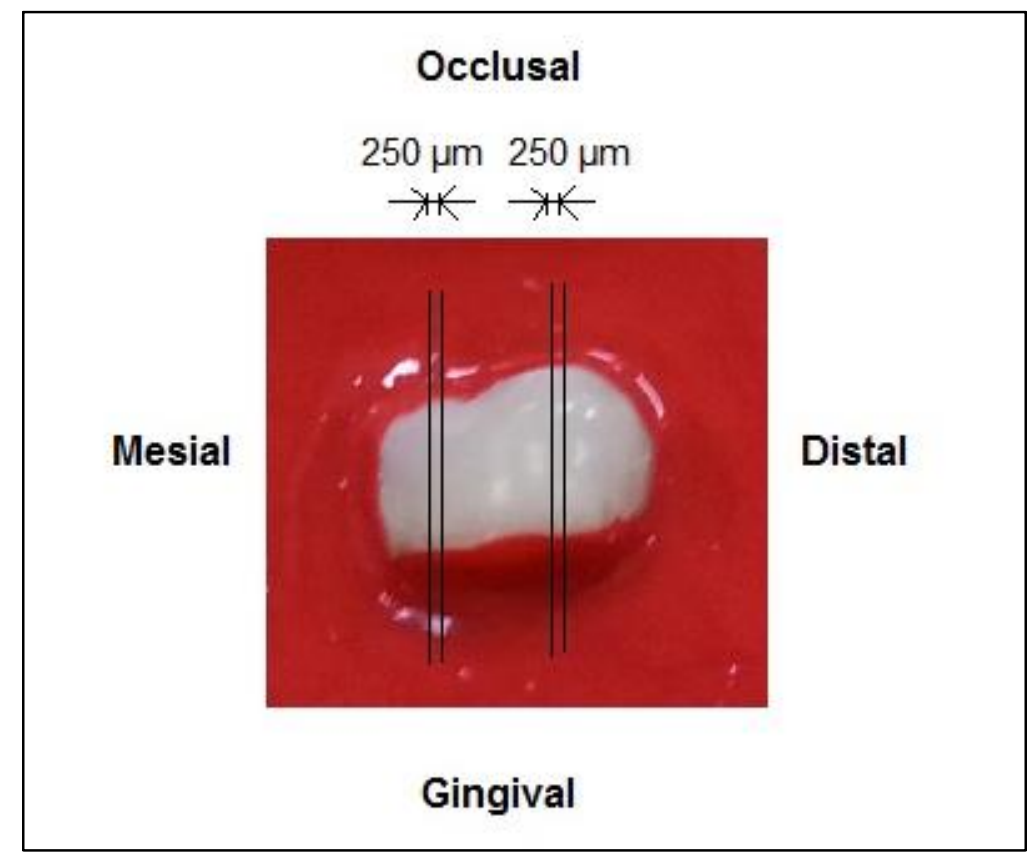

Figure 10. Two $250 \mu \mathrm{m}$-thick slices were made from mesial and distal areas. 
Each specimen was treated in Rhodamine B solution. Rhodamine B is a tracer dye that fluoresces under confocal microscopy. $0.1 \mathrm{mM}$ of Rhodamine B solution was prepared by adding $23.95 \mathrm{mg}$ of Rhodamine B dye (Aldrich Chemicals, Milwaukee, WI) to $500 \mathrm{ml}$ of deionized water. The sectioned specimens were stored in the solution for 24 hours, with no subsequent rinsing (Figure 11).

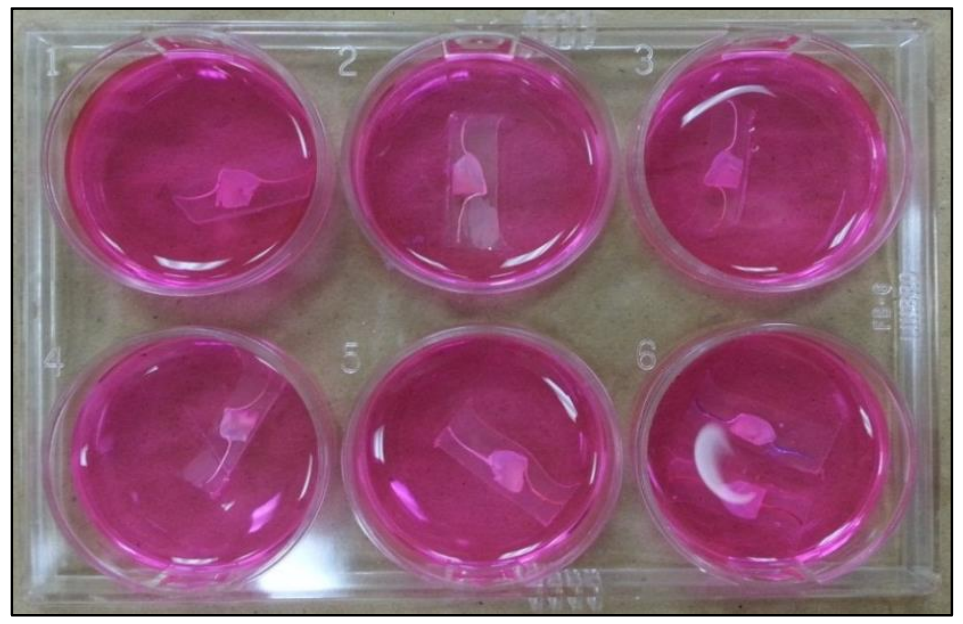

Figure 11. Sectioned samples were treated in Rhodamine B solution for 24 hours.

Rhodamine B dye is absorbed in demineralized tooth structure but does not penetrate into sound enamel or orthodontic resin. In a fluorescent confocal image, the dye absorbed in the demineralized tooth structure will fluoresce, and sound tooth structure or orthodontic resin would appear dark. In a transmitted image, the area with demineralization appears dark, but the sound tooth structure is visible. For this study, both fluorescent and transmitted images were recorded. The fluorescent and transmitted images were combined in the software to provide a composite image, which displays the fluorescent demineralized area, as well as the sound tooth structure and orthodontic sealant (Figure 12). 

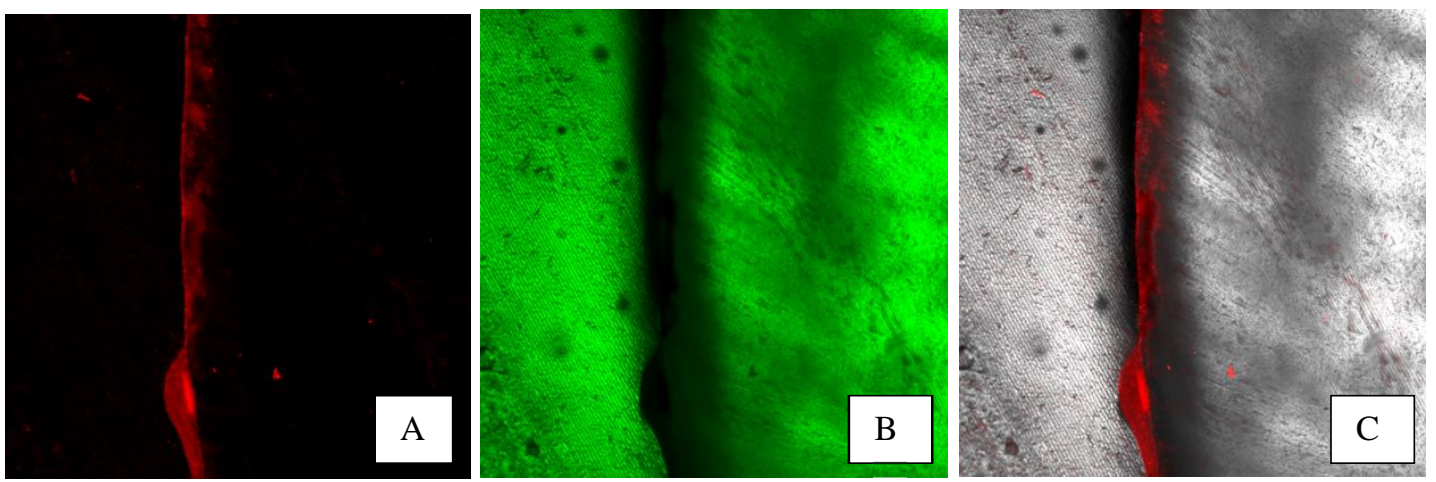

Figure 12. The confocal image (A) shows demineralized area in red, and the transmitted image (B) shows the outline of the tooth. The composite of the two images (C) show the demineralization, tooth structure, and the sealant.

The stained sample was placed under Zeiss Axiovert 100M Microscope (Thornwood, NY), and the specimen was adjusted into focus, using a Plan-Neofluar 10x objective, NA0.30. The specimens were illuminated with HeNe laser (Zeiss, Thornwood, $\mathrm{NY}$ ) with a 543nm excitation wave length under the microscope. Areas were scanned planoparallel to the cut surface of the specimen (Figure 13). Two confocal images were obtained from each slice: one from incisal and the other from gingival (Figure 14). The incisal image was captured at $500 \mu \mathrm{m}$ away from the edge of incisal nail polish. The gingival image was captured at $500 \mu \mathrm{m}$ away from the edge of gingival nail polish. The confocal image, translucent image, and the composite of both images were stored in Tiff format. The sections were stored in deionized water after completion of confocal imaging. 


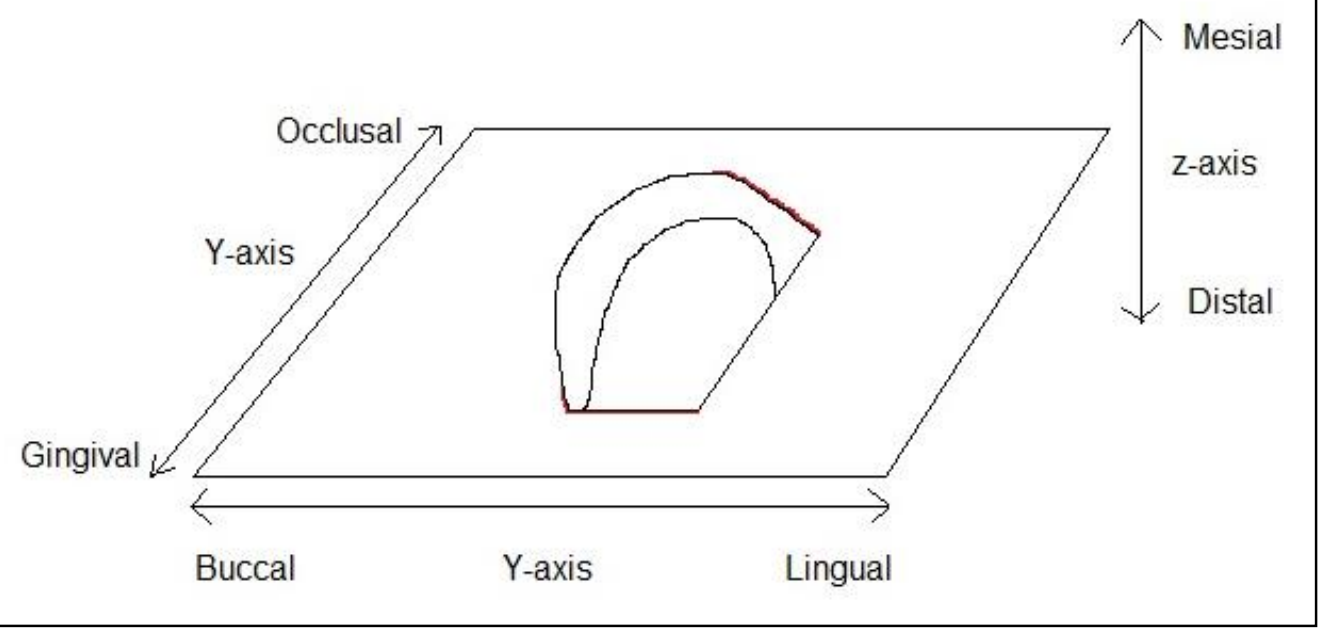

Figure 13. Areas were scanned planoparallel to the cut surface in $X$. $Y$, and $Z$ axis.

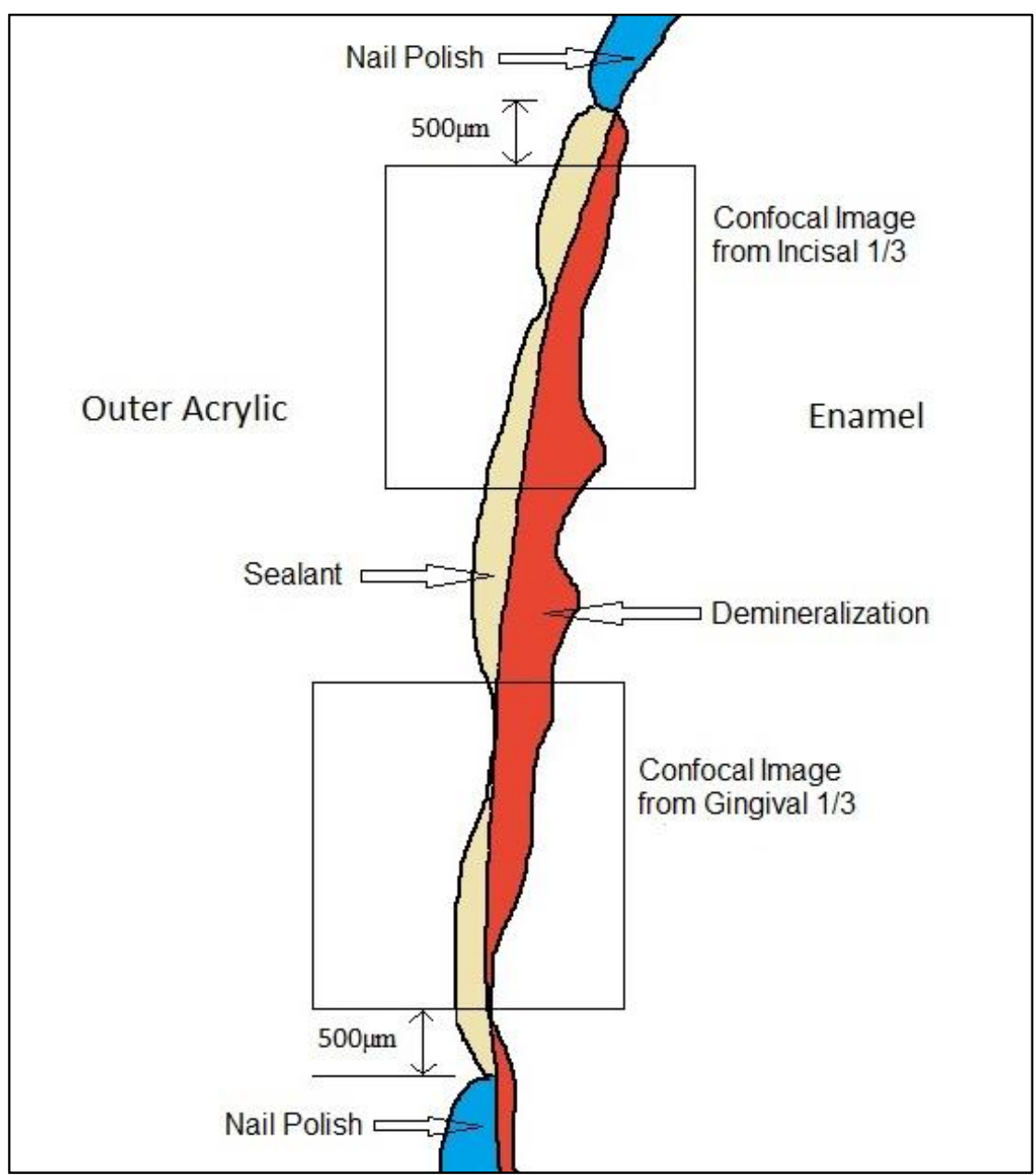

Figure 14. Sectioned slices were scanned with confocal microscopy in occlusal and gingival areas. 
All measurements were recorded using Image J Photoshop software. Three parameters were measured: thickness of remaining sealant, depth of the lesion, and area of the lesion. The sealant thickness and the lesion depth were measured by using the line morphometry feature of the Image $\mathbf{J}$ program. The size of the image was 921.4 $\mu \mathrm{mX} 921.4 \mu \mathrm{m}$, and two measurements were obtained at the $\mathrm{Y}$-axis values of $300 \mu \mathrm{m}$ and $600 \mu \mathrm{m}$ (Figure 15). Measurement of the area was performed by using the area morphometry feature of the Image J program. The demineralized area was identified on the composite image and outlined. The software measured the area of the lesion in $\mu \mathrm{m}^{2}$. Measurements of all the samples were entered into Microsoft Excel spread sheet. In order to check the reliability of the procedure, the measurements were repeated on 20 random samples after one week.

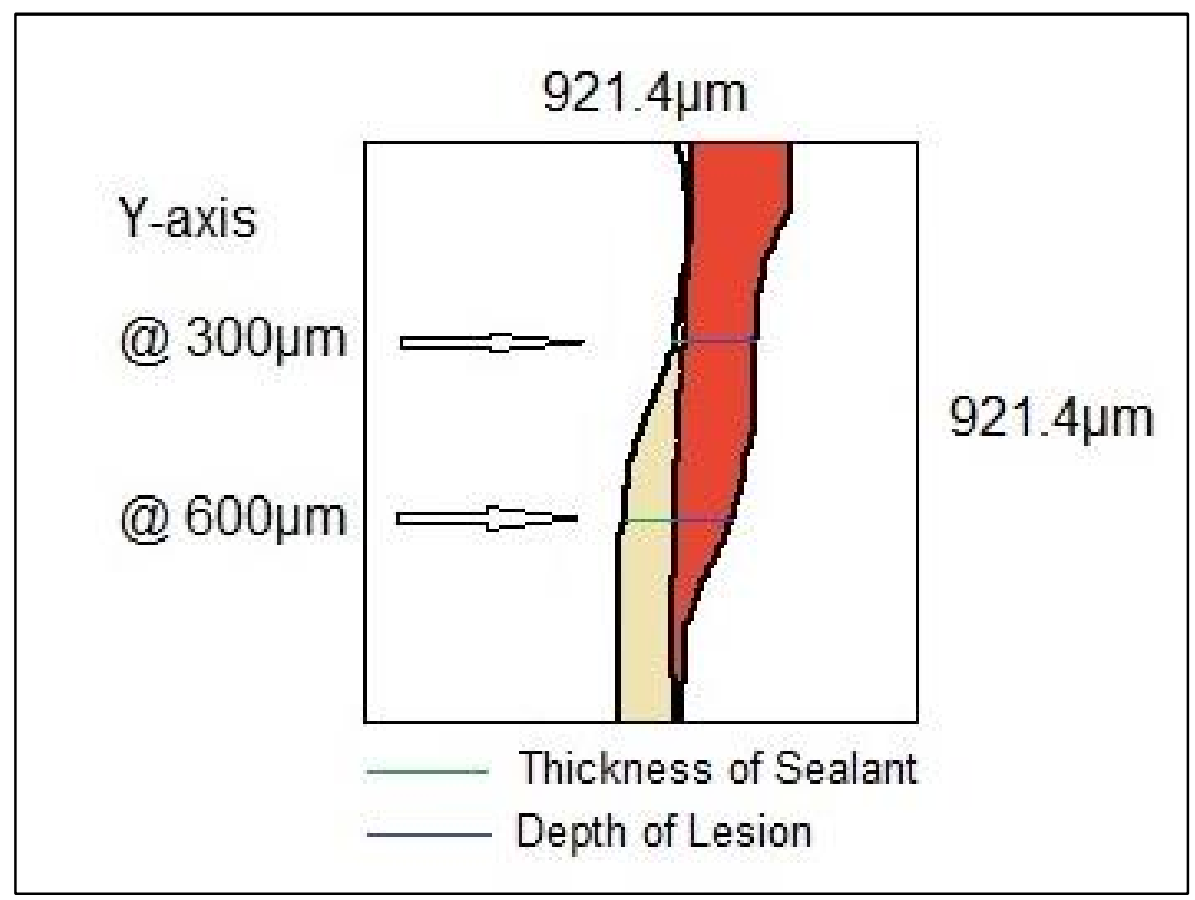

Figure 15. Thickness of remaining sealant and depth of lesion were measured perpendicular to the tooth surface. 


\section{STATISTICAL ANALYSIS}

Difference in sealant thickness, lesion depth, and area were analyzed using analysis of factorial experiments, also known as ANOVA, with p-value less than 0.05. Tukey Kramer test was performed to compare two sealant groups. Intra-class correlation coefficient was done to evaluate the operatorô reliability in measuring the lesions.

\section{EQUIPMENT AND MATERIALS}

54 extracted human tooth halves

Disposable mounting molds (Peel-A-Way® Embedding Mold, Polysciences, Inc., Warrington, PA)

Orthodontic acrylic

Nail varnish

Non-fluoridated pumice (First \& Final Orthodontic Prophy Pumice, Reliance

Orthodontic Products, Inc., Itasca, IL)

Latex prophy cups

Micro cotton tip applicator

Phosphoric acid etchant

Pro Seal

Opal Seal

Ten Cateô demineralizing solution with $\mathrm{pH} 4.46$

- $100 \mathrm{~g}$ of $\mathrm{CaCl}_{2}$ (Calcium chloride)

- $100 \mathrm{~g}$ of $\mathrm{KH}_{2} \mathrm{PO}_{4}$ (Potassium dihydrogen phosphate)

- $100 \mathrm{~g}$ of $\mathrm{KOH}$ (Potassium hydroxide)

- $500 \mathrm{~mL}$ of $\mathrm{CH}_{3} \mathrm{COOH}$ (Glacial acetic acid) 
- Deionized water

Remineralizing solution with $\mathrm{pH} 7$

- $100 \mathrm{~g}$ of $\mathrm{NaHCO}_{3}$ (Sodium bicarbonate)

- $100 \mathrm{~g}$ of $\mathrm{NaH}_{2} \mathrm{PO}_{4}$ (Sodium dihydrogen phosphate)

- $100 \mathrm{~g}$ of $\mathrm{CaCl}_{2}$ (Calcium chloride)

- $500 \mathrm{~mL}$ of $\mathrm{NaOH}$ (Sodium hydroxide)

- Deionized water

Laboratory equipment

- Pressure pot

- Electronic weight scale (Fisher Scientific, Pittsburgh, PA)

- Electronic pH meter (ORION Research, Jacksonville, FL)

- Thermix ${ }^{\circledR}$ stirring hot plate 310T (Fisher Scientific, Pittsburgh, PA)

- Magnetic stirring rods (Fisher Scientific, Pittsburgh, PA)

- Bueler® IsometÊ low speed saw (Lake Bluff, IL)

- Bueler® No. 11-4244 series 4òdiameter 15 HC diamond wafering blade (Lake Bluff, IL)

- LED curing light (Opal Orthodontics, South Jordan, UT)

Laboratory glassware

- $1 \mathrm{~L}$ bottle with caps (4)

- Microscope slides

- Microscope cover slips

- Pipettes

- 120 X 90 Pyrex dish (3) 


\section{IN VIVO}

\section{SAMPLE DESCRIPTION}

The permanent maxillary and mandibular incisors, canines, and premolars of 19 orthodontic patients, a total of 372 teeth, were studied in this study. The patients with more than two congenitally missing teeth, mucogingival defect, pre-existing mottling, or carious lesion were excluded from the study.

The selection criteria included

(1) healthy and free of any major medical condition

(2) fair oral hygiene with no periodontitis

(3) permanent dentition in both arches

(4) no previous orthodontic treatment

(5) comprehensive orthodontic treatment spanning from 16 to 20 months

(6) no functional appliances

\section{METHODOLOGY}

In order to protect the patient $\hat{Q}$ human right, Institutional Review Board approval had been achieved. With the intention of better controlling patient factors, such as oral hygiene, dexterity and diet, the split-mouth technique was used in this study. Each patient served as his or her own control. The patients were randomly assigned to be treated with Opal Seal in one arch and Pro Seal in the other arch. Seven patients had Pro Seal applied on maxillary teeth and Opal Seal on mandibular teeth. Twelve patients had Opal Seal applied on maxillary teeth and Pro Seal on mandibular teeth. 
Four time points were established. $T_{0}$ was at the time of bonding. $T_{6}$ was after 6 months of orthodontic treatment. $T_{12}$ was after 12 months of orthodontic treatment. $T_{D}$ was at the time of appliance removal.

For the purpose of evaluating the patientô oral hygiene, plaque and gingival indices were recorded at every time point $\left(T_{0}, T_{6}, T_{12}\right.$, and $\left.T_{D}\right)$. The modified versions of the indices for this study recorded facial and lingual surfaces of six teeth (

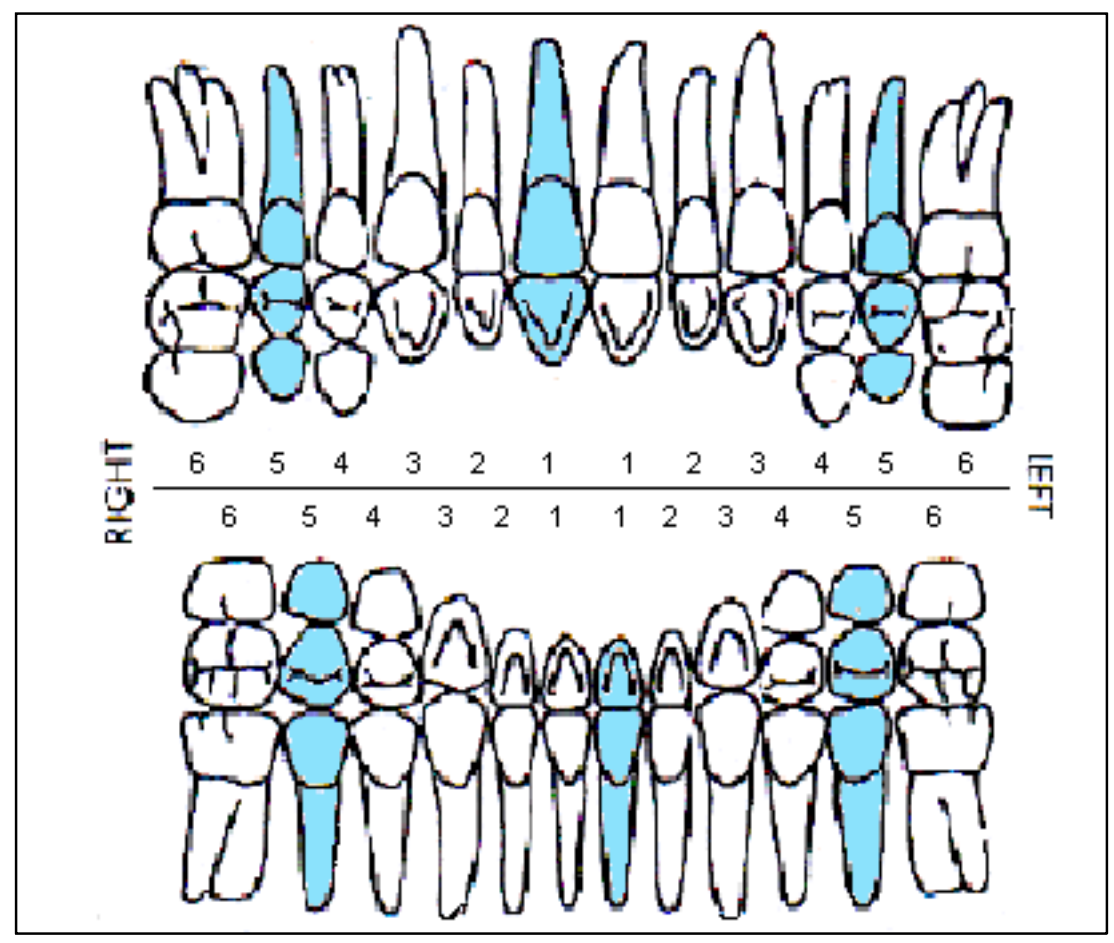

Figure 16): right second premolar (upper right five - UR5), right central incisor (UR1), and left second premolar (UL5) in the maxillary arch, and left second premolar (LL5), left central incisor (LL1), and right second premolar (LR5) in the mandibular arch. The criteria for plaque index were obtained from Silness-Löe Index (Table 4), and the criteria for gingival index were obtained from Gingival Periodontal Index by Oâeary (Table 5). 


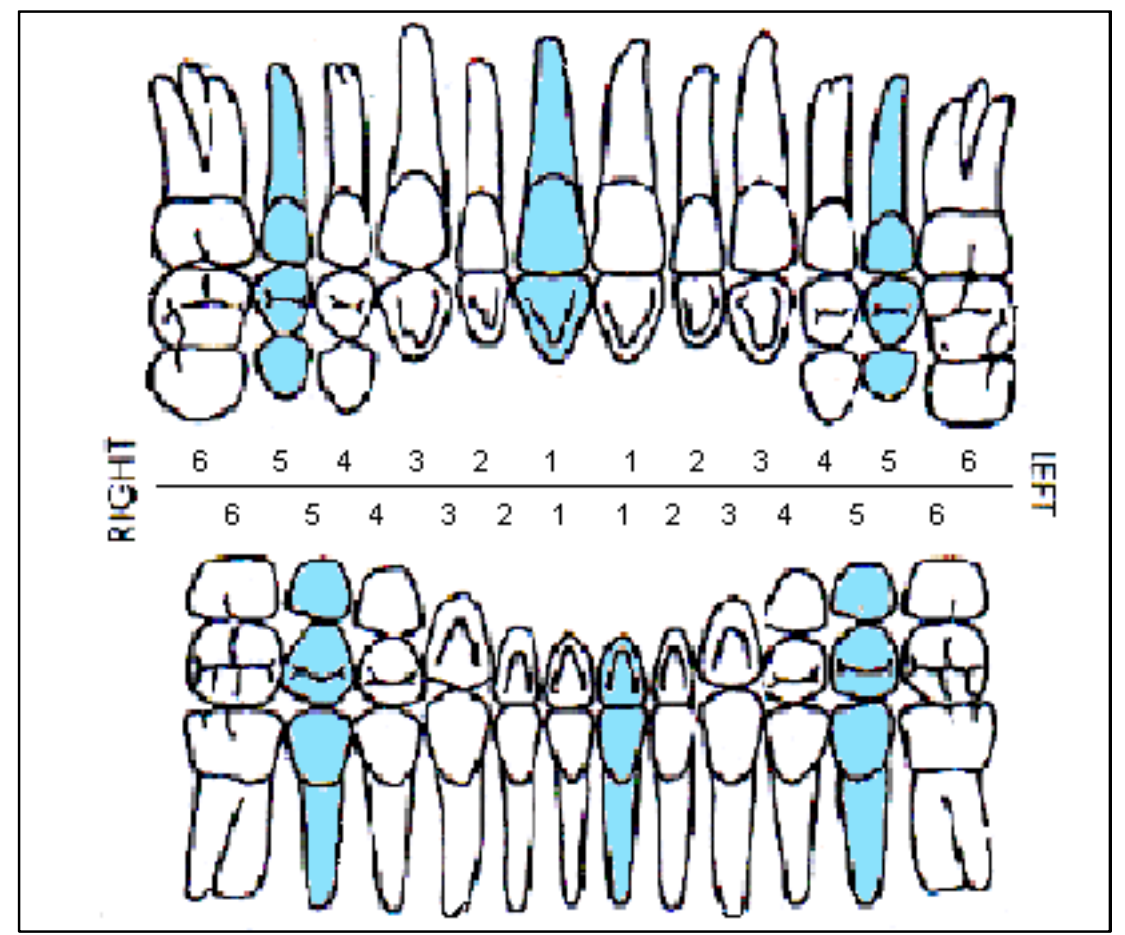

Figure 16. Six teeth, marked in blue, were examined in modified plaque and gingival indices.

\begin{tabular}{|c|l|}
\hline \multicolumn{2}{|l|}{ Silness-Löe Index } \\
\hline 0 & No plaque \\
\hline 1 & Thin film of plaque adhering to gingival margin \\
\hline 2 & Moderate accumulation of soft deposits on tooth surface and gingival margin \\
\hline 3 & Abundance of soft matter on tooth surface and gingival margin \\
\hline
\end{tabular}

Table 4. Plaque index was calculated by using this scoring system.

\begin{tabular}{|c|l|}
\hline \multicolumn{2}{|l|}{ Gingival periodontal index by Ođ̃eary } \\
\hline 0 & Healthy gingiva with no bleeding \\
\hline 1 & Bleeding on probing \\
\hline 2 & Calculus present \\
\hline 3 & Spontaneous bleeding \\
\hline
\end{tabular}


Table 5. Gingival index for a patient was calculated, using this scoring system.

At the time of bonding $\left(\mathrm{T}_{0}\right)$, after plaque and gingival indices were recorded, the teeth of interest were visually examined to ensure the sound enamel surfaces. Three intra-oral pictures were taken to record the enamel surfaces of the teeth at the time of bonding: frontal, left buccal, and right buccal shots. In case of a deep bite, the patients were instructed to disocclude the dentition for the frontal picture. The images were captured using Nikon Digital SLR Camera D90 (Nikon, Japan) equipped with a ring flash in order to eliminate any glare, and the camera lens was kept perpendicular to the surface of interest. The pictures were stored in jpeg format so that one investigator could evaluate them in the future.

\section{In-Vivo Bonding Protocol}

1. Clean the tooth surfaces with non-fluoride pumice (Reliance Orthodontic Products, Inc., Itasca, IL) using a prophy rubber cup

2. Rinse with copious water and dry with compressed air

3. Apply gel type $37 \%$ phosphoric acid etch for 20 seconds

4. Rinse with copious water and dry with compressed air

5. For Opal Seal arch, apply a thin coat of Opal Seal For Pro Seal arch, apply a thin coat of Pro Seal

6. Cure for 20 seconds with an LED curing light

7. Place a bracket on the prepared tooth surface using Transbond (3M Unitek Dental Products, Monrovia, CA)

8. Press the bracket to the surface 
9. Remove the excess bonding agent around the bracket with a scaler

10. Light cure for 20 seconds with an LED curing light

The extent of demineralization was recorded at $\mathrm{T}_{\mathrm{D}}$. The brackets were removed at $\mathrm{T}_{\mathrm{D}}$, and the sealant and bonding resin were removed by using a carbide finishing bur on a high speed handpiece. Three intra-oral pictures (frontal, left buccal, and right buccal) were taken and stored in jpeg format until they were evaluated.

\section{DATA COLLECTION}

\section{Oral Hygiene}

From all the time points, average plaque scores were calculated for maxillary and mandibular teeth. The same method was applied to get the overall gingival score. By the completion of orthodontic treatment, each arch had an overall plaque score and an overall gingival score. The average of plaque score and gingival score was calculated, and the arch was categorized into one of three oral hygiene groups depending on the average score (Table 6).

\begin{tabular}{|c|c|}
\hline Score & Oral Hygiene \\
\hline 0 to 0.49 & Excellent \\
\hline 0.5 to 0.99 & Fair \\
\hline Greater than 1.0 & Poor \\
\hline
\end{tabular}


Table 6. Patient's each arch was assigned to different oral hygiene groups according to plaque index and gingival index.

\section{Degree of Demineralization}

Digital photographs from the time points $\mathrm{T}_{0}$ and $\mathrm{T}_{\mathrm{D}}$ were examined by one operator, using the Universal Visual Scoring System for Smooth Surfaces (UniViSS) (Table 2). ${ }^{(45)}$ White spot lesions from the UniViSS with clinical examples were organized in Table 7 to facilitate the evaluation in this study. Each tooth surface was evaluated and received a numeric value, which was recorded in Microsoft Excel software. In order to check the reliability of the procedure, the measurements were repeated on 20 random samples after a week.

\begin{tabular}{|c|l|l|}
\hline Score & \multicolumn{1}{|c|}{$\begin{array}{c}\text { Clinical } \\
\text { Example }\end{array}$} & Degree of Demineralization \\
\hline 1 & & $\begin{array}{l}\text { No demineralization } \\
\text { No visible white spots or surface disruption }\end{array}$ \\
\hline 2 & & $\begin{array}{l}\text { Mild demineralization } \\
\text { Visible white spots without surface disruption }\end{array}$ \\
\hline 3 & & $\begin{array}{l}\text { Moderate demineralization } \\
\text { Visible white spot lesion with roughened surface but not } \\
\text { requiring a restoration }\end{array}$ \\
\hline 4 & & $\begin{array}{l}\text { Severe demineralization } \\
\text { Visible white spot lesions requiring restoration }\end{array}$ \\
\hline
\end{tabular}


Table 7. Visual Enamel Demineralization Scoring Chart was used in evaluation of white spot lesions.

\section{STATISTICAL ANALYSIS}

Change in demineralization scores between $\mathrm{T}_{0}$ and $\mathrm{T}_{\mathrm{D}}$ was analyzed using logistic regression. Intra-class correlation coefficient was done to evaluate the operatorô reliability in evaluating the demineralization. 


\section{EQUIPMENT AND MATERIALS}

Non-fluoridated pumice

Latex prophy cups

Micro cotton tip applicator

37\% Phosphoric acid etchant

Pro Seal

Opal Seal

Transbond

Orthodontic brackets

Small fluted carbide finishing bur

Clinical equipment

- Nikon N90 QD

- Sigma 105mm lens

- Clinipix point and ring flash

- Cheek retractors

- Periodontal probe

- Cotton pickup pliers

- Shepardôs hook explorer

- High speed and low speed hand pieces

- LED curing light 


\section{CHAPTER IV - RESULTS}

\section{IN VITRO}

\section{LESION DEPTH}

The samples were divided into three sealant categories (Pro Seal, Opal Seal, or Control), three brushing times ( 0,2 , or 4 hours), and two $\mathrm{pH}$-cycling times (24 or 48 hours) for analysis. The effect on the depths of the lesions was analyzed with ANOVA, using different factors, including sealants, brushing time, $\mathrm{pH}$-cycling time, and their interactions (Table 8). Statistical analysis using 3x3x2 factorial experiment indicated that brushing time was not a significant factor $(\mathrm{p}=0.5064)$.

\begin{tabular}{|l|c|c|}
\hline Source & Sum of Squares & P-value \\
\hline Sealant Group & 38816.04 & $<0.0001 *$ \\
\hline Brushing Time & 183.261 & 0.5064 \\
\hline pH-cycling Time & 5362.72 & $<0.0001 *$ \\
\hline Sealant*Brushing & 4425.60 & $<0.0001 *$ \\
\hline Sealant*pH-cycling & 3623.35 & $<0.0001 *$ \\
\hline Brushing*pH-cycling & 1469.04 & $0.0046 *$ \\
\hline Sealant*Brushing*pH-cycling & 1503.19 & $0.0259 *$ \\
\hline
\end{tabular}

Table 8. Multi-factorial ANOVA showed that every factor had significant effect on lesion depth except brushing. 
The average lesion depths of Opal Seal group $(21.44 \pm 12.46 \mu \mathrm{m})$ and Pro Seal group $(22.01 \pm 13.58 \mu \mathrm{m})$ were very close with no statistically significant difference between them. However, when those were compared to that of control group $(40.11 \pm 16.77 \mu \mathrm{m})$, there was a statistically significant difference $(\mathrm{p}<0.0001)$. The sealant groups were compared to the control group, using Tukey-Kramer comparison. The results showed that there was significant difference between control group and Opal Seal group and between control group and Pro Seal group. However, there was no significant difference between the two sealant groups (Figure 17).

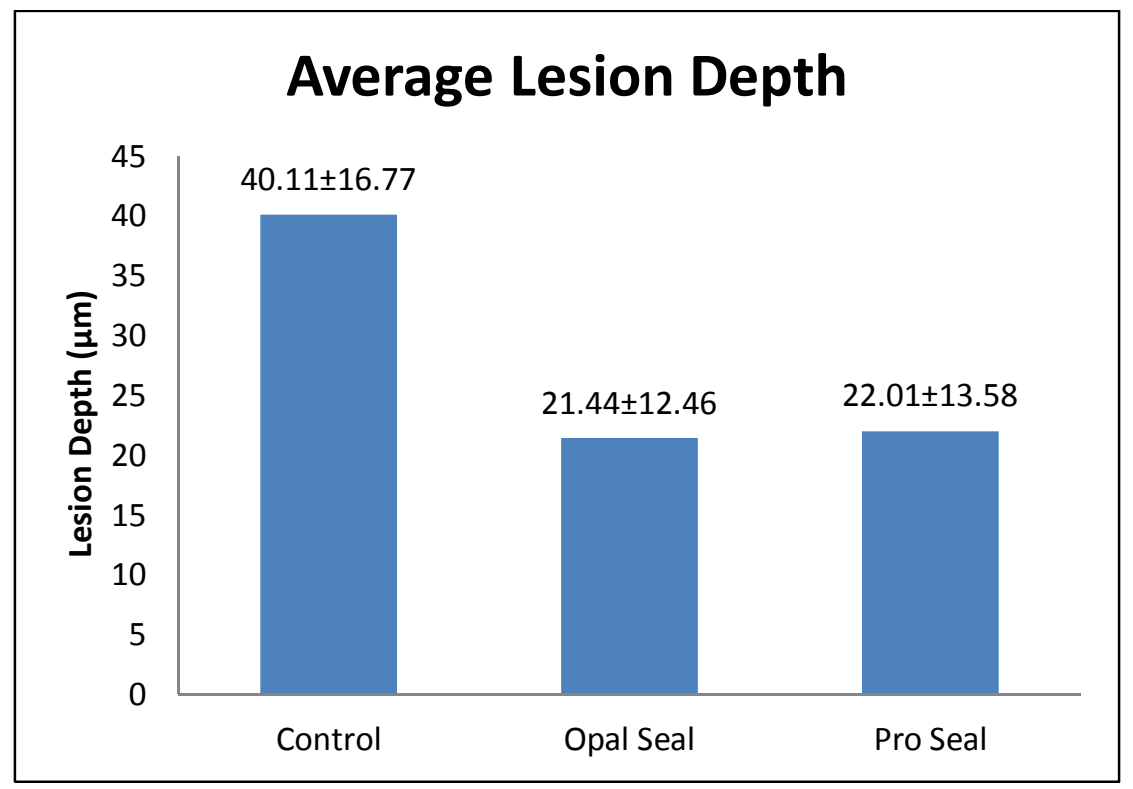

Figure 17. Tukey Kramer analysis showed that there was no difference in lesion depths between Opal Seal and Pro Seal, but there was a significant difference between both sealant groups compared to control group.

When sealant type and $\mathrm{pH}$-cycling treatment were cross examined, significant difference was observed between control group and sealant groups in both 24-hour and 48-hour treatment times, as clearly seen in Figure 18. The lesion depths of two sealant groups were very similar, yielding no statistically significant differences. For example, 
the average depth for control group after 48 hours of $\mathrm{pH}$-cycling treatment was $48.72 \pm 18.61 \mu \mathrm{m}$, which was much higher than that of Opal Seal group $(21.33 \pm 12.34 \mu \mathrm{m})$ and that of Pro Seal group $(20.78 \pm 11.28 \mu \mathrm{m})$. The difference at 48 hours was even larger than the difference at 24 hours, yielding less than 0.0001 of a p-value.

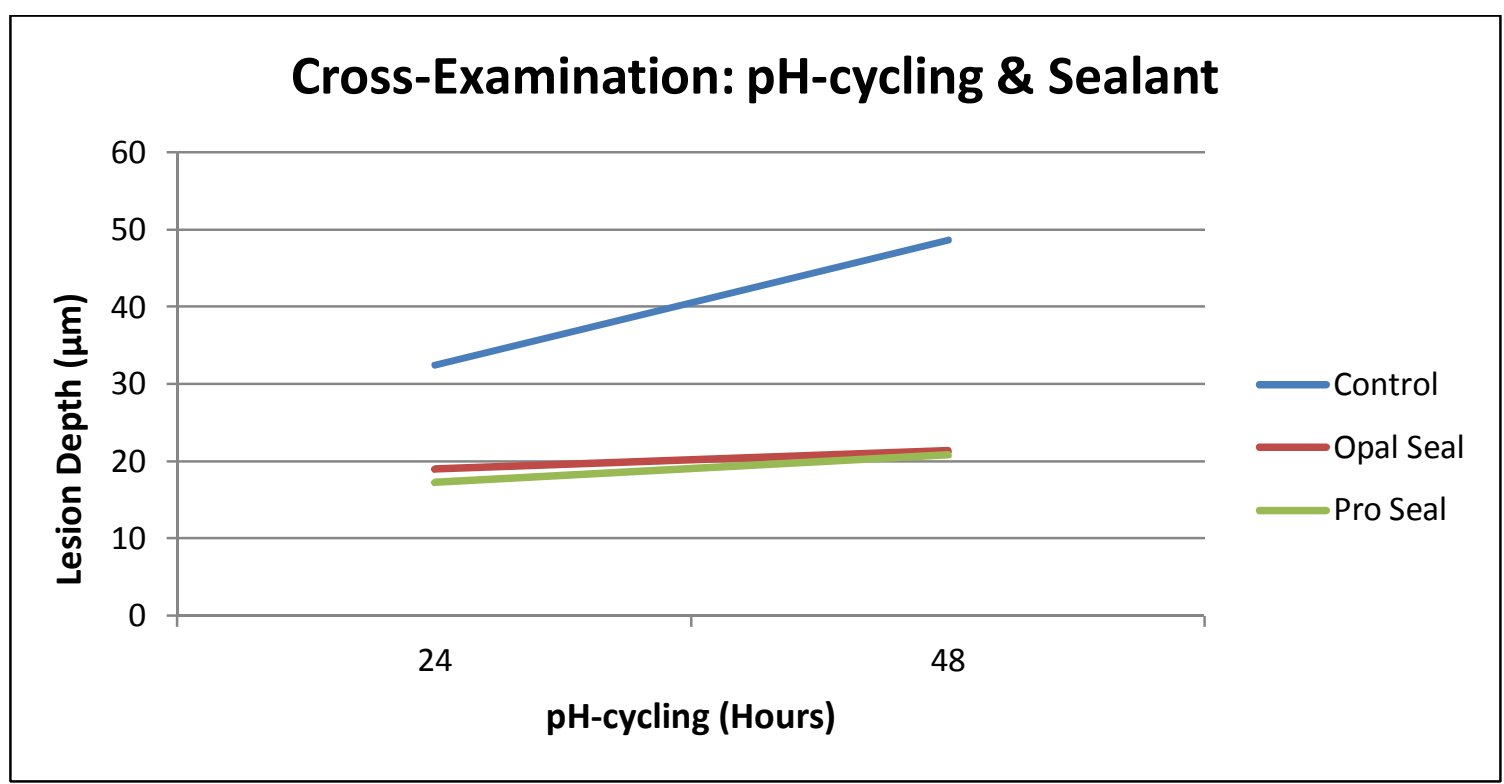

Figure 18. ANOVA of lesion depth showed significant difference between control group and sealant groups. The depths of the lesions in two sealant groups were similar, yielding no statistically significant difference.

\begin{tabular}{|c|c|c|c|}
\hline Sealant & pH-cycling & Mean Depth $(\boldsymbol{\mu m})$ & Std. Deviation \\
\hline Control & 24 & 32.45 & 10.06 \\
\hline Control & 48 & 48.72 & 18.61 \\
\hline Opal Seal & 24 & 18.94 & 11.63 \\
\hline Opal Seal & 48 & 21.33 & 12.34 \\
\hline Pro Seal & 24 & 17.27 & 7.37 \\
\hline Pro Seal & 48 & 20.78 & 11.28 \\
\hline
\end{tabular}

Table 9. Mean depth and std. deviation for each sealant group and pH-cycling time. 


\section{LESION AREA}

There were three sealant categories (Pro Seal, Opal Seal, or Control), three brushing times ( 0,2 , or 4 hours), and two $\mathrm{pH}$-cycling times ( 24 or 48 hours) in this study. The effect on the area of the lesion was analyzed with ANOVA, using different factors, including sealants, brushing time, $\mathrm{pH}$-cycling time, and their interactions (Table 10). Statistical analysis using $3 \times 3 \times 2$ factorial experiment indicated that brushing time was not a significant factor $(\mathrm{p}=0.1731)$.

\begin{tabular}{|l|c|c|}
\hline Source & Sum of Squares & P-value \\
\hline Sealant Group & $3.9565 \mathrm{e}^{10}$ & $<0.0001 *$ \\
\hline Brushing Time & 198748415 & 0.1731 \\
\hline pH-cycling Time & 2628382748 & $<0.0001 *$ \\
\hline Sealant*Brushing & 2071503835 & $<0.0001 *$ \\
\hline Sealant*pH-cycling & 4649971890 & $<0.0001 *$ \\
\hline Brushing*pH-cycling & 274654014 & 0.0890 \\
\hline Sealant*Brushing*pH-cycling & 842824447 & 0.0054 \\
\hline
\end{tabular}

Table 10. Multi-factorial ANOVA showed that every factor had significant effect on lesion area except brushing.

The average lesion areas of Opal Seal group $\left(15566.62 \pm 9339.36 \mu \mathrm{m}^{2}\right)$ and Pro Seal group $\left(16685.12 \pm 10375.36 \mu \mathrm{m}^{2}\right)$ did not have significant difference between them. Compared to the lesion area of control group $\left(35169.17 \pm 10816.08 \mu \mathrm{m}^{2}\right)$, however, there was a statistically significant difference $(\mathrm{p}<0.0001)$. The sealant groups were compared to the control group, using Tukey-Kramer comparison. The results showed no significant difference between two sealant groups. However, there were significant differences 
between control group and Opal Seal group and between control group and Pro Seal group (Figure 19).

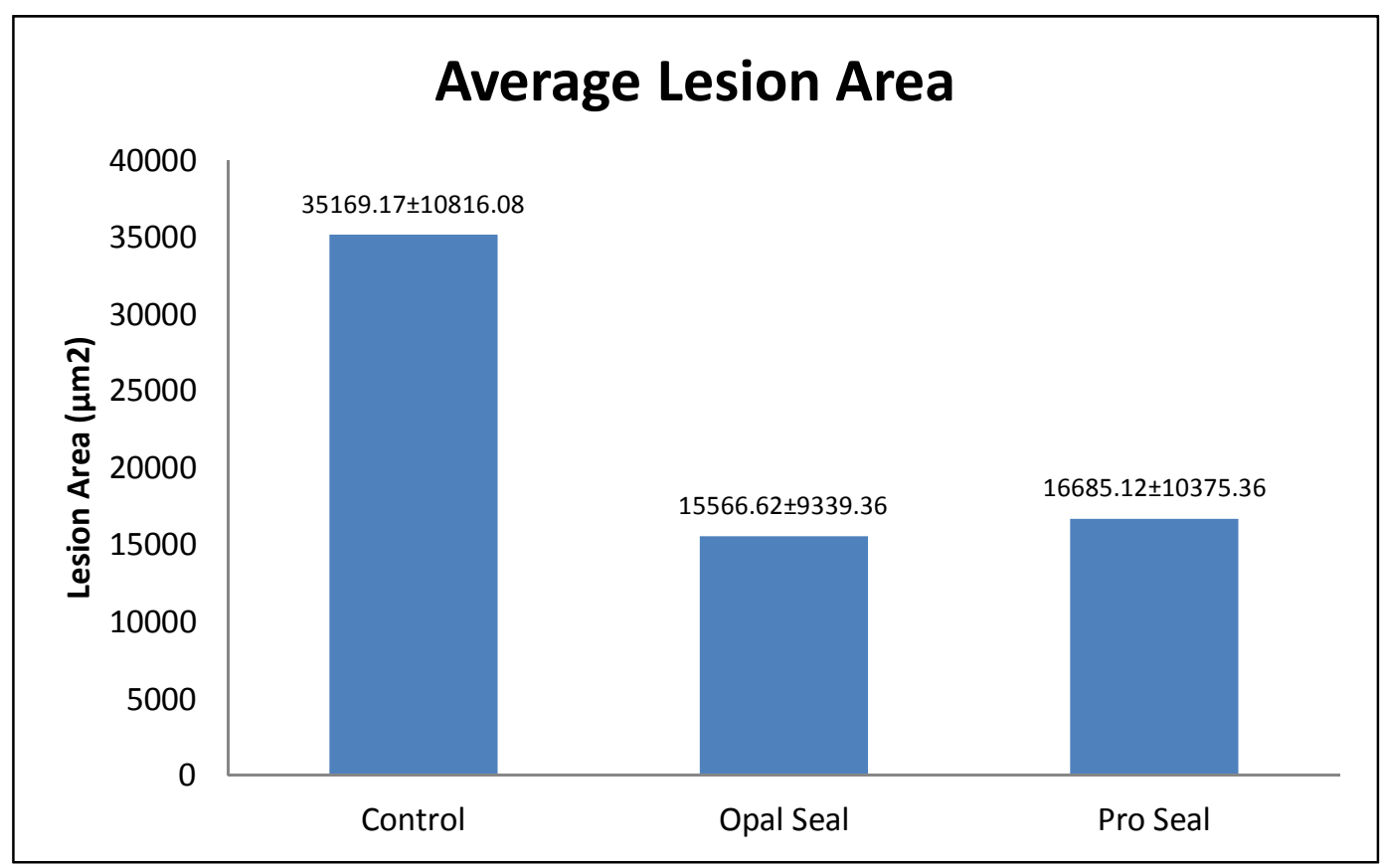

Figure 19. Tukey Kramer analysis showed that there was no difference in lesion areas between Opal Seal and Pro Seal, but there was a significant difference between both sealant groups compared to control group.

Similar pattern was observed when sealant type and $\mathrm{pH}-\mathrm{cycling}$ treatment were cross examined. The lesion areas of two sealant groups were very similar with no statistically significant difference. On the other hand, significant difference was apparent between control group and sealant groups in both 24 -hour and 48-hour treatment times, as seen in Figure 20. Average area for control group after 48 hours of $\mathrm{pH}$-cycling treatment was $42871.44 \pm 9476.23 \mu \mathrm{m}^{2}$, which was much higher than that of Opal Seal group $\left(14457.54 \pm 8269.58 \mu \mathrm{m}^{2}\right)$ and that of Pro Seal group $\left(15252.77 \pm 8101.19 \mu \mathrm{m}^{2}\right)$. The difference at 48 hours was even larger than the difference at 24 hours, yielding pvalue less than 0.0001 . 


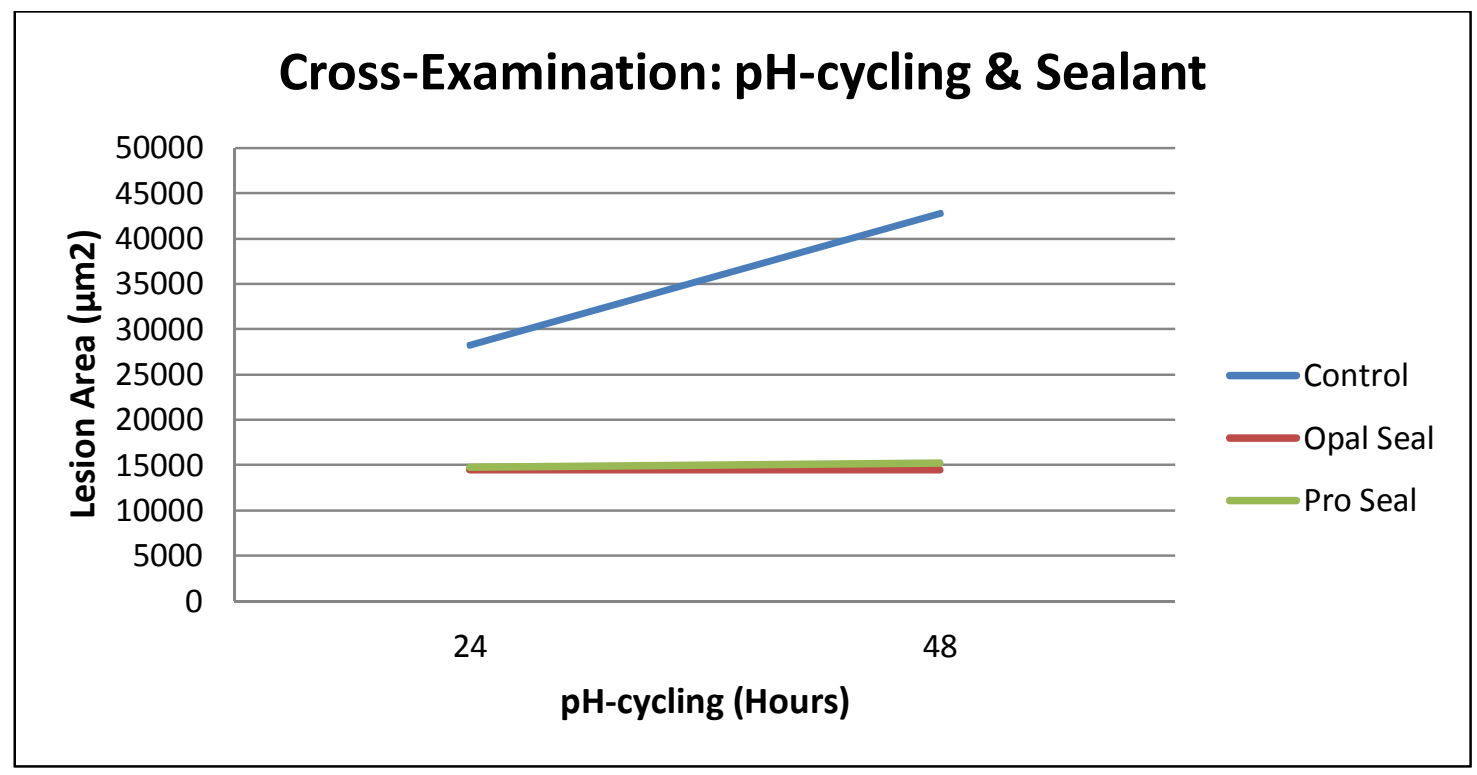

Figure 20. ANOVA of lesion area showed significant difference between control group and sealant groups. The areas of the lesions in two sealant groups were similar, yielding no statistically significant difference.

\begin{tabular}{|c|c|c|c|}
\hline Sealant & pH-cycling & Mean Area $\left(\boldsymbol{\mu m}^{\mathbf{2}}\right)$ & Std. Deviation \\
\hline Control & 24 & 28322.70 & 6461.42 \\
\hline Control & 48 & 42871.44 & 9476.23 \\
\hline Opal Seal & 24 & 14453.48 & 7882.08 \\
\hline Opal Seal & 48 & 14457.54 & 8269.58 \\
\hline Pro Seal & 24 & 14784.13 & 7321.51 \\
\hline Pro Seal & 48 & 15252.77 & 8101.19 \\
\hline
\end{tabular}

Table 11. Mean area and std. deviation for each sealant group and pH-cycling time. 


\section{REMAINING SEALANT THICKNESS}

For the remaining sealant thickness, control group was not considered, and the two sealants were compared to each other. Two factor ANOVA was performed, using different factors, including sealants, brushing time, $\mathrm{pH}$-cycling time, and their interactions. As shown in Table 12, brushing treatment, $\mathrm{pH}$-cycling treatment, and interaction between sealant and $\mathrm{pH}$-cycling treatment had statistical significance. However, type of sealant applied showed no statistical significance $(\mathrm{p}=0.9363)$.

\begin{tabular}{|l|c|c|}
\hline Source & Sum of Squares & P-value \\
\hline Sealant Group & 15.652 & 0.9363 \\
\hline Brushing Time & 55464.273 & $<0.0001 *$ \\
\hline pH-cycling Time & 79416.40 & $<0.0001 *$ \\
\hline Sealant*Brushing & 7531.16 & 0.2160 \\
\hline Sealant*pH-cycling & 30126.12 & 0.0005 \\
\hline Brushing*pH-cycling & 14780.48 & 0.00502 \\
\hline Sealant*Brushing*pH-cycling & 11980.75 & 0.0880 \\
\hline
\end{tabular}

Table 12. Multi-factorial ANOVA showed that brushing and demineralization factors had significant effect on remaining sealant thickness, while sealant type did not have any effect.

The thickness of the two sealants showed similar diminishing pattern over increased brushing time, and there was no statistically significant difference between two sealants $(\mathrm{p}=0.2160)$. Figure 21 shows almost parallel graphs for both sealants in regards to brushing hours. 


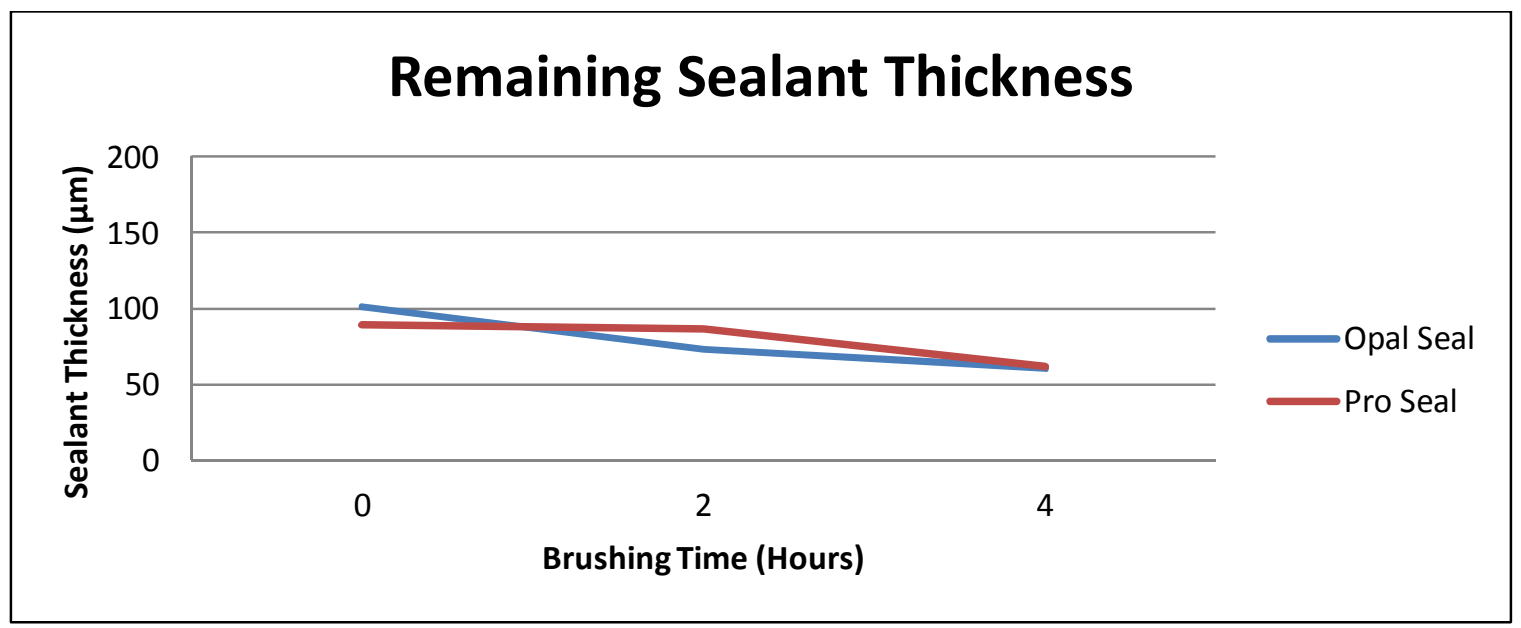

Figure 21. Thickness of Opal Seal and Pro Seal decreased at an equivalent rate over brushing time. There was no significant difference between the sealant thickness changes between two sealants.

\section{ERROR MEASUREMENTS}

Intra-class correlation coefficient was done to evaluate the operatorôs reliability in measuring the lesions. Twenty measurements were repeated seven days apart. The reliability of the investigator in measuring the lesions was $96.8 \%$.

\section{SAMPLE IMAGES}

Every image had the tooth sample placed on the right side and the surrounding acrylic on the left. The red area is from Rhodamine B staining, and it represents demineralized portion of enamel. Although the sealant layer sometimes absorbs some of the dye and gets stained, it is obvious to distinguish between demineralized area and sealant layer. A sample z-stack is included in Appendix D. Since the images were very similar in every layer, a most focused representative image was analyzed for this study. The confocal images in Figure 22 and Figure 23 show two samples from Opal Seal group 
and Pro Seal group respectively. The images are marked with the acrylic (A), sealant layer (S), and enamel (E).

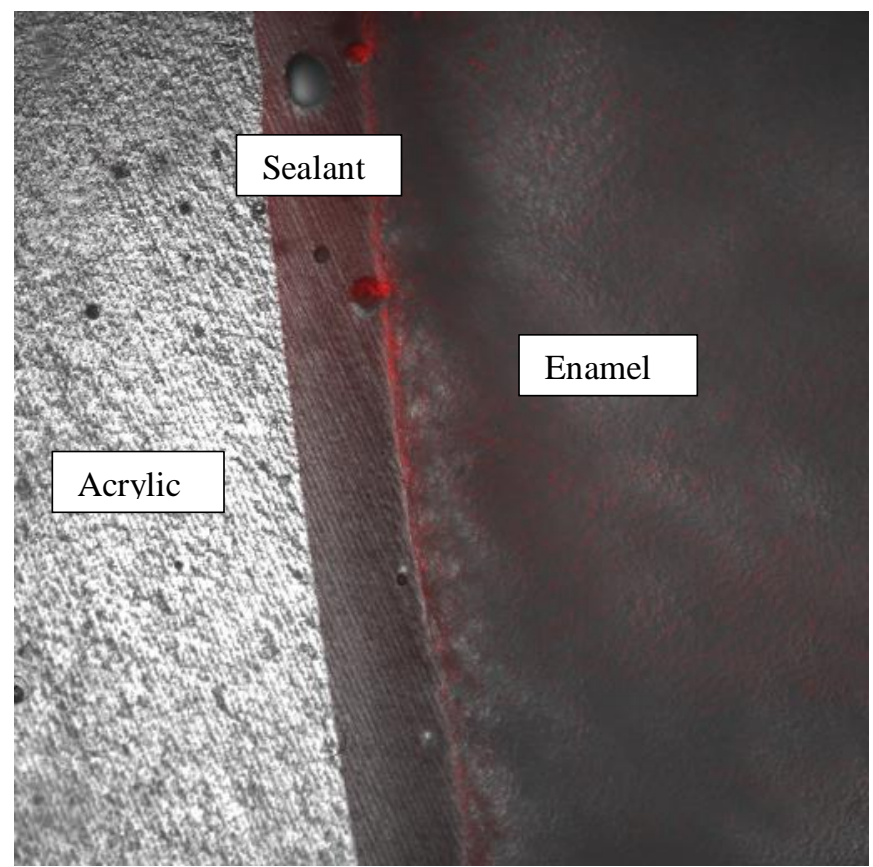

Figure 22. Confocal image of a sample from the Opal Seal group with no lesion.

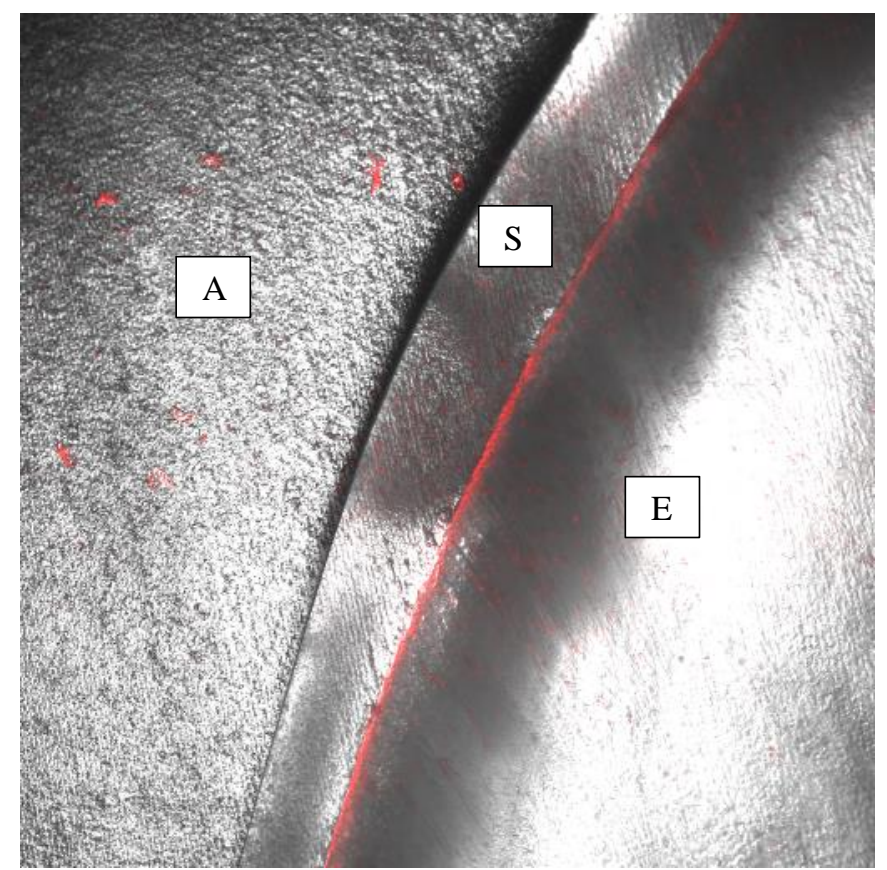

Figure 23. Confocal image of a sample from the Pro Seal group with no lesion 
Figure 24 is a typical confocal image of samples from the control group. The rhodamine B dye is incorporated in the demineralized area, producing fluorescence that can be captured in confocal microscopy.

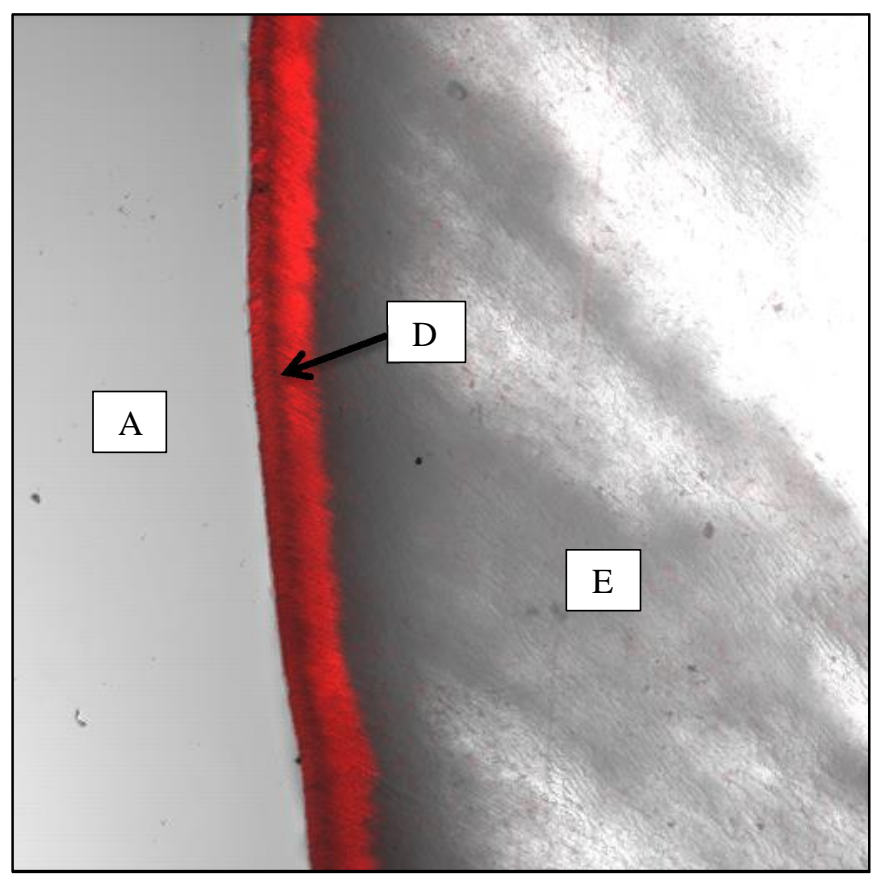

Figure 24. Confocal image of a sample from the control group with lesion

Figure 25 shows a confocal image of a sample from a sealant group with a lesion. The remaining sealant from brushing treatment is shown at the bottom of the image, and the demineralized area of the enamel (D) is evident where the sealant is removed. 


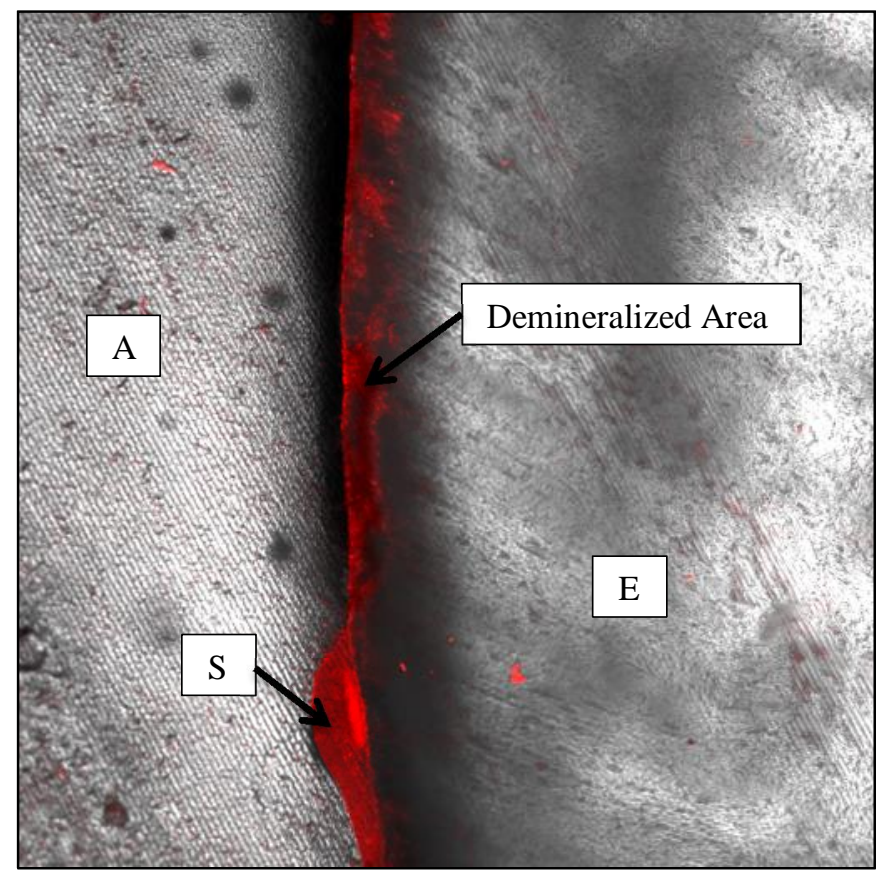

Figure 25. Confocal image of a sample from the Sealant group with lesion 


\section{IN VIVO}

\section{LESION INCIDENCE}

Twenty-four patients were initially recruited for the study. However, two of the patients dropped out of the study, and three patients could not complete the full treatment during the study period. When scoring individual tooth as a subject, there were a total of 372 teeth studied. The patientô age range was from 11 years and 2 months to 19 years and 11 months of age with the average of 13.7 years. Since several teeth had pre-existing demineralization before orthodontic treatment, the change in demineralization status was recorded for the study. The change in demineralization was recorded along categorical values, instead of numerical values (Table 7).

It was found that 84 teeth $(22.6 \%)$ presented with positive change in demineralization. Seven of these decalcified teeth $(8 \%)$ had large or multiple demineralization areas. There were no teeth with severe enough demineralization, requiring dental restorations.

\section{INCIDENCE BY GENDER}

Among 372 teeth in this study, 178 of them belonged to female patients, and 194 belonged to male patients. Thirty out of 178 female samples underwent demineralization process, which comprised $16.9 \%$ of the entire samples. Fifty-four out of 194 male samples underwent demineralization process, which comprised $27.8 \%$ of the entire samples (Figure 26). However, when the data were analyzed with ANOVA method to verify its significance, $\mathrm{p}$ value of 0.10285 failed to show any statistical significance. 


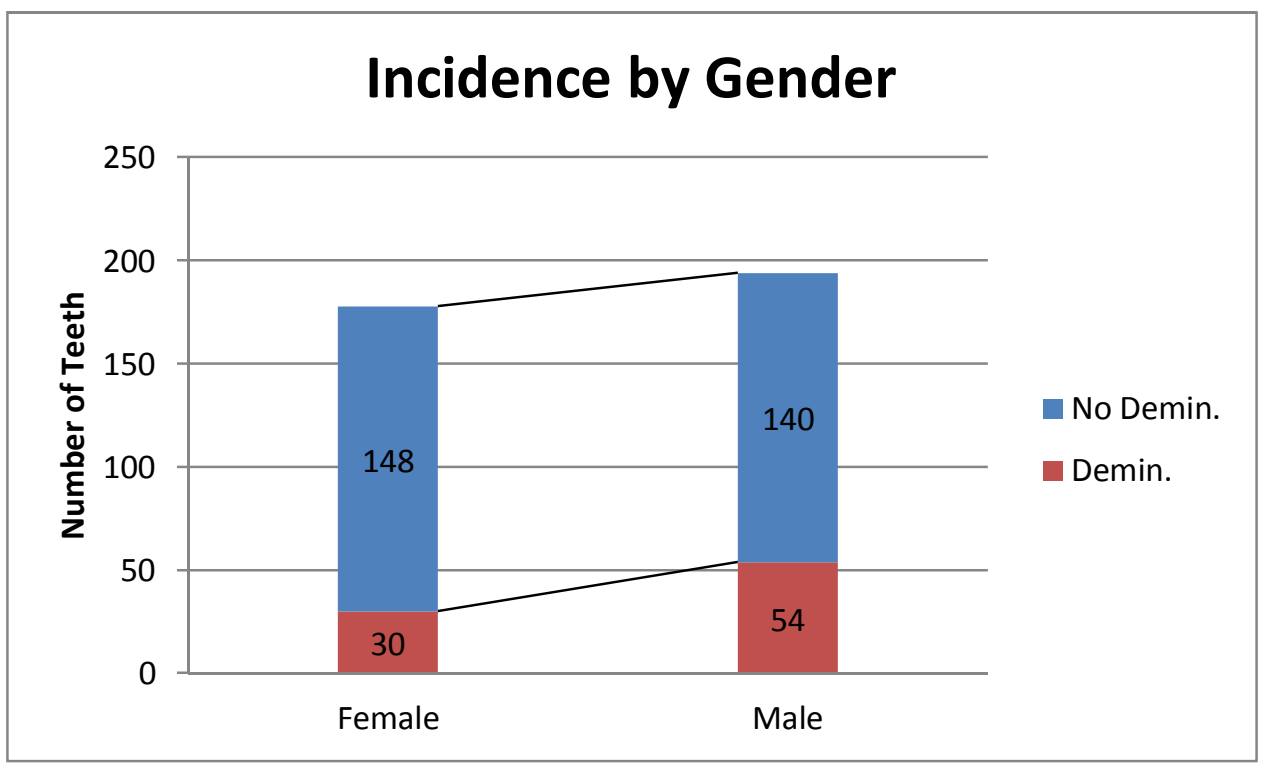

Figure 26. Female teeth have shown less likely incidence for demineralization.

\section{INCIDENCE BY LOCATION}

The total of 372 teeth in this study was composed of $186(50 \%)$ maxillary teeth and $186(50 \%)$ mandibular teeth. Eighty-four decalcified teeth with positive change in demineralization status were made up with 44 maxillary teeth and 40 mandibular teeth. This difference was not found to be significant using Stepwise Logistic Regression test (p $=0.01542$ ). However, when the data were tested more closely using Likelihood-Ratio test, mandibular arch showed slight reverse relation to lesion development $(\mathrm{p}=0.0005)$.

\section{INCIDENCE BY TREATMENT TIME}

The overall treatment time for all subjects ranged from 5 months and 8 days to 19 months and 6 days with the average of 14 months. For the teeth with no change in demineralization, the average treatment time was 412.42 days (13 months and 22 days) with the maximum of 576 days and the minimum of 158 days. The average treatment 
time for those with minor demineralization change was 441.34 days ( $14 \mathrm{~m} 21 \mathrm{~d}$ ) with the maximum of 576 days and the minimum of 174 days. For the samples with moderate demineralization change, the average treatment time was 480.38 days ( $16 \mathrm{~m}$ ) with the maximum of 565 days and the minimum of 394 days (Figure 27). Even though there was a slight trend in the data, $\mathrm{p}$ value of 0.27512 showed no statistical significance.

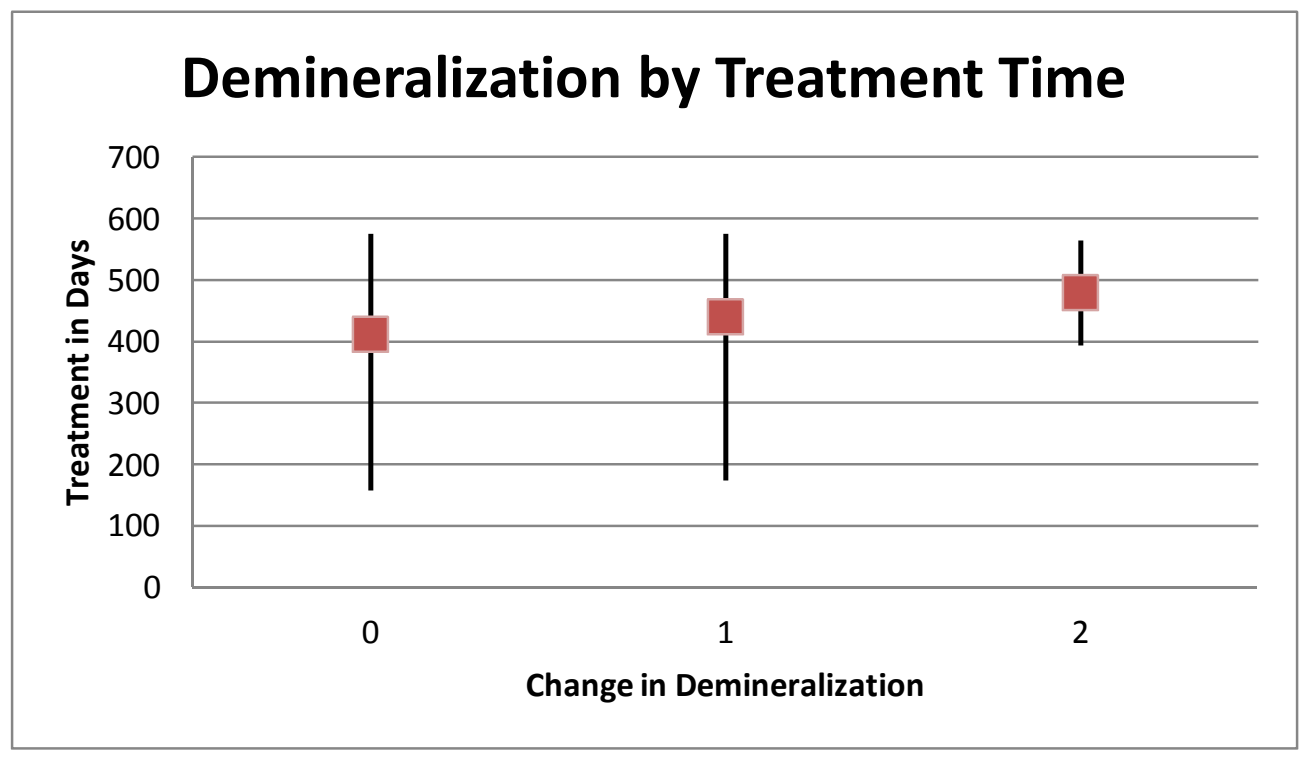

Figure 27. Total treatment time was plotted according to the change in demineralization to show the increasing trend. 


\section{INCIDENCE BY SEALANT}

Among 186 maxillary teeth, 68 of them had Pro Seal treatment, and 118 teeth had Opal Seal treatment. Among 186 mandibular teeth, 68 of them had Opal Seal treatment, and 118 teeth had Pro Seal treatment (Table 13).

\begin{tabular}{|c|c|c|c|}
\hline & Maxillary & Mandibular & Maxillary \\
\hline Opal Seal & $118(\mathrm{Mx}-\mathrm{O})$ & $68(\mathrm{Md}-\mathrm{O})$ & 186 \\
\hline Pro Seal & $68(\mathrm{Mx}-\mathrm{P})$ & $118(\mathrm{Md}-\mathrm{P})$ & 186 \\
\hline Total & 186 & 186 & 372 \\
\hline
\end{tabular}

Table 13. The distribution of the studied samples according to sealants is shown here.

Forty-four teeth treated with Opal Seal and forty teeth treated with Pro Seal showed the evidence of demineralization. As shown in Figure 28, 15 were mandibular teeth (22.1\% of Md-O), and 29 were maxillary teeth (24.6\% of Mx-O) among the Opal Seal group. Among the Pro Seal group, 25 were mandibular teeth (21.2\% of Md-P), and 15 were maxillary teeth $(22.1 \%$ of Mx-P). The difference between two sealants was not statistically significant $(\mathrm{p}=0.57)$.

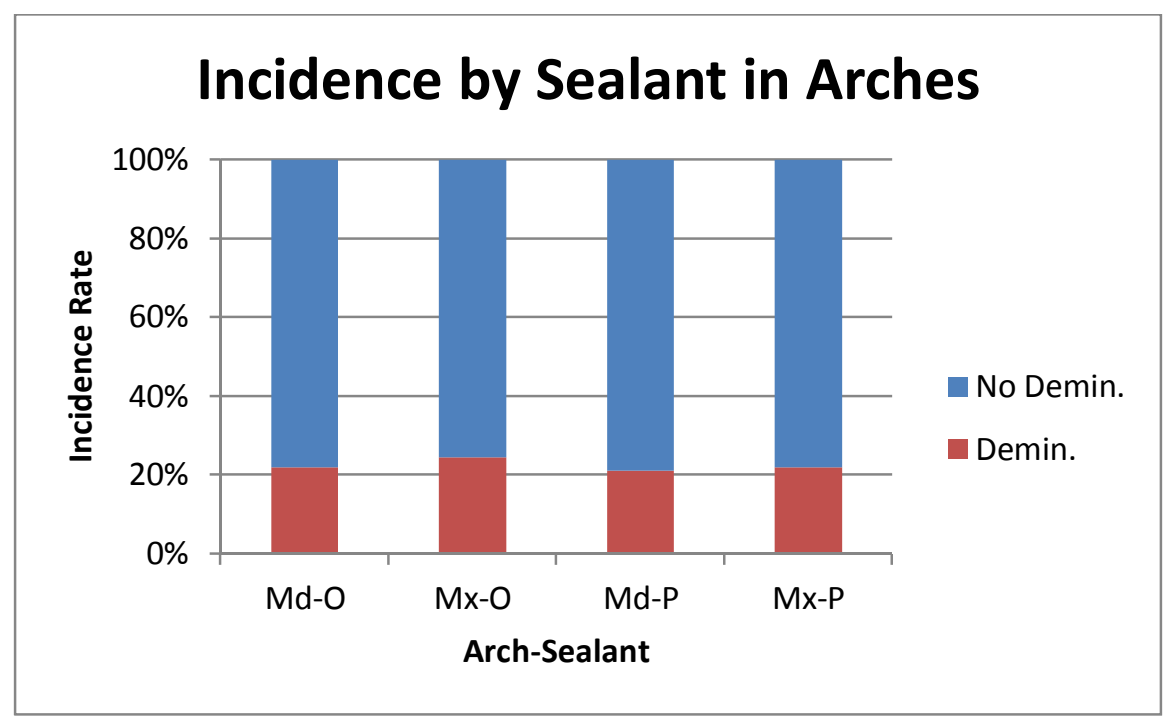

Figure 28. Incidence of demineralization showed so significant difference according to different sealant and arch. 


\section{INCIDENCE BY ORAL HYGIENE}

A stepwise Logistic Regression analysis was performed to predict the probability of having no cavity using the explanatory variables: sealant type, gender, age, duration, arch, and oral hygiene. The analysis indicated that the oral hygiene level is the only factor that had significant effect on demineralization (p-value $<0.0001)$.

The probability of having no demineralization process can be explained by using oral hygiene score, and estimated probability is displayed in Figure 29. The formula for the given graph is: $P($ No Cavity $)=\frac{1}{1+e^{-4.21+0.708(\text { Oral Hygine Score })}}$

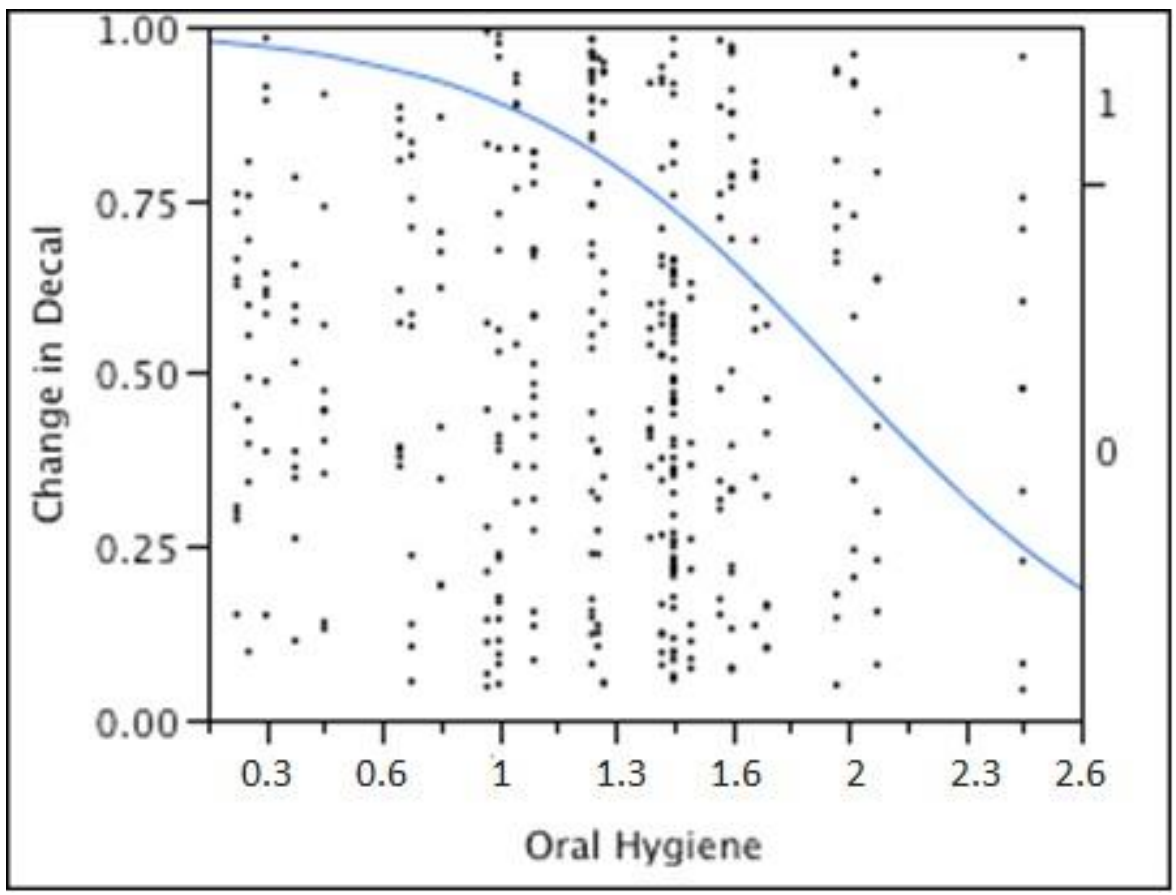

Figure 29. Probability of having no demineralization decreased rapidly with higher oral hygiene score, meaning more unfavorable oral hygiene.

The area under the graph indicates the probability of not having demineralization, and the area above the graph indicates the probability of having demineralization. Increased oral hygiene score, meaning unfavorable oral hygiene status, shows 
significantly higher probability of demineralization taking place. For example, the estimated probability of having no cavity is about 0.75 if the oral hygiene score is 2 . On the other hand, the estimated probability of having no cavity is about 0.25 if the oral hygiene score is 2.3 .

When the lesion incidence data were categorized according to oral hygiene level (Figure 30), there was also a clear trend of increased lesion incidence with unfavorable oral hygiene level. Patients with excellent oral hygiene had little to no demineralization development ( $0.023 \%$ of total samples), while patients with poor oral hygiene had much higher prevalence ( $0.79 \%$ of total samples).

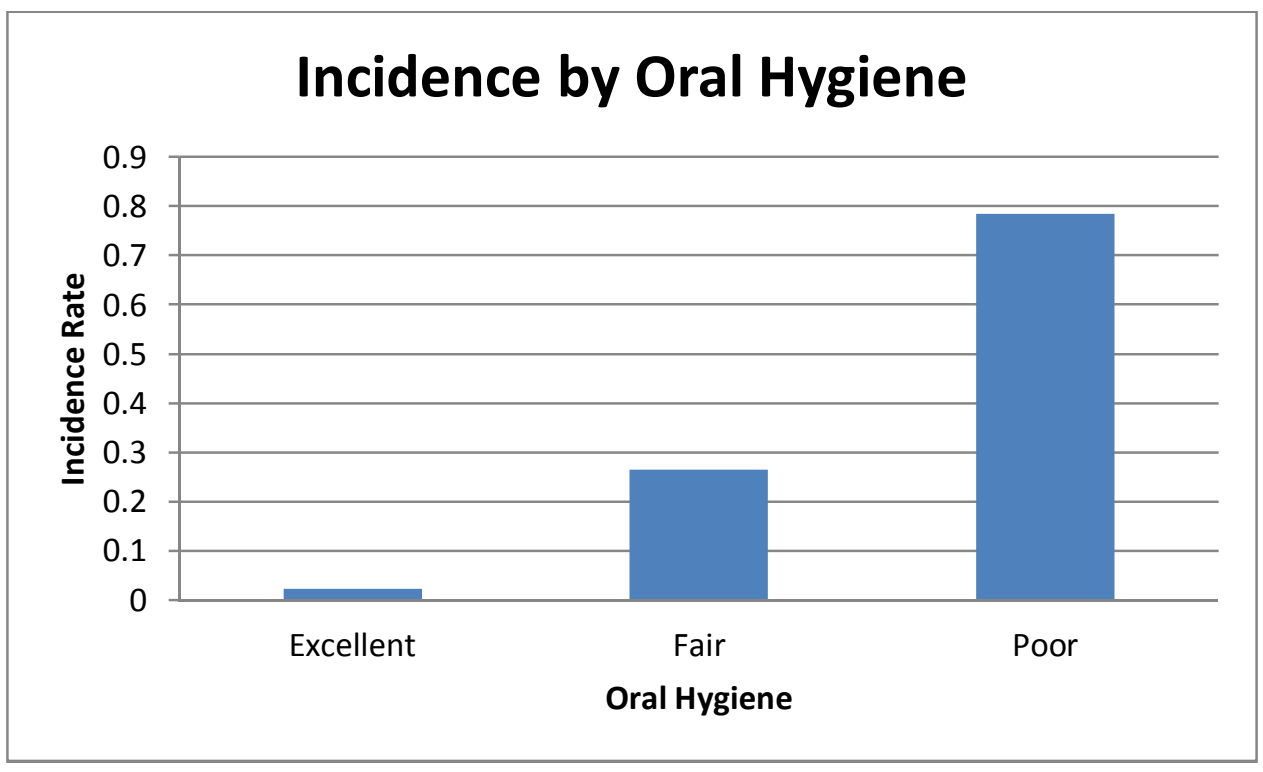

Figure 30. The rate demineralization incidence according to level of hygiene compliance shows increasing trend towards poor oral hygiene. 


\section{ERROR MEASUREMENTS}

Intra-class correlation coefficient was done to evaluate the operatorô reliability in measuring the lesions from photographs. Twenty measurements were repeated seven days apart. The reliability of the investigator in measuring the lesions was $91.2 \%$. 


\section{CHAPTER V - DISCUSSION}

\section{IN VITRO}

In-vitro part of this study compared the efficacy of Opal Seal and Pro Seal against control group in preventing demineralization under mechanical and chemical treatment simulating oral environment during orthodontic treatment.

Both lesion depths and lesion areas were affected mainly by the type of sealants and the demineralization treatment time. Sealant groups showed significantly decreased lesion depth and lesion area compared to control group, and the same was observed when demineralization treatment time and sealant groups were cross-examined.

This shows the efficacy of both sealants against demineralization process, preventing its penetration through enamel layer. This finding confirms Buren et al $\hat{\mathbf{s}}$ finding, where $72 \%$ reduction in lesion depth among the specimens treated with unfilled sealant was noted in the study. ${ }^{(21)}$ Also in Behnanôs study, the depth and the severity of lesions were significantly reduced in Pro Seal treated specimens. ${ }^{(7)} \mathrm{Hu}$ and Featherstone found almost complete inhibition of demineralization with the use of Pro Seal, and they concluded that the thickness and the abrasion resistance of a sealant highly affect its duration and protection. ${ }^{(5)}$ This study showed no statistically significant difference between Opal Seal and Pro Seal regarding both lesion depth and lesion area. It is safe to say that the two sealants provide comparable efficacy in enamel protection against demineralization.

Frazier and Tanna found their control groups to have the average depth of

approximately $150 \mu \mathrm{m}$, which is much higher value than the one found in this study. ${ }^{(20,94)}$ 
This could be explained by several factors that were present in this study: different exposure time of demineralization treatment, use of fluoride toothpaste during brushing treatment, and remineralization treatment in artificial saliva. However, this is only a speculation, and further study may be indicated for further assurance.

Remaining sealant thickness showed high correlations with brushing time and demineralization time, but not with type of sealant. The remaining sealant thickness decreased as the brushing time and demineralization time increased, and the rates of the changes were similar to both sealants. In the studies done by Frazier and Tanna, they found lesion developments in sealant groups similar to the lesions of control groups if there was a break in the sealant layer. ${ }^{(20,94)}$ In this study, no break in the sealant was noticed during confocal microscopy. However, demineralization process was observed in sealant groups after the sealant layer was removed from brushing treatment, as shown in Figure 25.

Even though certain samples showed no sealant remaining after four hours of brushing, the average sealant thickness was still positive. In order to anticipate the remaining sealant, prediction of the change in the remaining sealant thickness was performed, assuming the same environment can be maintained. The relationship between the brushing time and the remaining sealant was numerically quantified, and a linear regression analysis was done (Figure 31). 


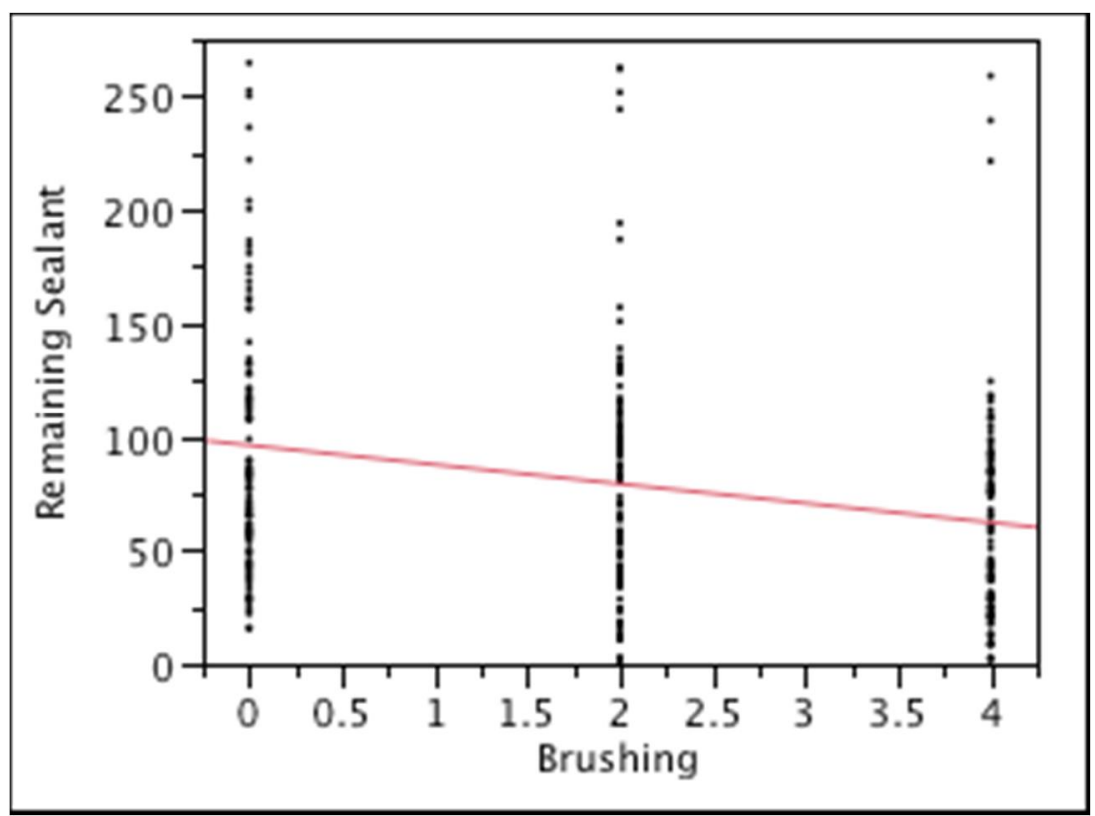

Figure 31. Change in sealant thickness was projected over brushing time to discover the linear formula.

The formula for the linear fit was: (Remaining Sealant) $=95.97-8.49 \mathrm{X}$

(Brushing Time). According to the formula, the sealant thickness will be zero when the brushing time is 11.3 hours. Since two hours of brushing time is equivalent to one month of brushing twice a day, the duration of the sealants can be assume to be 5.65 months with brushing twice a day.

Average orthodontic treatment lasts anywhere between 12 months and 24 months. If the duration of sealant staying intact is predicted to be less than six months, majority of orthodontic patients could be more benefitted with repeated sealant application every six month. On the other hand, Ceen speculated that the unpolymerized oxygen inhibited layer can be even more readily removed by mouth-rinsing and normal function, a process called ñwashingò ${ }^{(91)}$ Zachrisson also described this phenomenon and observed sealant failure which was caused by non-polymerization due to oxygen inhibition, technique 
sensitivity, and low abrasion resistance. ${ }^{(92)}$ These complications could make the sealant layer to wash away even quicker than six months.

\section{IN VIVO}

In-vivo part of this study compared the efficacy of two different sealants, Opal Seal and Pro Seal, in preventing enamel demineralization among 19 orthodontic patients during their treatment. The study consisted of 372 teeth bonded with orthodontic brackets. The average treatment time for these teeth was 14 months, with the minimum of 5 months 8 days and the maximum of 19 months 6 days.

Thirteen patients, $68.4 \%$ of the total subjects, had one or more teeth with positive change in demineralization. This figure is higher than the one found in the study conducted by Gorelick et al, where $50 \%$ of the patients had the incidence of white spot lesions. ${ }^{(29)}$ However, Boersma et al noted $97 \%$ occurrence of white spot lesions in their study, which was even higher than the result in this study. ${ }^{(27)}$ This trend is congruent with the fact that many studies have observed a wide range of decalcification incidence among orthodontic patients. When individual teeth were counted, 84 teeth, $22.6 \%$ of the total, showed positive change in demineralization. This finding was similar to $20.9 \%$ of occurrence found in Ghiz et alôs study, where the same method of counting individual teeth was utilized. ${ }^{(19)}$

Out of eighty-four teeth with demineralization, 30 of them were of female patients $(35.7 \%)$, and 54 of them were male patients $(64.3 \%) .27 .8 \%$ of the total male subjects and $16.9 \%$ of the total female subjects showed positive change in 
demineralization. Higher prevalence of white spot lesions among male patients was also reported in the study done by Boersma et al with a higher incidence found in male patients $(40 \%)$ than female patients $(22 \%) .{ }^{(27)}$ Al Maaitah et al, on the other hand, noted that male patients showed a greater degree of demineralization once the process took place. ${ }^{(36)}$ However, this study could not confirm any statistically significant difference between male and female genders.

The location in the oral cavity had the second most significant effect on the degree of demineralization in this study. The lesion incidence was slightly lower in mandibular dentition. Analysis proved that being located in mandibular arch had a negative correlation with undergoing demineralization process. Wenderoth et al also noted higher frequency of white spot lesions in the maxillary arch. ${ }^{(38)}$ This phenomenon is supported by several factors. Salivary gland openings are in the close proximity of mandibular teeth, and cariostatic properties of saliva can help preventing demineralization. The active movement of tongue muscles behind the mandibular teeth also prevents cariogenic material from accumulating on the tooth surfaces.

Geiger et al found a positive correlation between the length of the treatment and the incidence and severity of white spot lesions. ${ }^{(37)}$ This study found a slightly increasing trend in average treatment duration along with increased severity of lesion development. However, the difference was not statistically significant. It is possible that longer treatment time and larger sample size may fully illustrate the trend.

Increased amount of plaque around orthodontic brackets due to complex shape and design of the appliances has been a concern in orthodontics. ${ }^{(34)}$ Even with diligent oral hygiene instruction from an operatorô part, oral hygiene status among orthodontic 
patients gets worse over short period of time. ${ }^{(33)}$ From the statistical analysis, it was indicated that the oral hygiene level was the only factor that governed the demineralization outcome in this in-vivo study. Compared to other factors considered, oral hygiene score showed the statistical significance. As the oral hygiene status diminished, the probability of undergoing demineralization process increased exponentially. Although the efficacy of sealants could not be compared to control with no sealant in this study, Ghiz et al concluded that sealant application was more beneficial in patients with poor oral hygiene. ${ }^{(19)}$

Opal Seal and Pro Seal, investigated in this in-vivo study did not show any statistically significant difference in their efficacy. The incidence of demineralization among treated teeth was very comparable between two groups. In many other studies, Pro Seal was regarded as gold standard and shown to reduce the lesion depth by up to $92 \% .^{(7,21)}$ Also, sealant treatment has decreased the incidence of white spot lesions by half when compared to control group. ${ }^{(19,95)}$ With its well-documented efficacy, Pro Seal can serve as a positive control in this in-vivo study. Therefore, it would be safe to infer that Opal Seal can provide an equivalent level of enamel protection against demineralization during orthodontic treatment. 


\section{CHAPTER VI \\ SUMMARY, CONCLUSION, AND RECOMMENDATIONS}

\section{SUMMARY}

The purpose of this study was to evaluate the efficacy of two sealants, Opal Seal and Pro Seal, in prevention of enamel demineralization during orthodontic treatment. The efficacy was evaluated in vitro on 27 extracted human teeth and in vivo in 19 patients undergoing orthodontic treatment.

The in-vitro investigation consisted of 54 extracted human molar halves embedded in orthodontic resin with either buccal or lingual tooth surface exposed. All samples were pumiced with fluoride-free pumice. The samples were equally assigned to control, Opal Seal, and Pro Seal groups. Opal Seal group and Pro Seal group were treated with appropriate sealant, following manufacturerô instructions. The samples underwent mechanical brushing treatment $(0,2$, or 4 hours $)$, and $\mathrm{pH}$-cycling treatment ( 24 or 48 hours). Following the oral-cavity simulated treatments, the samples were sectioned to provide two $250-\mu \mathrm{m}$ thick specimens. Occlusal and gingival areas of each slice were examined utilizing confocal microscopy. The lesion depth, lesion area, and remaining sealant thickness were recorded using Image J program. Statistical analysis was performed using factorial ANOVA and Tukey Kramer analysis (pÒ.05).

The in-vivo investigation included 19 participants who received comprehensive fixed orthodontic treatment for an average span of 14 months. All the study samples were treated with sealant in order to minimize the ethical issues; therefore, the efficacy of 
applying sealant could not be compared to no sealant application. Initial photographs were taken for frontal and two buccal segments. Gingival and plaque index readings were done at the start of the treatment and on a 6-month interval. Opal Seal and Pro Seal were applied in a split-mouth method, and the orthodontic brackets were bonded according to the manufacturerô instructions. At the end of treatment, intraoral pictures were taken for frontal and two buccal segments. The incidence of lesion formation and level of decalcification were evaluated according to sealant type, gender, dental arch, treatment duration, and oral hygiene compliance. Statistical analysis was performed using logistic regression.

\section{CONCLUSIONS}

The following conclusions were made in vitro:

1. Regarding the lesion depth and area, the sealant type and $\mathrm{pH}$-cycling time were the governing factors.

2. There was no statistically significant difference between Opal Seal and Pro Seal in degree of demineralization.

3. There was a significant difference in degree of demineralization between control group and sealant groups (p-value $<0.0001)$.

4. There was no statistically significant difference between Opal Seal and Pro Seal in remaining sealant thickness.

5. Sealant thickness decreased over brushing time at a linear fashion, and it was predicted to be fully removed from enamel surface after 11.3 hours of brushing. 
The following conclusions were made in vivo:

1. The level of demineralization incidence was $68.4 \%$ of the participants and $22.6 \%$ of the tooth samples.

2. Tooth samples with demineralization were composed of $64.3 \%$ of male and $35.7 \%$ of female, but the difference did not have statistical significance.

3. Teeth in mandibular arch were less likely to undergo demineralization process.

4. More severe demineralization was noticed in samples undergoing longer treatment duration, but the difference was not statistically significant.

5. Two sealants did not present any statistical difference in incidence of enamel demineralization $(\mathrm{p}$-value $=0.57)$

6. Oral hygiene status was the only factor that had statistical significance over the incidence of demineralization ( $\mathrm{p}$-value $<0.0001)$.

7. Subjects with poor oral hygiene showed higher probability of developing enamel demineralization. 


\section{RECOMMENDATIONS}

Based on the findings of this study, the following recommendations are offered.

The sample size for in-vitro study can be increased in each group to clearly show statistical significance. Increased brushing time and demineralization treatment time can add to the result of the study. Other properties of the two sealants can also be studied, such as staining and bond strength.

A larger sample for in-vivo study may also be indicated. If more clinical patients are included for the study, the results will have increased level of significance. It can be recommended to conduct a same study with different split-mouth techniques: (1) one arch as a control and the other arch with a type of sealant, (2) left and right side split, and (3) quadrant split. Different methods of evaluation for demineralization can be used, such as QLF or DiagnoDent, instead of visual and photographic examination. This can render results that are more objective and quantifiable. 


\section{REFERANCES}

1. Ogaard B, Rolla G, Arends J. Orthodontic appliances and enamel demineralization. Part 1. Lesion development. Am J Orthod Dentofacial Orthop. 1988 Jul;94(1):68-73.

2. O'Reilly MM, Featherstone JD. Demineralization and remineralization around orthodontic appliances: an in vivo study. Am J Orthod Dentofacial Orthop. 1987 Jul;92(1):33-40.

3. Schmit JL, Staley RN, Wefel JS, Kanellis M, Jakobsen JR, Keenan PJ. Effect of fluoride varnish on demineralization adjacent to brackets bonded with RMGI cement. Am J Orthod Dentofacial Orthop. 2002 Aug;122(2):125-34.

4. Benson PE, Pender N, Higham SM. Quantifying enamel demineralization from teeth with orthodontic brackets--a comparison of two methods. Part 2: validity. Eur J Orthod. 2003 Apr;25(2):159-65.

5. Hu W, Featherstone JD. Prevention of enamel demineralization: an in-vitro study using lightcured filled sealant. Am J Orthod Dentofacial Orthop. 2005 Nov;128(5):592,600; quiz 670.

6. Chong SL, Darling CL, Fried D. Nondestructive measurement of the inhibition of demineralization on smooth surfaces using polarization-sensitive optical coherence tomography. Lasers Surg Med. 2007 [cited 21 February 2011];39(5):422-7.

7. Behnan SM, Arruda AO, Gonzalez-Cabezas C, Sohn W, Peters MC. In-vitro evaluation of various treatments to prevent demineralization next to orthodontic brackets. Am J Orthod Dentofacial Orthop. 2010 Dec;138(6):712.e1,7; discussion 712-3. 
8. Behnan SM, Arruda AO, Gonzalez-Cabezas C, Sohn W, Peters MC. In-vitro evaluation of various treatments to prevent demineralization next to orthodontic brackets. Am J Orthod Dentofacial Orthop. 2010 Dec;138(6):712.e1,7; discussion 712-3.

9. Aljehani A, Tranaeus S, Forsberg CM, Angmar-Mansson B, Shi XQ. In vitro quantification of white spot enamel lesions adjacent to fixed orthodontic appliances using quantitative lightinduced fluorescence and DIAGNOdent. Acta Odontol Scand. 2004 Dec;62(6):313-8.

10. Heinrich-Weltzien R, Kuhnisch J, van der Veen M, de Josselin de Jong E, Stosser L. Quantitative light-induced fluorescence (QLF)--a potential method for the dental practitioner. Quintessence Int. 2003 Mar;34(3):181-8.

11. Aljehani A, Yang L, Shi XQ. In vitro quantification of smooth surface caries with DIAGNOdent and the DIAGNOdent pen. Acta Odontol Scand. 2007 Feb;65(1):60-3.

12. Pinelli C, Loffredo Lde C, Serra MC. Effect of drying on the reproducibility of DIAGNOdent to detect caries-like lesions. Braz Dent J. 2010;21(5):405-10.

13. Artun J, Brobakken BO. Prevalence of carious white spots after orthodontic treatment with multibonded appliances. Eur J Orthod. 1986 Nov;8(4):229-34.

14. Anderson AM, Kao E, Gladwin M, Benli O, Ngan P. The effects of argon laser irradiation on enamel decalcification: An in vivo study. Am J Orthod Dentofacial Orthop. 2002 Sep;122(3):2519.

15. Wilson RM, Donly KJ. Demineralization around orthodontic brackets bonded with resinmodified glass ionomer cement and fluoride-releasing resin composite. Pediatr Dent. 2001 MayJun;23(3):255-9. 
16. Alexander SA, Ripa LW. Effects of self-applied topical fluoride preparations in orthodontic patients. Angle Orthod. 2000 Dec;70(6):424-30.

17. Sudjalim TR, Woods MG, Manton DJ, Reynolds EC. Prevention of demineralization around orthodontic brackets in vitro. Am J Orthod Dentofacial Orthop. 2007 Jun;131(6):705.e1,705.e9.

18. Farhadian N, Miresmaeili A, Eslami B, Mehrabi S. Effect of fluoride varnish on enamel demineralization around brackets: an in-vivo study. Am J Orthod Dentofacial Orthop. 2008 Apr;133(4 Suppl):S95-8.

19. Ghiz MA, Ngan P, Kao E, Martin C, Gunel E. Effects of sealant and self-etching primer on enamel decalcification. Part II: an in-vivo study. Am J Orthod Dentofacial Orthop. 2009 Feb;135(2):206-13.

20. Frazier MC, Southard TE, Doster PM. Prevention of enamel demineralization during orthodontic treatment: an in vitro study using pit and fissure sealants. Am J Orthod Dentofacial Orthop. 1996 Nov;110(5):459-65.

21. Buren JL, Staley RN, Wefel J, Qian F. Inhibition of enamel demineralization by an enamel sealant, Pro Seal: an in-vitro study. Am J Orthod Dentofacial Orthop. 2008 Apr;133(4 Suppl):S88-94.

22. Clark TJ. <br /> The efficacy of ProSealÊE, SeLECT DefenseÊE, OrthoCoatÊE, and Biscover LVÊ resin sealants on the prevention of enamel demineralization and white spot lesion formation. Iowa Research Online. 2010.

23. Benson PE, Shah AA, Millett DT, Dyer F, Parkin N, Vine RS. Fluorides, orthodontics and demineralization: a systematic review. J Orthod. 2005 Jun;32(2):102-14. 
24. Silverstone LM. Structure of carious enamel, including the early lesion. Oral Sci Rev. $1973 ; 3: 100-60$.

25. ten Cate JM, Damen JJ, Buijs MJ. Inhibition of dentin demineralization by fluoride in vitro. Caries Res. 1998;32(2):141-7.

26. Mitchell L. Decalcification during orthodontic treatment with fixed appliances--an overview. Br J Orthod. 1992 Aug;19(3):199-205.

27. Boersma JG, van der Veen MH, Lagerweij MD, Bokhout B, Prahl-Andersen B. Caries prevalence measured with QLF after treatment with fixed orthodontic appliances: influencing factors. Caries Res. 2005 Jan-Feb;39(1):41-7.

28. Sudjalim TR, Woods MG, Manton DJ. Prevention of white spot lesions in orthodontic practice: a contemporary review. Aust Dent J. 2006 Dec;51(4):284,9; quiz 347.

29. Gorelick L, Geiger AM, Gwinnett AJ. Incidence of white spot formation after bonding and banding. Am J Orthod. 1982 Feb;81(2):93-8.

30. Silverstone LM, Poole DF. Histologic and ultrastructural features of remineralized carious enamel. J Dent Res. 1969 Sep-Oct;48(5):766-70.

31. Scheie AA, Arneberg P, Krogstad O. Effect of orthodontic treatment on prevalence of Streptococcus mutans in plaque and saliva. Scand J Dent Res. 1984 Jun;92(3):211-7.

32. Tufekci E, Dixon JS, Gunsolley JC, Lindauer SJ. Prevalence of white spot lesions during orthodontic treatment with fixed appliances. Angle Orthod. 2011 Mar;81(2):206-10. 
33. Arslan SG, Akpolat N, Kama JD, Ozer T, Hamamci O. One-year follow-up of the effect of fixed orthodontic treatment on colonization by oral Candida. J Oral Pathol Med. 2008 Jan;37(1):26-9.

34. Balenseifen JW, Madonia JV. Study of dental plaque in orthodontic patients. J Dent Res. 1970 Mar-Apr;49(2):320-4.

35. Ogaard B. Prevalence of white spot lesions in 19-year-olds: a study on untreated and orthodontically treated persons 5 years after treatment. Am J Orthod Dentofacial Orthop. 1989 Nov;96(5):423-7.

36. Al Maaitah EF, Adeyemi AA, Higham SM, Pender N, Harrison JE. Factors affecting demineralization during orthodontic treatment: a post-hoc analysis of RCT recruits. Am J Orthod Dentofacial Orthop. 2011 Feb;139(2):181-91.

37. Geiger AM, Gorelick L, Gwinnett AJ, Griswold PG. The effect of a fluoride program on white spot formation during orthodontic treatment. Am J Orthod Dentofacial Orthop. 1988 Jan;93(1):29-37.

38. Wenderoth CJ, Weinstein M, Borislow AJ. Effectiveness of a fluoride-releasing sealant in reducing decalcification during orthodontic treatment. Am J Orthod Dentofacial Orthop. 1999 Dec;116(6):629-34.

39. Banks PA, Richmond S. Enamel sealants: a clinical evaluation of their value during fixed appliance therapy. Eur J Orthod. 1994 Feb;16(1):19-25.

40. Topping GV, Pitts NB, International Caries Detection and Assessment System Committee. Clinical visual caries detection. Monogr Oral Sci. 2009;21:15-41. 
41. Tranaeus S, Shi XQ, Angmar-Mansson B. Caries risk assessment: methods available to clinicians for caries detection. Community Dent Oral Epidemiol. 2005 Aug;33(4):265-73.

42. Younis O, Hughes DO, Weber FN. Enamel decalcification in orthodontic treatment. Am J Orthod. 1979 Jun;75(6):678-81.

43. Ekstrand KR, Martignon S, Ricketts DJ, Qvist V. Detection and activity assessment of primary coronal caries lesions: a methodologic study. Oper Dent. 2007 May-Jun;32(3):225-35.

44. Ekstrand KR, Zero DT, Martignon S, Pitts NB. Lesion activity assessment. Monogr Oral Sci. 2009;21:63-90.

45. Kuhnisch J, Goddon I, Berger S, Senkel H, Bucher K, Oehme T, et al. Development, methodology and potential of the new Universal Visual Scoring System (UniViSS) for caries detection and diagnosis. Int J Environ Res Public Health. 2009 Sep;6(9):2500-9.

46. Van Bebber L, Campbell PM, Honeyman AL, Spears R, Buschang PH. Does the amount of filler content in sealants used to prevent decalcification on smooth enamel surfaces really matter? Angle Orthod. 2011 Jan;81(1):134-40.

47. Nunn JH, Murray JJ, Reynolds P, Tabari D, Breckon J. The prevalence of developmental defects of enamel in 15-16-year-old children residing in three districts (natural fluoride, adjusted fluoride, low fluoride) in the north east of England. Community Dent Health. 1992 Sep;9(3):23547.

48. Heinrich-Weltzien R, Kuhnisch J, Ifland S, Tranaeus S, Angmar-Mansson B, Stosser L. Detection of initial caries lesions on smooth surfaces by quantitative light-induced fluorescence and visual examination: an in vivo comparison. Eur J Oral Sci. 2005 Dec;113(6):494-8. 
49. Croll TP, Tyma MS. Caries detection using laser fluorescence. Compend Contin Educ Dent. 2001 Oct;22(10):838,42, 844.

50. Angmar-Mansson B, ten Bosch JJ. Quantitative light-induced fluorescence (QLF): a method for assessment of incipient caries lesions. Dentomaxillofac Radiol. 2001 Nov;30(6):298-307.

51. Aljehani A, Bamzahim M, Yousif MA, Shi XQ. In vivo reliability of an infrared fluorescence method for quantification of carious lesions in orthodontic patients. Oral Health Prev Dent. 2006;4(2):145-50.

52. Feng Y, Yin W, Zhang YY, Zhang B, Hu DY. Comparison of primary caries detection on smooth surface in the maxillary anterior teeth using QLF, digital photo and visual diagnosis]. Shanghai Kou Qiang Yi Xue. 2005 Dec;14(6):565-8.

53. Shi XQ, Tranaeus S, Angmar-Mansson B. Comparison of QLF and DIAGNOdent for quantification of smooth surface caries. Caries Res. 2001 Jan-Feb;35(1):21-6.

54. Phankosol P, Ettinger RL, Hicks MJ, Wefel JS. Histopathology of the initial lesion of the root surface: an in vitro study. J Dent Res. 1985 May;64(5):804-9.

55. Featherstone JD, ten Cate JM, Shariati M, Arends J. Comparison of artificial caries-like lesions by quantitative microradiography and microhardness profiles. Caries Res. 1983;17(5):385-91.

56. Fontana M, Li Y, Dunipace AJ, Noblitt TW, Fischer G, Katz BP, et al. Measurement of enamel demineralization using microradiography and confocal microscopy. A correlation study. Caries Res. 1996;30(5):317-25. 
57. De Medeiros RC, Soares JD, De Sousa FB. Natural enamel caries in polarized light microscopy: differences in histopathological features derived from a qualitative versus a quantitative approach to interpret enamel birefringence. J Microsc. 2012 May;246(2):177-89.

58. Ourique SA, Magdaleno JP, Arrais CA, Rodrigues JA. Effect of different concentrations of carbamide peroxide on microhardness of dental ceramics. Am J Dent. 2011 Feb;24(1):57-9.

59. Price RB, Fahey J, Felix CM. Knoop hardness of five composites cured with single-peak and polywave LED curing lights. Quintessence Int. 2010 Nov-Dec;41(10):e181-91.

60. de Moura MS, de Melo Simplicio AH, Cury JA. In-vivo effects of fluoridated antiplaque dentifrice and bonding material on enamel demineralization adjacent to orthodontic appliances. Am J Orthod Dentofacial Orthop. 2006 Sep;130(3):357-63.

61. Gorton J, Featherstone JD. In vivo inhibition of demineralization around orthodontic brackets. Am J Orthod Dentofacial Orthop. 2003 Jan;123(1):10-4.

62. Van Eygen I, Vannet BV, Wehrbein H. Influence of a soft drink with low pH on enamel surfaces: an in vitro study. Am J Orthod Dentofacial Orthop. 2005 Sep;128(3):372-7.

63. Longo C, Galimberti M, De Pace B, Pellacani G, Bencini PL. Laser skin rejuvenation: epidermal changes and collagen remodeling evaluated by in vivo confocal microscopy. Lasers Med Sci. 2012 Jul 6.

64. Hamrah P, Sahin A, Dastjerdi MH, Shahatit BM, Bayhan HA, Dana R, et al. Cellular Changes of the Corneal Epithelium and Stroma in Herpes Simplex Keratitis: An In Vivo Confocal Microscopy Study. Ophthalmology. 2012 May 16. 
65. Chen Y, Liang CP, Liu Y, Fischer AH, Parwani AV, Pantanowitz L. Review of advanced imaging techniques. J Pathol Inform. 2012;3:22.

66. Berger SB, Pavan S, Dos Santos PH, Giannini M, Bedran-Russo AK. Effect of bleaching on sound enamel and with early artificial caries lesions using confocal laser microscopy. Braz Dent J. 2012;23(2):110-5.

67. Sidhu SK, Pilecki P, Cheng PC, Watson TF. The morphology and stability of resin-modified glass-ionomer adhesive at the dentin/resin-based composite interface. Am J Dent. 2002 Apr;15(2):129-36.

68. Kwon SR, Wertz PW, Li Y, Chan DC. Penetration pattern of rhodamine dyes into enamel and dentin: confocal laser microscopy observation. Int J Cosmet Sci. 2012 Feb;34(1):97-101.

69. Cook RJ, Azzopardi A, Thompson ID, Watson TF. Real-time confocal imaging, during active air abrasion -- substrate cutting. J Microsc. 2001 Aug;203(Pt 2):199-207.

70. Watson TF, Pilecki P, Cook RJ, Azzopardi A, Paolinelis G, Banerjee A, et al. Operative dentistry and the abuse of dental hard tissues: confocal microscopical imaging of cutting. Oper Dent. 2008 Mar-Apr;33(2):215-24.

71. Mannocci F, Ferrari M, Watson TF. Microleakage of endodontically treated teeth restored with fiber posts and composite cores after cyclic loading: a confocal microscopic study. J Prosthet Dent. 2001 Mar;85(3):284-91.

72. Gonzalez-Cabezas C, Fontana M, Dunipace AJ, Li Y, Fischer GM, Proskin HM, et al. Measurement of enamel remineralization using microradiography and confocal microscopy. A correlational study. Caries Res. 1998;32(5):385-92. 
73. Heintze SD, Jost-Brinkmann PG, Loundos J. Effectiveness of three different types of electric toothbrushes compared with a manual technique in orthodontic patients. Am J Orthod Dentofacial Orthop. 1996 Dec;110(6):630-8.

74. Heasman P, Wilson Z, Macgregor I, Kelly P. Comparative study of electric and manual toothbrushes in patients with fixed orthodontic appliances. Am J Orthod Dentofacial Orthop. 1998 Jul;114(1):45-9.

75. Blankenau RJ, Powell G, Ellis RW, Westerman GH. In vivo caries-like lesion prevention with argon laser: pilot study. J Clin Laser Med Surg. 1999 Dec;17(6):241-3.

76. Noel L, Rebellato J, Sheats RD. The effect of argon laser irradiation on demineralization resistance of human enamel adjacent to orthodontic brackets: an in vitro study. Angle Orthod. 2003 Jun;73(3):249-58.

77. Elaut J, Wehrbein $\mathrm{H}$. The effects of argon laser curing of a resin adhesive on bracket retention and enamel decalcification: a prospective clinical trial. Eur J Orthod. 2004 Oct;26(5):553-60.

78. Ogaard B. The cariostatic mechanism of fluoride. Compend Contin Educ Dent. 1999;20(1 Suppl):10,7; quiz 34 .

79. Ogaard B, Arends J, Helseth H, Dijkman G, van der Kuijl M. Fluoride level in saliva after bonding orthodontic brackets with a fluoride containing adhesive. Am J Orthod Dentofacial Orthop. 1997 Feb;111(2):199-202.

80. Ogaard B, Rolla G, Arends J, ten Cate JM. Orthodontic appliances and enamel demineralization. Part 2. Prevention and treatment of lesions. Am J Orthod Dentofacial Orthop. 1988 Aug;94(2):123-8. 
81. Geiger AM, Gorelick L, Gwinnett AJ, Benson BJ. Reducing white spot lesions in orthodontic populations with fluoride rinsing. Am J Orthod Dentofacial Orthop. 1992 May;101(5):403-7.

82. Stratemann MW, Shannon IL. Control of decalcification in orthodontic patients by daily selfadministered application of a water-free 0.4 per cent stannous fluoride gel. Am J Orthod. 1974 Sep;66(3):273-9.

83. Vivaldi-Rodrigues G, Demito CF, Bowman SJ, Ramos AL. The effectiveness of a fluoride varnish in preventing the development of white spot lesions. World J Orthod. 2006 Summer;7(2):138-44.

84. Shafi I. Fluoride varnish reduces white spot lesions during orthodontic treatment. Evid Based Dent. 2008;9(3):81.

85. Todd MA, Staley RN, Kanellis MJ, Donly KJ, Wefel JS. Effect of a fluoride varnish on demineralization adjacent to orthodontic brackets. Am J Orthod Dentofacial Orthop. 1999 Aug;116(2):159-67.

86. Gontijo L, Cruz Rde A, Brandao PR. Dental enamel around fixed orthodontic appliances after fluoride varnish application. Braz Dent J. 2007;18(1):49-53.

87. McNeill CJ, Wiltshire WA, Dawes C, Lavelle CL. Fluoride release from new light-cured orthodontic bonding agents. Am J Orthod Dentofacial Orthop. 2001 Oct;120(4):392-7.

88. Bishara SE, Swift EJ,Jr, Chan DC. Evaluation of fluoride release from an orthodontic bonding system. Am J Orthod Dentofacial Orthop. 1991 Aug;100(2):106-9.

89. Williams B. Fissure sealants: a review. J Int Assoc Dent Child. 1990 Dec;20(2):35-41. 
90. Simonsen RJ. Retention and effectiveness of dental sealant after 15 years. J Am Dent Assoc. 1991 Oct;122(10):34-42.

91. Ceen RF, Gwinnett AJ. Microscopic evaluation of the thickness of sealants used in orthodontic bonding. American Journal of Orthodontics. 1980;78(6):623-9.

92. ZACHRISSON B, HEIMGARD E, RUYTER I, MJOR I. Problems with Sealants for Bracket Bonding. American Journal of Orthodontics and Dentofacial Orthopedics. 1979;75(6):641-9.

93. Farrow ML, Newman SM, Oesterle LJ, Shellhart WC. Filled and unfilled restorative materials to reduce enamel decalcification during fixed-appliance orthodontic treatment. Am J Orthod Dentofacial Orthop. 2007 Nov;132(5):578.e1,578.e6.

94. Tanna N, Kao E, Gladwin M, Ngan PW. Effects of sealant and self-etching primer on enamel decalcification. Part I: an in-vitro study. Am J Orthod Dentofacial Orthop. 2009 Feb;135(2):199205.

95. Heinig N, Hartmann A. Efficacy of a sealant : study on the efficacy of a sealant (Light Bond) in preventing decalcification during multibracket therapy. J Orofac Orthop. 2008 May;69(3):15467. 


\title{
APPENDIX A - IRB IN VITRO
}

\author{
W. WestVirginiaUniversity. \\ Office of Research Integrity and Compliance \\ Acknowledgement Letter - Not Human Subject Research (NHSR) \\ To: \\ From: \\ Approval Period: \\ Subject: \\ Protocol Tracking\#: \\ Title: \\ Peter Ngan \\ WVU Office of Research Integrity and Compliance \\ 04/08/2013 Expiration Date: 04/07/2018 \\ Not Human Subject Research Acknowledgment \\ 1209000428 \\ Comparison of Efficacy in Prevention of Enamel Demineralization between Opal \\ Seal and Pro Sealant: In-Vitro Study
}

Thank you for your submission to the West Virginia University Institutional Review Board (IRB)

It has been determined that your project does not meet the definition of human subject research for the following reason(s):

- In order to be considered human subject research, individually identifiable private information must be obtained or used in the research. If there is no individually identifiable private information involved, the project is not human subject research and does not require being submitted to the Office of Research Integrity \& Compliance. Private information must be individually identifiable (i.e., the identity of the subject is or may be readily ascertained by the investigator or someone else associated with the information) in order to constitute research involving human subjects.

If you have any questions, please contact the IRB at (304) 293-7073.

Thank you.

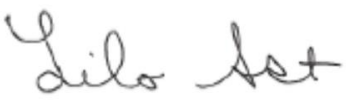

Board Designee: Lilo Ast

Letter Sent By: Lilo Ast on 04/08/2013 at 19:55:59-04:00 


\section{APPENDIX B - IRB IN VIVO}

\section{WestVirginiaUniversity. \\ Office of Research Compliance}

\section{IRB Protocol-Exemption}

To: $\quad$ Ngan, Peter

From: $\quad$ WVU Office of Research Compliance

Date: $\quad$ Monday, September 10, 2012

Subject: Exemption Acknowledgement

Tracking \#: $\mathrm{H}-24300$

Title: $\quad$ Comparison of Efficacy in Prevention of Enamel Demineralization between Opal®) Seal and Pro Seal ${ }^{\mathrm{TM}}$ : In-Vivo Study

The above-referenced study was reviewed by the West Virginia University Institutional Review Board (IRB) and was granted exemption in accordance with 45 CFR 46.101(4).

This protocol was reviewed using the following:

This research study was granted an exemption in accordance with Research on existing data, documents, records, pathological specimens, or diagnostic specimens [45 CFR 46.101(4)].

The following documents have been acknowledged for use in this study and are available in the BRAAN system:

Miscellaneous Attachments Attachments Dr Hazey Signature.jpg Dr. Hazey's permission to access his patients' information Exempt Research Checklist (210r)

Thank you
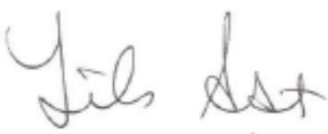

Board Designee: Ast, Lilo

Letter Sent By: Ast, Lilo, 9/10/2012 7:24 PM

Once you begin your human subject research, the following regulations apply:

1. Any modifications to the study protocol must be reviewed and acknowledged by the IRB prior to implementation.

2. You may not use a modified form until it has been acknowledged by the IRB. 


\section{APPENDIX C - AUTHORIZATION TO USE OR DISCLOSE PROTECTED HEALTH INFORMATION}

I, Michael Hazey, D.D.S., hereby grant Doyoung Choi, D.D.S. the access to the patient health information at my private practice in the effort of conducting the study "Comparison of Efficacy in Prevention of Enamel Demineralization between Opal® Seal and Pro Seal' ${ }^{\mathrm{m}}$ : In-Vitro and In-Vivo Study."

The patient health information will include the basic demographics, pre and post treatment intra-oral pictures, patient assessment, and treatment records.

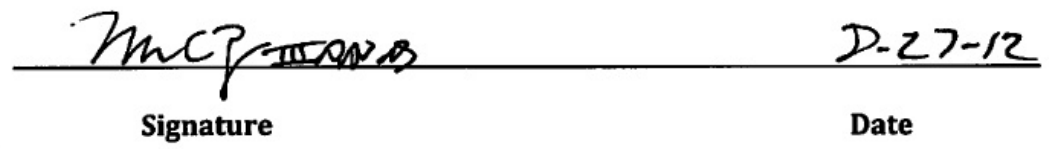




\section{APPENDIX D - SAMPLE Z-STACK}

Twenty layers of a sample from control group were recorded for a z-stack. The 921.4 $\mu \mathrm{mX} 921.4 \mu \mathrm{m}$ images were captured at every $167 \mu \mathrm{m}$ interval. The demineralized areas were very similar in all the layers, and the most representative image in focus was utilized for the analysis in the in-vitro study.

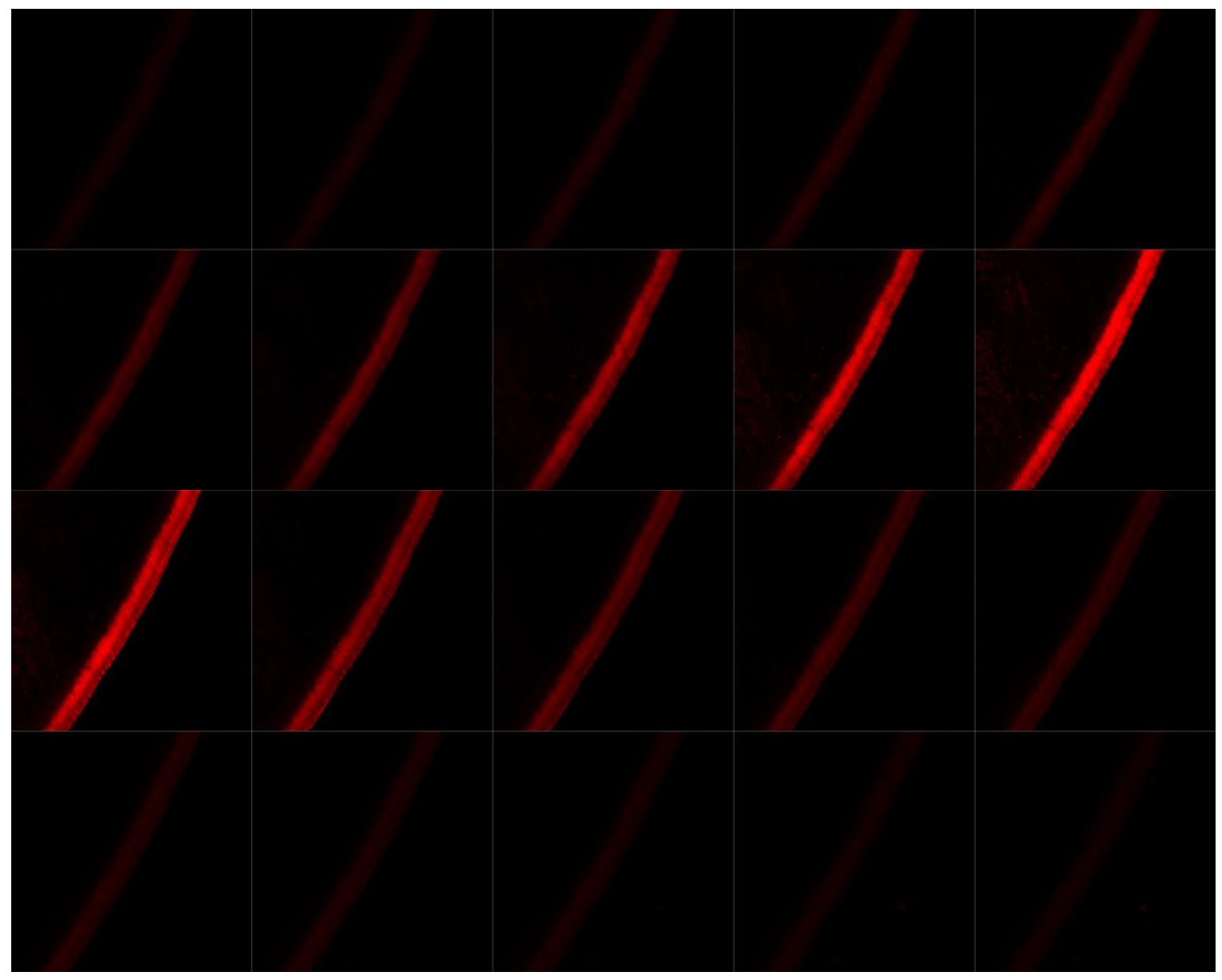




\section{CURRICULUM VITAE}

\section{EDUCATION}

July 2010 - Present

West Virginia University School of Dentistry Department of Orthodontics. Morgantown, WV

- Masters of Science in Orthodontics

- GPA 3.89

- Andrews Six Elements Philosophy

August 2006 - May 2010

West Virginia University School of Dentistry. Morgantown, WV

- Doctor of Dental Surgery

- GPA 3.88

- Vice president of the class

- Table Clinic: Effect of Patient, Provider, and Procedural Familiarity on Endodontic Fear

- Research: The Effectiveness of Student Research Group ñGet Acquaintedò Luncheon: Evaluation as a Tool to Stimulate Student Research (\#361 in ADEA 87 ${ }^{\text {th }}$ Annual Session) August 2003 - May 2006

Wheeling Jesuit University. Wheeling, WV

- Bachelor of Science in Biology

- GPA 3.94

\section{AWARDS \& DISTINCTIONS}

May 2010 West Virginia University School of Dentistry Class of 2010 Valedictorian

May 2010 Alumni Association Award for Outstanding Clinical Competency \& Professionalism

May $2010 \quad$ Certificate of Honor for Excellent Scholarship in Pursuit of Degree

May 2009 Omicron Kappa Upsilon Junior Clinical Dental Sciences Award

May 2008 Omicron Kappa Upsilon Basic Sciences Award

May 2007 West Virginia University Alumni Association Instrument Scholarship

\section{LICENSES \& CERTIFICATION}

March 2013

June 2012

June 2012

April 2012

August 2011

July 2010

March 2010

October 2009
Ohio State Dental License

Invisalign ${ }^{\circledR}$ Certification

Incognito $\hat{E}$ Hidden Braces Certification

American Board of Orthodontics Written Examination

CPR Certification

West Virginia State Dental License

Completion of Southern Regional Testing Agency

Diode Laser Certification 


\section{PROFESSIONAL AFFILIATIONS}

2010 - Present

2010 - Present

2010 - Present

2010 - Present

2007 - Present
Member of American Association of Orthodontists

Member of Southern Association of Orthodontists

Member of American Dental Association

Member of Omicron Kappa Upsilon

Member of Delta Sigma Delta Fraternity

\section{PREVIOUS EMPLOYMENT HISTORY}

2012 - Present

$2008-2010$

$2004-2006$
Clinical Student Assisting at West Virginia University Hospital Student Dentist at West Virginia University Emergency Dental Clinic Biology Tutor at Wheeling Jesuit University

\section{VOLUNTEER EXPERIENCES}

August 2009

March 2009

June 2008
Dental Mission Trip to Holt Ilsan, South Korea

Dental Mission Trip to Guatemala

Mission of Mercy at Hedgesville High School, West Virginia

\section{PERSONAL INTERESTS}

Hiking, cooking, house renovation, and traveling 